\title{
AVALIAÇÃO MOLECULAR, TOMOGRÁFICA E MICROSCÓPICA DOS CÔNDILOS APÓS AVANÇO CIRÚRGICO MANDIBULAR UTILIZANDO FIXAÇÃO RÍGIDA E SEMI-RÍGIDA - ESTUDO EM MINIPIGS
}

\section{Ricardo de Lima Navarro}

Tese apresentada à Faculdade de Odontologia de Bauru da Universidade de São Paulo, como parte dos requisitos para obtenção do título de Doutor em Odontologia, área de Ortodontia.

\section{BAURU}

2007 


\section{AVALIAÇÃO MOLECULAR, TOMOGRÁFICA E MICROSCÓPICA DOS CÔNDILOS APÓS AVANÇO CIRÚRGICO MANDIBULAR UTILIZANDO FIXAÇÃO RÍGIDA E SEMI- RÍGIDA, ESTUDO EM MINIPIGS}

\section{Ricardo de Lima Navarro}

Tese apresentada à Faculdade de Odontologia de Bauru da Universidade de São Paulo, como parte dos requisitos para obtenção do título de Doutor em Odontologia, área de Ortodontia.

Orientador: Prof. Dr. Eduardo Sant'Ana

\section{BAURU}

2007 


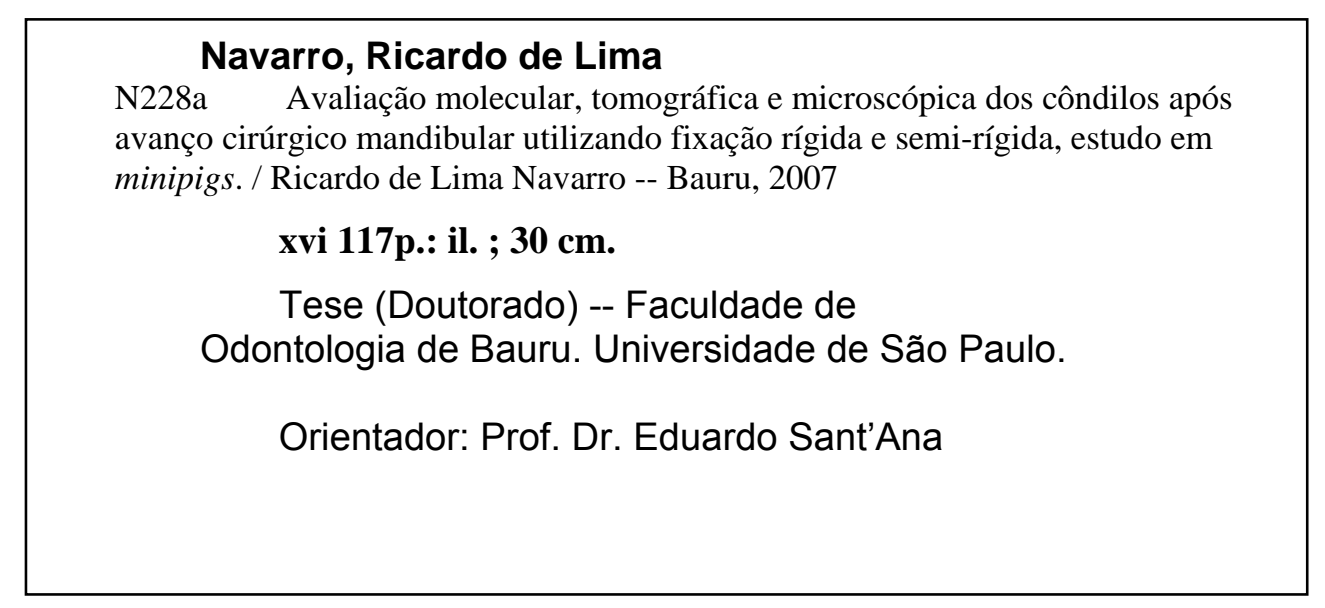

Autorizo, exclusivamente para fins acadêmicos e científicos, a reprodução total ou parcial desta dissertação/tese, por processos fotocopiadores e outros meios eletrônicos.

\section{Assinatura:}

Data:

\section{Comissão de Ética no Ensino e Pesquisa em Animais FOB/USP:}

$N^{\circ}$ do Protocolo: $41 / 2003$

Data: 05 de dezembro de 2003. 
Folha de aprovação 


\title{
Ricardo de Lima Navarro
}

\author{
Nascimento \\ 28 de Março de 1977 \\ Naturalidade \\ Bauru - SP \\ Filiação \\ João Adolfo Caldas Navarro e \\ Maria Fidela de Lima Navarro \\ $1996-1999$ \\ Curso de Graduação em Odontologia na Faculdade de Odontologia de \\ Bauru - Universidade de São Paulo (FOB - USP). \\ $1997-1999$ \\ Iniciação Científica na Disciplina de Anatomia da Faculdade de \\ Odontologia de Bauru - Universidade de São Paulo (FOB - USP). \\ $2000-2002$ \\ Curso de Mestrado em Odontologia, Área de Patologia Bucal na \\ Faculdade de Odontologia - Universidade de São Paulo, São Paulo-SP. \\ $2004-2006$ \\ Especialização em Cirurgia e Traumatologia Bucomaxilofacial na \\ Universidade do Sagrado Coração - USC, Bauru-SP. \\ $2003-2007$ \\ Curso de Doutorado em Odontologia, Área de Ortodontia na Faculdade \\ de Odontologia de Bauru - Universidade de São Paulo, Bauru-SP. \\ ASSOCIAÇõES: $\quad$ Associação Paulista de Cirurgiões - Dentistas - APCD; \\ Sociedade Brasileira de Pesquisa Odontológica - SBPqO; \\ International Association for Dental Research (IADR).
}




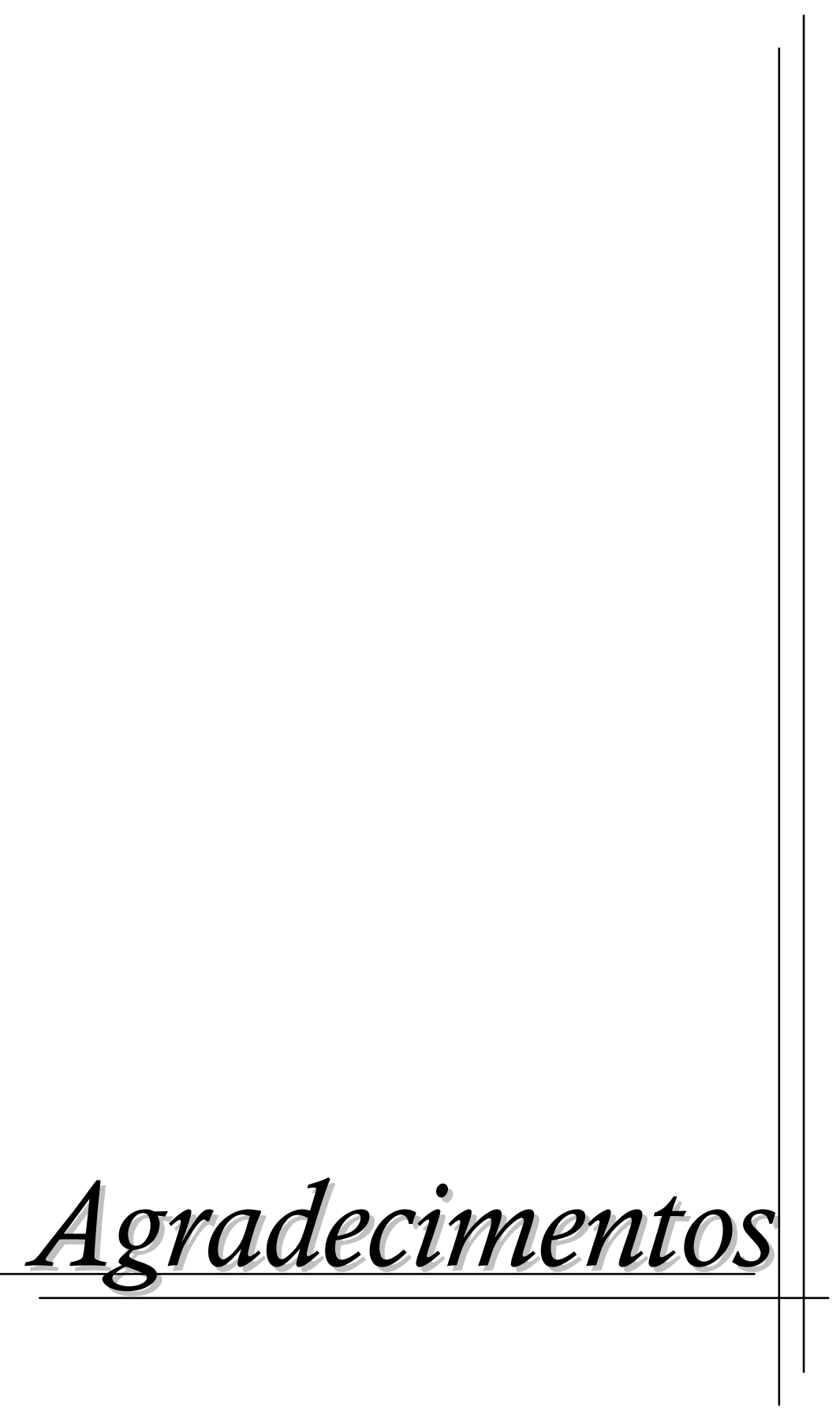




\section{Dedicatória}

Aos meus pais, João Adolfo (in memorian) e Maria Fidela, por estarem sempre presentes em todas grandes decisões de minha vida, orientando e confortando, sempre que precisei.

À minha noiva Paula, onde e quando precisei, ela já estava lá... Através da sua dedicação, inteligência e perseverança e, sobretudo, do seu amor este sonho transformou-se em realidade. Que muitos outros sonhos venham, e que nossa realidade fique ainda mais bela do que já é. Paula, dedico este trabalho a você!

Aos meus irmãos, cunhadas e sobrinhos: Paulo, Priscila, e seus filhos Felipe e Fernando; João, Luíza e seu filho João Pedro; Marcos e Thaís, por entenderem minha distância.

À família OLTRAMARI, Altamir e Arlete, Marcos, Cris e Eldir, apesar da barreira geográfica estão sempre presentes em minha vida, muito obrigado por tudo. 


\section{Agradecimentos}

Ao meu orientador, Prof. Dr. Eduardo Sant'Ana, pessoa esforçada e bem humorada, profissional de competência inspiradora e, ainda assim, presente e disponível. Agradeço por sua confiança e dedicação na execução deste trabalho.

Aos Professores da Disciplina de Ortodontia, Dr. Arnaldo Pinzan, Dr. Décio Rodrigues Martins, Dr. Guilherme Janson, Dr. José Fernando Castanha Henriques, Dr. Marcos Roberto Freitas e Dr. Renato Rodrigues de Almeida, por terem contribuído tanto ao meu aprendizado.

Aos professores colaboradores deste trabalho: Dra. Ana Lúcia Álvares Capelozza (Radiologia), Dr. Carlos Ferreira dos Santos (Farmacologia), Dr. José Roberto Pereira Lauris (Saúde Coletiva), Dr. Paulo César Rodrigues Conti (Prótese) e Dr. Rumio Taga (Histologia), pela orientação e incentivo em todos os momentos que precisei.

Aos Professores da Disciplina de Cirurgia e Traumatologia da Universidade do Sagrado Coração, Dr. Hugo Nary Filho, Dr. Eduardo Sanches Gonçalves, Dr. Luis Eduardo Marques Padovan, Dr. Paulo Domingos Ribeiro Junior, Dr. Ricardo Falcão, Dr. Onassis Leme da Silva, 
Dra. Mariza Akemi Matsumoto, Dr. Aparício Fiúza de Carvalho Dekon e Dr. Roberto Yoshio Kawakami, pela oportunidade de aprendizado que me propiciaram em Cirurgia.

Aos amigos Daniel, Diogo, Gustavo, Lucindo, Marinele, Murilo, Rafael, Renata, Rodrigo, Prof. Rodrigo e Tiago, pela imensa contribuição no início e na execução prática deste trabalho.

Aos amigos e "professores" Alexandre, Alessandro, Antônio Carlos e Paulo, aprendizado para toda a vida.

Aos funcionários do Biotério da FOB: Luiz Carlos, Erasmo, Wagner, Richard e Elias, pelas invenções e por todas as "horas extras" de constante ajuda.

Ao Prof. Dr. Fernando Cunha (Farmacologia USP - Ribeirão Preto) e ao Dr. José Augusto Carvalho (Clínica Image Diagnosis Conselheiro Lafaiete-MG), pela contribuição fundamental na fase experimental do trabalho.

À Tânia e Daniele (Histologia FOB-USP), amigas sinceras e valiosas, que tantas vezes contribuíram para o andamento deste trabalho. 
Ao Thiago, técnico do Laboratório da Disciplina de Farmacologia (FOB-USP), pela ajuda nos experimentos práticos e parte da montagem de tabelas.

À Giuliana, técnica do Laboratório de Farmacologia (FMRP-USP), pela imensa colaboração na fase experimental com os testes ELISA.

Aos meus amigos do doutorado Analu, Célia, Fabrício, Fernanda, José Eduardo, Karina Freitas, Karina Lima, Leniana, Rejane e Rodrigo, pelo companheirismo.

Aos meus colegas do Doutorado novo: Alexandre, Carlos Henrique, Carlos Alberto, Darwin, Fernando Torres, Fernando Pedrin, Kelly, Lívia, Marcus, Marise, Paula, Rafael, Renata e Sérgio, e aos colegas do Mestrado Caio, Douglas, Eduardo, Janine, Leonardo, Luiz Filipe, Luiz Fernando, Mayara, Patrícia, Rachelle, Tassiana, Wladimir, pela edificante convivência.

Aos funcionários da Ortodontia: Cristina, Daniel, Luciana, Neide, Sérgio e Verinha, que sempre estiveram prontos a me ajudar.

De forma geral, aos professores e funcionários das disciplinas da FOB-USP, envolvidas neste extenso trabalho: Anatomia, Bioquímica Cirurgia, Dentística, Farmacologia, Histologia, Prótese e Radiologia. 
À Fundação CAPES, que, através de auxílio financeiro, possibilitou a execução deste trabalho.

Às empresas Minipig.com e MDT Indústria e Comércio de Implantes Ortopédicos Ltda., por suas contribuições imprescindíveis à execução desta pesquisa.

À clinica IMAGE DIAGNOSIS (Conselheiro Lafaiete-MG), onde gentilmente foram realizadas as tomografias computadorizadas. 


\section{Sumário}

LISTA DE FIGURAS $\quad$ XV

LISTA DE TABELAS Xix

RESUMO $\quad$ Xx

1 INTRODUÇÃO 1

2 REVISÃO DE LITERATURA $\quad 5$

2.1 Deformidades Dentofaciais Severas 6

2.2 Osteotomia de Mandíbula $\quad 7$

2.2.1 Osteotomia Sagital Bilateral do Ramo Mandibular 8

2.3 Osteossíntese de Mandíbula 10

2.3.1 Osteossíntese para Osteotomia Sagital Bilateral do Ramo 11 Mandibular

2.4 Articulação Temporomandibular e Deformidades Dentofaciais 17 Severas

2.5 Posicionamento Condilar Transcirúrgico 18

2.5.1 Posicionamento Condilar e Estabilidade do Tratamento de 19 Deformidades Dentofaciais Severas

2.6 Métodos de análise da ATM 22

2.7 O minipig como modelo experimental 23

3 PROPOSIÇÃO 33

4 MATERIAL E MÉTODOS 35

4.1 Amostra 36

4.2 Contenção 37

4.3 Anestesia dos animais 38

4.4 Divisão dos Grupos 39

4.5 Preparo dos animais e procedimentos cirúrgicos 40

4.6 Coleta do líquido sinovial, realização do teste ELISA e obtenção da 48 biópsia

$\begin{array}{lll}4.7 & \text { Realização das Tomografias Computadorizadas } & 51 \\ 4.8 & \text { Preparo histotécnico } & 53\end{array}$ 
4.9 Forma de análise dos resultados 53

4.9.1 Análise Histológica $\quad 54$

4.9.2 Análise Molecular 54

4.9.3 Análise Tomográfica $\quad 54$

5 RESULTADOS

5.1 Aspectos histológicos 56

5.2 Aspectos moleculares 73

5.3 Aspectos tomográficos $\quad 74$

$\begin{array}{lll}5.4 & \text { Utilização dos minipigs para pesquisa odontológica } & 77\end{array}$

$\begin{array}{lll}6 & \text { DISCUSSÃO } & 79\end{array}$

6.1 Amostra 80

6.2 Material e Métodos 82

6.2.1 Contenção 82

6.2.2 Anestesia 82

6.2.3 Técnica Cirúrgica $\quad 84$

6.2.4 Análises histológica, molecular e tomográfica 85

6.3 Resultados 86

6.3.1 Aspectos histológicos 86

6.3.2 Aspectos moleculares $\quad 87$

6.3.3 Aspectos tomográficos 88

6.4 Implicações Clínicas 89

7 CONCLUSÕES $\quad 91$

REFERÊNCIAS BIBLIOGRÁFICAS 93

$\begin{array}{ll}\text { ABSTRACT } & 111\end{array}$

$\begin{array}{ll}\text { APENNDICES } & 115\end{array}$ 


\section{Lista de Figuras}

Figura 1 -Gráfico ilustrando a crescimento do número de pesquisas indexadas no PUBMED utilizando o minipig como modelo experimental nas diferentes áreas da biomedicina

Figura 2 - Diagrama do "Sistema Australiano" para assinalamento de suínos. Vista frontal do animal

Figuras 3 A e B - Vista do Biotério da Faculdade de Odontologia de Bauru USP, mostrando o setor das baias, no qual os animais permaneceram durante a pesquisa. Foram mantidos dois animais em cada baia durante a realização dos experimentos

Figuras 4 A e B - Figura ilustrando o procedimento para contenção do animal, utilizando o cachimbo

Figuras 5 A-D: A) Veia marginal da orelha após tricotomia na região; B) Introdução do catéter; C) Catéter em posição e estabilizado; D) Animal na fase pré-cirúrgica em venóclise

Figura 6 - Foto mostrando a equipe atuando durante as intervenções

Figuras 7 A-F: A e B) Anti-sepsia intra e extrabucal com PVPI tópico; C) Animais cobertos com campos operatórios estéreis; D) Anestesia local; E e F) Incisão da comissura labial

Figuras 7 G-L: G) Incisão intrabucal; $\mathrm{H}$ e I) Descolamento mucoperiostal; J) Início da osteotomia com broca esférica; K) Demarcação da extensão da osteotomia; L) Osteotomia sagital da mandíbula

Figuras 7 M-R: M e N) Finalização da osteotomia com cinzel e separação dos cotos; O e P) Medição da quantidade de avanço mandibular (6mm); Q) Osteossíntese com fixação rígida; R) Osteossíntese com fixação semi-rígida

Figuras 7 S-Y: S) Sutura intrabucal; T-V) Sutura da comissura labial por planos; X) Pós-operatório imediato: animal estabilizado em um dispositivo para não se machucar; Y) Alimentação pastosa na fase pós-cirúrgica

Figuras 8 A-F: A e B) Dissecção das ATMs até a região próxima à cápsula articular C e D) Coleta do líquido sinovial; E e F) Centrifugação do líquido coletado para separar o sobrenadante do material sólido indesejável

Figuras 9 A-D: A e B) ATMs posicionadas no tomógrafo; C e D) Ajuste da inclinação das peças 
Figuras 9 E-G: E) Série de cortes coronais do grupo controle; F) Série de cortes coronais do grupo com fixação rígida; G) Série de cortes coronais do grupo com fixação semi-rígida

Figuras 10 A e B: Corte sagital do côndilo mandibular do grupo controle. A) Visão panorâmica mostrando a distribuição dos tecidos: disco intra-articular (DI), côndilo mandibular (CO), cápsula articular (CA), músculo pterigóideo lateral (MP); B) Detalhe da região medial: músculo pterigóideo (MP), superfície do tecido ósseo (TO) demonstrando áreas de reabsorção por osteoclastos (setas), espessa camada de tecido conjuntivo (TC) ricamente celularizada recobrindo o tecido ósseo, cápsula fibrosa (CF) na região mais externa. Hematoxilina-eosina

Figuras 11 A e B: Corte sagital do côndilo mandibular do grupo controle. A) Visão panorâmica mostrando a distribuição dos tecidos: disco intra-articular (DI), côndilo mandibular (CO), cápsula articular (CA), músculo pterigóideo lateral (MP); B) Detalhe da região central mostrando: zona de superfície articular fibrosa (ZF), zona proliferativa (ZP) e zona da cartilagem condilar secundária $(Z C)$. A ZC é formada por áreas de diferenciação e proliferação dos condrócitos $(A)$, área de hipertrofia dos condrócitos $(B)$ e área de mineralização da cartilagem, degeneração dos condrócitos e ossificação (C). Hematoxilinaeosina

Figuras 12 A-C: Corte sagital do côndilo mandibular do grupo controle. A) Visão panorâmica mostrando a distribuição dos tecidos: disco intra-articular (DI), côndilo mandibular (CO), cápsula articular (CA), músculo pterigóideo lateral (MP); B-C) Detalhes das regiões lateral (Figura B) e central (Figura C) do côndilo, mostrando diferença na espessura das superfícies articular fibrosa (ZF), zona proliferativa (ZP) e zona condilar secundária (ZC). Observar, ainda, as fibras colágenas na periferia do disco intra-articular (DI), ricamente celularizado e vascularizado (seta vazada). Hematoxilina-eosina

Figuras 13 A e B: Corte sagital do côndilo mandibular do grupo controle. A) Visão panorâmica mostrando a distribuição dos tecidos: disco intra-articular (DI), côndilo mandibular (CO), cápsula articular (CA), músculo pterigóideo lateral (MP); B) detalhes da região lateral, exibindo tecido ósseo (TO) recoberto por tecido conjuntivo ricamente celularizado (TC) e superficialmente pela cápsula fibrosa (CF). Observar mais externamente a cápsula articular. Hematoxilina-eosina

Figuras 14 A e B: Corte sagital do côndilo mandibular do grupo controle. A) Visão panorâmica mostrando a distribuição dos tecidos: disco intra-articular (DI), côndilo mandibular (CO), cápsula articular (CA), músculo pterigóideo lateral (MP); B) detalhes da região lateral: na porção mais posterior, observa-se tecido ósseo (TO) de arranjo mais compacto, com sinais de reabsorção (seta vazada) na porção mais externa envolta por cápsula fibrosa (CF), decorrente do crescimento articular. Hematoxilina-eosina

Figuras 15 A e B: Corte sagital do côndilo mandibular do grupo 2 (fixação rígida). A) Visão panorâmica mostrando a distribuição dos tecidos: disco intraarticular (DI), côndilo mandibular (CO), músculo pterigóideo lateral (MP); B) Detalhes da região medial na porção posterior, exibindo tecido ósseo (TO) com áreas de reabsorção por osteoclastos (setas), recoberto por tecido fibroso (CF) semelhante à fibrocartilagem, com algumas áreas acidofílicas (cabeça de seta) 
e células (seta vazada) dispersas aleatoriamente. Hematoxilina-eosina

Figuras 16 A e B: Corte sagital do côndilo mandibular do grupo 2 (fixação rígida). A) Visão panorâmica mostrando a distribuição dos tecidos: disco intraarticular (DI), côndilo mandibular (CO) e músculo pterigóideo lateral (MP); B) detalhe da região medial: músculo pterigóideo (MP), superfície do tecido ósseo (TO) apresentando áreas de reabsorção por osteoclastos (setas), espessa camada de tecido conjuntivo (TC) ricamente celularizada recobrindo o tecido ósseo, cápsula fibrosa (CF) na região mais externa. Hematoxilina-eosina

Figuras 17 A-C: Corte sagital do côndilo mandibular do grupo 2 (fixação rígida). A) Visão panorâmica mostrando a distribuição dos tecidos: disco intraarticular (DI), côndilo mandibular (CO), músculo pterigóideo lateral (MP); B) detalhe da região central: zona de superfície articular fibrosa (ZF), zona proliferativa $(Z P)$ e zona da cartilagem condilar secundária (ZC). A ZC é formada por áreas de diferenciação e proliferação dos condrócitos $(A)$, área de hipertrofia dos condrócitos (B) e área de mineralização da cartilagem, degeneração dos condrócitos e ossificação (C), C) Região do côndilo apresentando descontinuidade da cápsula fibrosa, desorganização e espessamento da cartilagem articular secundária. $\mathrm{DI}=$ disco intercalar, $\mathrm{TO}=$ tecido ósseo. Hematoxilina-eosina

Figuras 18 A e B: Corte sagital do côndilo mandibular do grupo 2 (fixação rígida). A) Visão panorâmica mostrando a distribuição dos tecidos: disco intraarticular (DI), côndilo mandibular (CO) e músculo pterigóideo lateral (MP); B) Detalhes da região lateral: zona de superfície articular fibrosa (ZF), zona proliferativa (ZP) e zona da cartilagem condilar secundária de espessura variada associada ao tecido ósseo (TO). Hematoxilina-eosina

Figuras 19 A e B: Corte sagital do côndilo mandibular do grupo 2 (fixação rígida). A) Visão panorâmica mostrando a distribuição dos tecidos: disco intraarticular (DI), côndilo mandibular (CO) e músculo pterigóideo lateral (MP); B) Detalhes da região lateral na porção mais posterior: aumento em espessura da tábua óssea (seta) acompanhado por toda extensão da região condilar, da porção central à lateral (ver linha tracejada na Figura 19A). Hematoxilinaeosina

Figuras 20 A e B: Corte sagital do côndilo mandibular do grupo 3 (fixação semi-rígida). A) Visão panorâmica mostrando a distribuição dos tecidos: disco intra-articular (DI), côndilo mandibular (CO), cápsula articular (CA) e músculo pterigóideo lateral (MP); B) Detalhe da região medial mostrando o tecido ósseo (TO) com extensas áreas de reabsorção por osteoclastos (setas). Recobrindo o tecido ósseo, uma espessa camada de tecido conjuntivo (TC) ricamente celularizado e pequenos vasos sanguíneos (seta vazada). Mais externamente, a cápsula fibrosa (CF) desorganizada, com alguns feixes remanescentes (asteriscos), indicando remodelação da cápsula. Hematoxilina-eosina

Figuras 21 A-C: Corte sagital do côndilo mandibular do grupo 3 (fixação semirígida). A) Visão panorâmica mostrando a distribuição dos tecidos: disco intraarticular (DI), côndilo mandibular (CO), cápsula articular (CA) e músculo pterigóideo lateral (MP); B) detalhe da região central: zona de superfície articular fibrosa (ZF), zona proliferativa (ZP) e zona da cartilagem condilar 
secundária (ZC). A ZC é formada por áreas de diferenciação e proliferação dos condrócitos $(A)$, área de hipertrofia dos condrócitos $(B)$ e área de mineralização da cartilagem, degeneração dos condrócitos e ossificação (C); C) Região do côndilo mais lateral, apresentando tecido ósseo (TO) de arranjo trabecular, associado externamente ao tecido conjuntivo ricamente celularizado e, mais superficialmente, a cápsula fibrosa (CF). Hematoxilina-eosina

Figuras 22 A e B: Corte sagital do côndilo mandibular do grupo 3 (fixação semi-rígida). A) Visão panorâmica mostrando a distribuição dos tecidos: disco intra-articular (DI), côndilo mandibular (CO), cápsula articular (CA), músculo pterigóideo lateral (MP); B) Detalhes da região lateral: cortical óssea (TO) compacta, camada de tecido conjuntivo ricamente celularizado e superficialmente a cápsula fibrosa (CF). Observar também a membrana sinovial (seta vazada) revestindo as margens da cavidade articular inferior. Aumento em espessura está representado pela linha tracejada na Figura A. Hematoxilina-eosina

Figura 23: Gráfico a quantidade de IL-6 e IL-10 no líquido sinovial das amostras dos grupos 1, 2 e 3. Destaque para a quantidade de IL-10 no grupo 2 significantemente maior $\left({ }^{*}\right)$ em relação ao grupo 1 


\section{Lista de Tabelas}

Tabela 1 - Quantificação da IL-6 em picogramas $(\rho g) / m L$ nos grupos 1 , 2 e 3 : média, erro-padrão, teste ANOVA

Tabela 2 - Quantificação da IL-10 pg/mL nos grupos 1, 2 e 3: média, erropadrão, teste ANOVA

Tabela 3 - Escores obtidos nas duas avaliações $\left(1^{\mathrm{a}}\right.$ e $\left.2^{\mathrm{a}}\right)$ para erosão, achatamento e osteófito, nos grupos 1, 2 e 3 e teste Kappa (K)

Tabela 4 - Escores obtidos para erosão, nos grupos 1, 2 e 3: média, mediana, desvio-padrão e teste Kruskal-Wallis

Tabela 5 - Escores obtidos para achatamento, nos grupos 1, 2 e 3: média, mediana, desvio-padrão e teste Kruskal-Wallis

Tabela 6 - Escores obtidos para osteófito, nos grupos 1, 2 e 3: média, mediana, desvio-padrão e teste Kruskal-Wallis

Tabela 7 - Soma dos escores obtidos para todas as alterações (erosão, achatamento e osteófito), nos grupos 1, 2 e 3: média, mediana, desvio-padrão e teste Kruskal-Wallis 


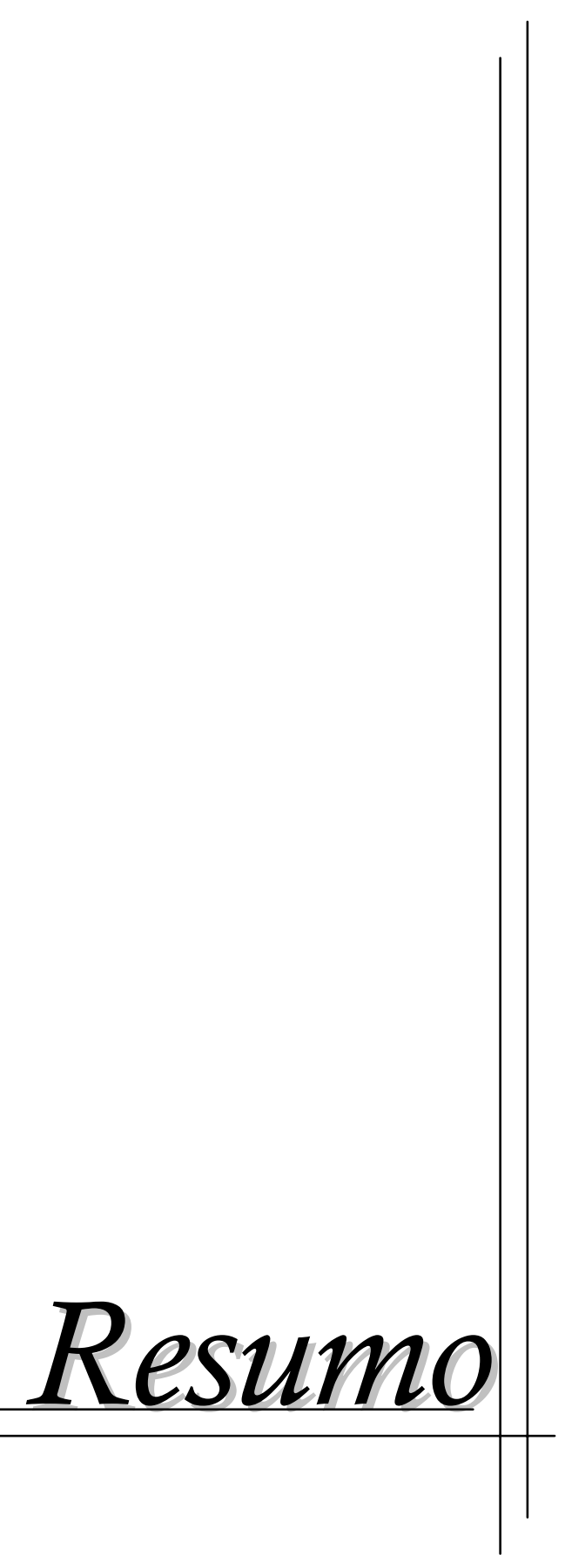




\section{Resumo}

Este trabalho objetivou elucidar as mudanças ocorridas na articulação temporomandibular (ATM) após o avanço cirúrgico mandibular com diferentes técnicas de fixação: fixação rígida (parafusos bicorticais) e fixação semi-rígida (mini-placas). Doze minipigs (BR-1 Minipig), com 15 meses de idade, divididos igualmente em dois grupos (Grupo 2, Fixação rígida e Grupo 3, fixação semi-rígida) foram operados e formaram os grupos experimentais; seis animais, com a mesma idade e não operados, formaram o grupo controle (Grupo 1). Quatro meses após as cirurgias, os animais foram mortos e todas as ATMs e amostras de líquido sinovial foram coletadas. As ATMs foram preparadas para análise histológica após a realização de tomografias computadorizadas (TC), as quais objetivaram a detecção de osteófito, erosão e achatamento. A presença de um marcador pró-inflamatório, a interleucina (IL)6, e um marcador antiinflamatório, IL-10 no líquido sinovial, foi determinada pelo teste ELISA. A avaliação por TC demonstrou significantes alterações na forma do côndilo (erosão, $P=0,0010$; osteófito, $P<0,0001$ ) no grupo 2, quando comparado aos grupos 1 e 3. No grupo controle, os mesmos níveis de IL-6 e IL-10 foram observados (83,2 pg/mL e $80,6 \mathrm{pg} / \mathrm{mL}$, respectivamente), compatíveis com ausência de sinais inflamatórios. No grupo com fixação semirígida, valores mais elevados de IL-6 em comparação à IL-10 indicaram um processo de inflamação ativo (140.0 pg/mL e $95.6 \mathrm{pg} / \mathrm{mL}$, respectivamente). Ao contrário, no grupo com fixação rígida obtiveram-se valores mais baixos de IL-6 comparados à IL-10 (103,5 pg/mL e 138,9 pg/mL, respectivamente) sugerindo inflamação recente já cessada ou se encerrando. Foi possível concluir que a fixação rígida provoca sinais mais pronunciados de remodelação óssea nas ATMs, enquanto que a fixação semi-rígida promove uma atividade inflamatória mais duradoura. Portanto, fatores intrínsecos da fixação rígida transmitem maior impacto das forças mastigatórias pós-cirúrgicas para a ATM em comparação à fixação semi-rígida.

Palavras-chave: Avanço Mandibular; Osteossíntese; Articulação temporomandibular; Remodelação óssea. 


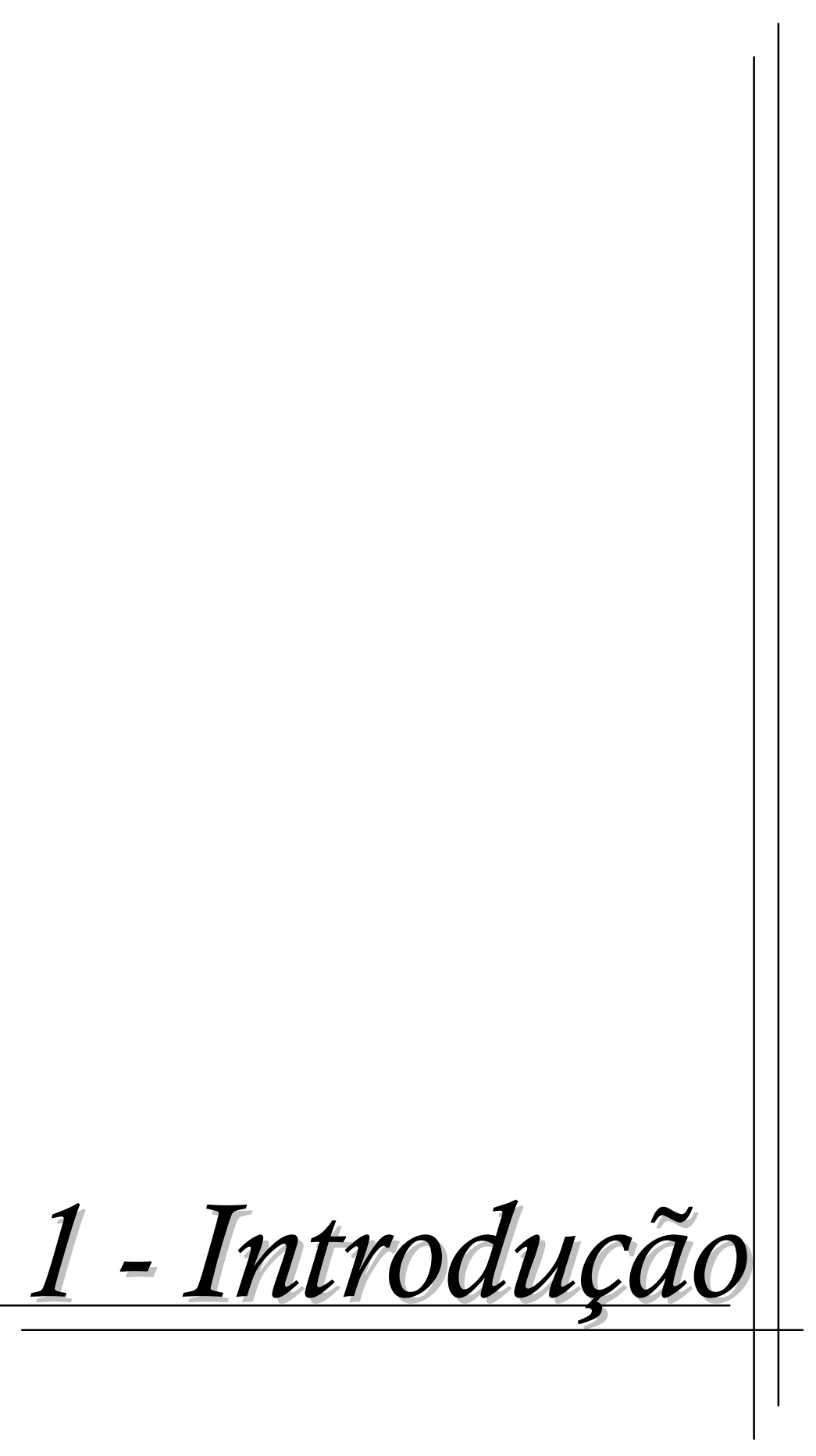




\section{1 - Introdução}

A articulação temporomandibular (ATM) é uma estrutura delicada por meio da qual outros componentes do sistema mastigatório podem gerar, dissipar e controlar os movimentos mandibulares. Em função das suas características como um tecido vivo, quando uma situação de estresse persiste por um longo período com intensidade compatível, a ATM tem a tendência de se adaptar ${ }^{17,78,113}$.

A interação entre a Cirurgia e a Ortodontia tornou possível o tratamento das más oclusões severas, que geralmente estão associadas às deformidades dentofaciais ${ }^{67,122,124,125}$. Entre 2 a $4 \%$ da população norteamericana é portadora de DDFS ${ }^{122,125}$. O tratamento de pacientes nestes casos é invasivo e, embora diversas técnicas de osteotomias mandibulares já tenham sido descritas (vertical do ramo ascendente, subcondilar, do corpo mandibular, subapical parcial ou total e da linha média ${ }^{125}$, somente uma é executada rotineiramente pela maioria os cirurgiões bucomaxilofacias ${ }^{122}$, a osteotomia sagital bilateral ${ }^{15,40,49,66,158}$.

No passado, a maioria dos procedimentos de cirurgia ortognática usava fixação com fios de aço inoxidável para estabilizar os segmentos ósseos durante a cirurgia ${ }^{46,57,98,125,139}$. Este procedimento era seguido de aproximadamente seis semanas de fixação intermaxilar enquanto os segmentos ósseos cicatrizavam. Apesar deste procedimento produzir resultados satisfatórios, a flexibilidade entre os segmentos com a fixação de fios de aço inoxidável permitia algum movimento dos segmentos contribuindo para a recidiva. A estabilidade foi, então, alcançada com a introdução da Fixação Interna Rígida (FIR) ${ }^{148}$ e da Fixação Interna Semi-rígida (FIS) ${ }^{29-32,96,97}$.

$O$ efeito das diferentes técnicas de fixação sobre a ATM é uma área de constante interesse na literatura ${ }^{3,4,6,11,39,61,165-167,183}$. A FIR, dentre as demais técnicas, é a mais resistente em testes mecânicos $33,51,100,111,117,119,149$. Em contraste com o ganho de estabilidade, está o fato de que a FIR pode causar torque nos côndilos em relação à fossa glenóide, o que não acontece na fixação com fios de aço inoxidável ${ }^{16}$. Esta força aplicada sobre os côndilos 
pode ultrapassar sua capacidade adaptativa causando remodelação óssea ${ }^{6,113}$. A alteração da morfologia da ATM pode afetar a função articular de diversas maneiras, gerando dinsfunções temporomandibulares (DTMs). Além disso, esta remodelação óssea secundária da ATM pode induzir à perda da estabilidade do resultado cirúrgico ${ }^{6}$.

Com o objetivo de observar se existem mudanças na ATM causadas pela cirurgia ortognática, neste caso o avanço mandibular, duas das mais eficientes técnicas de fixação ${ }^{33,51,100,117}$ foram realizadas neste estudo: Fixação Interna Semi-rígida - FIS (mini-placas) ${ }^{149}$ e Fixação Interna Rígida - FIR (parafusos bicorticais) $^{111}$. 


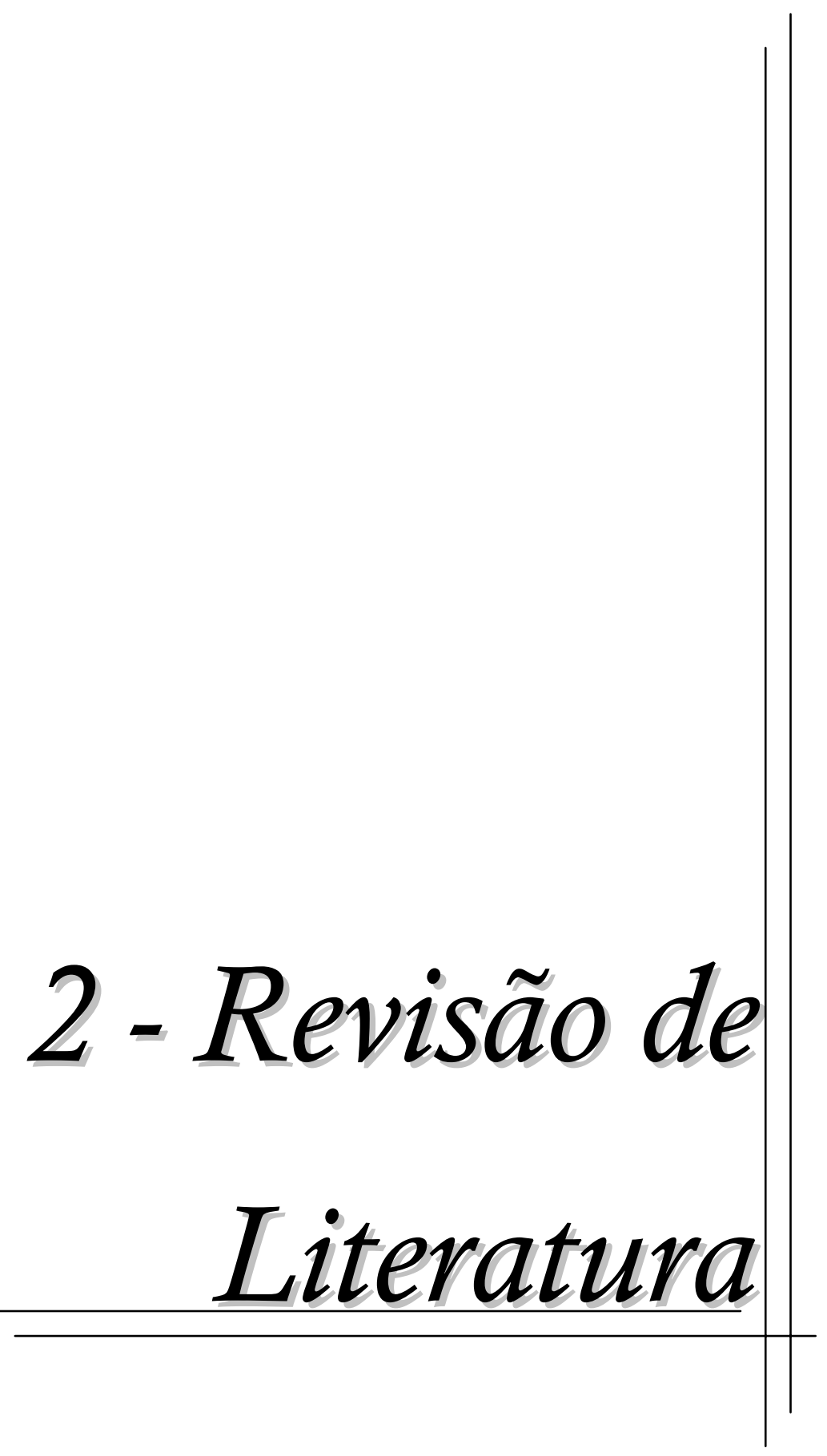




\section{2 - Revisão de Literatura}

Com a finalidade de facilitar a compreensão e a interpretação dos resultados desta pesquisa e de suas implicações clínicas, dividiu-se este capítulo em tópicos concernentes aos estudos correlacionados ao tema deste trabalho, de acordo com a seqüência descrita abaixo:

\subsection{Deformidades Dentofaciais Severas}

As deformidades Dentofaciais Severas (DDFSs) foram definidas por PROFFIT; WHITE JR.; SARVER ${ }^{125}$, 2003, como sendo discrepâncias entre as proporções faciais e as relações dentárias severas, numa magnitude que torna o indivíduo deficiente. Nestes pacientes, as funções bucais (oclusão, mastigação, deglutição, fala e respiração) encontram-se alteradas de tal maneira que é comum algum nível de discriminação em suas relações sociais. As DDFSs são alterações do desenvolvimento, e em raras ocasiões a causa é única, o mais freqüente é a interação de múltiplos fatores na alteração do desenvolvimento e crescimento. É muito difícil determinar exatamente quais são todos os fatores e quais são as parcelas de contribuição para que causem DDFS. Todavia, é possível deduzir muito sobre o padrão de crescimento de uma criança sabendo sua história familiar, a existência de hábitos, sua postura e ação muscular em sua face. Esta interação de potencial de crescimento (genótipo) e a ação do meio (fenótipo) irão determinar a instalação ou não de uma DDFS.

São raros os dados epidemiológicos mundiais, estando os estudos principais concentrados nos Estados Unidos ${ }^{122,123}$. Nestes estudos, os dados mostram que em populações distintas (leucodermas, melanodermas e xantodermas) uma faixa de aproximadamente 3\% irá apresentar DDFS. Em parte desses pacientes, o tratamento ortodôntico isolado pode corrigir $\mathrm{o}$ problema oclusal, mas sempre com pobre resultado nas relações entre as bases ósseas, permanecendo com a mesma, ou ainda pior, desarmonia facial $^{8,125}$. Outros aspectos não abordados pelo tratamento ortodôntico são os problemas funcionais de respiração e deglutição. Para um tratamento global e 
completo das DDFSs, a integração entre ortodontistas e cirurgiões tem atingido resultados cada vez mais precisos e permanentes. A evolução da técnica cirúrgica e do material utilizado como fixação, assim como o maior controle dos fatores coadjuvantes ao tratamento, têm contribuído de maneira efetiva para o aprimoramento do tratamento das DDFSs.

Muitas técnicas foram descritas ao longo do século $X X^{18,26,27,42}$, mas foi por volta da década de 70 que elas se difundiram com publicações de trabalhos experimentais ${ }^{15}$ e clínicos $^{49,57,169,170}$, demonstrando suas características e seu desempenho. Outro fator que contribuiu muito para a maior credibilidade desta modalidade de tratamento foi a evolução da fixação interna rígida e seus materiais. O desenvolvimento de ligas metálicas biocompatíveis e a constatação das propriedades do titânio em contato com tecidos ósseos foi outro marco para a melhora dos materiais de fixação, que até então sofriam com a corrosão apresentada nas ligas de aço inoxidável $^{143,184}$.

\subsection{Osteotomia de Mandíbula}

No início do século 20 , já estavam descritas na literatura ${ }^{18}$ formas de osteotomia mandibular para corrigir deformidades faciais. No entanto, esses procedimentos ainda não eram praticados rotineiramente, pois muito sobre sua execução (materiais de fixação, técnicas cirúrgica e medicamentosa) ainda necessitava evoluir. Até meados da década de 50, vários relatos descreveram formas diferentes de correção para retrognatismo e prognatismo ${ }^{26,27,42}$, discrepâncias no tamanho da mandíbula. Para as correções de excesso mandibular (prognatismo), as osteotomias de ramo ascendente, hoje denominadas de verticais do ramo mandibular ${ }^{27}$, obtiveram mais sucesso devido às características do movimento cirúrgico executado - recuo possibilitando contato ósseo. Outra característica desta técnica é a estabilidade da posição condilar, porém às custas de prolongado período de bloqueio intermaxilar. As diferentes técnicas descritas até hoje atendem à demanda, mas todas apresentam características próprias e limitações. Em 1957, quando TRAUNER; OBWEGESER ${ }^{158}$ publicaram seu trabalho sobre correção de retrognatismo e prognatismo mandibular, foi introduzida a técnica de 
osteotomia sagital da mandíbula. Atualmente, esta é a técnica mais praticada para correção de DDFS de mandíbula ${ }^{122,125}$.

\subsubsection{Osteotomia Sagital Bilateral do Ramo Mandibular}

As técnicas de osteotomia sagital mandibular executadas hoje são variações da primeira descrição de TRAUNER; OBWEGESER ${ }^{158}$, 1957. A partir da descrição original, obtiveram-se maior estabilidade e resultados cada vez mais previsíveis. A importante contribuição da primeira descrição relacionou-se à boa mobilidade entre os segmentos gerados, grande área de contato ósseo (melhor fixação e reparo ósseo), pouca mudança na posição condilar, e boa reprodutibilidade e previsibilidade quando comparada às técnicas existentes na época.

Após essa descrição inicial, os cirurgiões europeus e norteamericanos relataram modificações no desenho da ostetomia, na forma de fixação e no posicionamento condilar transcirúrgico ${ }^{40,66}$. Em função das suas características de maior previsibilidade, maior contato ósseo e menor área de tecidos moles desinseridos, a técnica de osteotomia sagital bilateral do ramo mandibular (OSBRM) é a mais utilizada mundialmente para tratamento de DDFS em mandíbula ${ }^{122,125}$.

DAL PONT ${ }^{40}$, 1959, descreveu duas formas de variação da técnica de OSBRM para tratamento de prognatismo mandibular em comparação àquela descrita por TRAUNER; OBWEGESER ${ }^{158}$, 1957. Ambas possibilitam maior contato ósseo e menor reposicionamento muscular, gerando melhores condições para correção de retrognatismo ou prognatismo, como por exemplo, em casos de micrognatia. O autor ainda apresentou o tratamento de uma paciente com excesso mandibular utilizando sua técnica de osteotomia retromandibular. Das duas técnicas apresentadas por DAL PONT, a que ele denominou de osteotomia sagital retromolar é a que exerceu maior impacto nos procedimentos executados atualmente ${ }^{40}$. Esta técnica diferenciava-se da original na sua extensão para inferior e anterior, onde a linha de osteotomia devia separar o ramo mandibular superior à língula mandibular e, também, inferior a esta estrutura toda a cortical vestibular do ramo ascendente, do ângulo mandibular e de parte do corpo mandibular logo após os molares. 
HUNSUCK $^{66}, 1968$, introduziu o uso de splint cirúrgico fixado pelos pré-molares superiores, além disso, a execução de osteotomia da cortical medial do ramo ascendente logo acima da língula e do feixe vásculo-nervoso, sem que a mesma fosse até a borda posterior da mandíbula. Ainda, sugeriu que com estas modificações não seria necessário fazer nenhum tipo de fixação óssea. Em seus relatos, o autor também ressalta que os 16 pacientes operados nesta técnica ficaram sob bloqueio intermaxilar por quatro semanas (duas a menos que a técnica original).

EPKER; WORTH ${ }^{49}$, 1977, revisaram a técnica de OSBRM e publicaram sugestões de execução para diminuição de edema, sangramento, lesões do nervo alveolar inferior, necrose avascular e recidiva. Eles seguiram os princípios de osteotomia, revisados por HUNSUCK ${ }^{66}, 1968$, e descreveram uma série de cuidados trans e pós-operatórios, desde infiltração de anestésico local até cuidados com suturas e curativos.

Ainda no mesmo ano, BELL; SCHENDEL ${ }^{15}$ descreveram sugestões para as técnicas de TRAUNER; OBWEGESER ${ }^{158}$, DAL PONT ${ }^{40}$ e HUNSUCK ${ }^{66}$. Eles estudaram em macacos o reparo ósseo e dos tecidos moles envolvidos em cirurgias que utilizaram a técnica de OSBRM. Dez macacos rhesus (Macaca mulatta) foram operados, sendo que de um lado empregaram a técnica descrita por TRAUNER; OBWEGESER ${ }^{158}$, modificada por DAL PONT ${ }^{40}$, e do outro, uma técnica adaptada por eles. Em seus resultados encontraram que quanto menos são removidas as inserções musculares e os tecidos que envolvem a superfície óssea, menores eram as tendências de complicações pós-operatórias, e melhor era o reparo tecidual local.

GALLO et al. ${ }^{57}, 1976$, elaboraram um desenho de osteotomia com o objetivo de facilitar a estabilidade em deslocamentos anteriores de mandíbula. Para isso, utilizaram um degrau anterior que propiciava maior contato ósseo após o avanço. Anos após, WOLFORD; BENNET; RAFFERTY ${ }^{180}, 1987$, publicaram um estudo sugerindo algumas variações na execução da técnica de osteotomia sagital de mandíbula, que em parte podem ser vistas como refinamento e evolução da descrição de GALLO et al. ${ }^{57}$, 1976. Estas variações foram citadas como facilitadoras dos movimentos a serem atingidos com o tratamento, o que propiciaria maior estabilidade final. Duas variações estavam presentes em todos os tipos de osteotomias, a osteotomia horizontal e a 
extensão para lingual da osteotomia vertical. A primeira, permitia a formação de um ângulo que poderia adquirir graus variados dependendo do tipo de movimento a ser executado. A segunda, seria responsável por fazer com que a linha de fratura não fosse executada para vestibular, e sim para lingual. Além dessas duas variações, os autores ainda comentaram sobre pequenas alterações na extensão da osteotomia horizontal, gerando um ângulo mais aberto ou mais fechado, facilitando movimentos cirúrgicos com rotações horárias e anti-horárias. Ainda sobre a forma da osteotomia horizontal em casos de recuo mandibular, uma curva possibilitaria melhor adaptação dos segmentos após osteotomia. Segundo os autores, estas modificações facilitariam a técnica, minimizando complicações e fortalecendo o segmento posterior pela alteração do design da osteotomia.

Com essas características, utiliza-se a técnica de osteotomia sagital bilateral do ramo mandibular há 50 anos. Seus aperfeiçoamentos contribuíram para uma execução cada vez mais segura e com morbidade bastante reduzida em relação aos primeiros procedimentos. Contudo, alguns aspectos inerentes à técnica ainda permanecem como tema de constante discussão para potencializar os resultados obtidos, dentre eles estão os tipos de fixação e seus reflexos no formato e posicionamento condilar.

\subsection{Osteossíntese em cirurgias de mandíbula}

Dentre os modelos de imobilização óssea de mandíbula podemos distinguir três modalidades principais: bloqueio intermaxilar (odontossíntese ou fixação esquelética), osteossíntese com bloqueio intermaxilar e osteossíntese sem bloqueio intermaxilar ${ }^{13,14}$.

O bloqueio intermaxilar pode ser executado por meio da colagem de braquetes ortodônticos passivos, amarrilho dentário direto ou indireto, barra de aço, recobrimento dentário ou, ainda, por fixação esquelética com fios de aço inoxidável associados ou não a parafusos de fixação intermaxilar ${ }^{13}$. O bloqueio foi bastante executado para complementar a fixação utilizada ${ }^{46}$. Atualmente, o que mais se aproxima do conceito de bloqueio intermaxilar em um tratamento rotineiro é a estabilização maxilomandibular por meio de elásticos intermaxilares, atuando para guiar a nova oclusão do paciente nos primeiros dias após a cirurgia ${ }^{149}$. Esta estabilização objetiva propiciar maior conforto ao 
paciente nos primeiros dias após a cirurgia, fornecer a referência espacial em reconstruções após trauma, e manter a oclusão estável nos tratamentos cirúrgicos de DDFS, enquanto algum tipo de osteossíntese é aplicada ${ }^{111,149}$.

A osteossíntese sem bloqueio intermaxilar, mais utilizada como fixação tanto em osteotomias como em fraturas da face, pode ser executada com pequenas placas não compressivas, mini-placas com parafusos monocorticais e parafusos bicorticais, placas e parafusos reabsorvíveis e placas tridimensionais pré-moldadas ${ }^{13}$. Nesta modalidade de osteossíntese, as placas devem ser instaladas em áreas que possibilitem a transmissão das forças geradas principalmente pelos músculos da mastigação. No caso da mandíbula, as áreas envolvidas pela OSBRM que melhor estabilizam os segmentos quando fixadas são aquelas próximas à linha obliqua externa e outra mais próxima à base da mandíbula ${ }^{13,14}$.

\subsubsection{Osteossíntese para Osteotomia Sagital Bilateral do Ramo Mandibular}

A grande quantidade de sobreposição dos segmentos ósseos obtida com a OSBRM permite que muitas modalidades de fixação possam ser aplicadas $^{111}$. Os primeiros relatos da osteotomia sagital descreveram a utilização de fixação com fios de aço inoxidável para estabilizar os segmentos ósseos $^{19,40,49,57,158}$, e em algumas variações de técnica, os autores sugeriram apenas a utilização de bloqueio intermaxilar sem aplicar métodos de fixação óssea direta ${ }^{15,40,66}$. A partir de pesquisas como as da Fundação AO/ASIF $F^{35,36,121}$ e as descrições do Método de Champy, por MICHELET et al. ${ }^{96,97}$ e CHAMPY et al. ${ }^{29-32}$ houve a divulgação das vantagens da utilização de uma eficiente técnica de osteossíntese, a fixação interna rígida (FIR). Destas pesquisas, derivaram duas técnicas de fixação mandibular: a rígida e a semi-rígida.

O método conhecido como Champy de fixação, que na verdade foi descrito pela primeira vez por MICHELET et al. ${ }^{96,97}$, 1971, utiliza placas e parafusos monocorticais metálicos. CHAMPY na verdade produziu uma seqüência de trabalhos $^{29-32}$ publicados sobre este tema que propagaram a utilização desta técnica. Freqüentemente, são utilizadas placas de quatro ou seis furos fixadas logo abaixo da linha oblíqua externa e, seguindo sua orientação, assumem posição estratégica na distribuição de forças ${ }^{96,97}$. As 
forças mastigatórias resultantes de movimentos verticais favorecem a compressão entre os fragmentos ósseos. Apenas forças laterais podem gerar pequenos movimentos, mas que em condições normais não impedem a consolidação óssea.

O método rígido (parafusos bicorticais), inicialmente descrito por SPIESSL ${ }^{148}, 1971$, consiste na fixação dos fragmentos por três parafusos que devem ser travados nas corticais vestibular (segmento proximal) e lingual

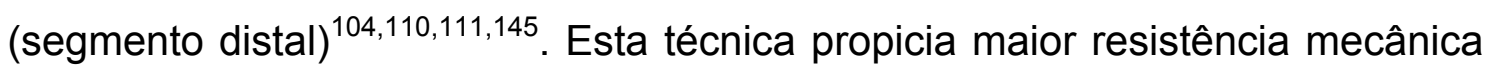
aos segmentos após fixação. Segundo $\mathrm{OCHS}^{111}, 2003$, a área da secção transversa de três parafusos bicorticais de $2,0 \mathrm{~mm}$ de diâmetro excede a área equivalente de uma placa utilizada no Método Champy. Várias posições para os parafusos podem obter boa resistência sem apresentar maior morbidade ${ }^{111}$.

Em casos de fraturas indesejadas (cortical lingual ou vestibular), ou em casos onde há interferência causada pelo terceiro molar ou sua remoção, alguns autores ${ }^{111,160,164,179}$ sugerem que ambas as fixações possam ser utilizadas em conjunto para atingir maior resistência mecânica. É comum encontrar a denominação híbrida para essa combinação de técnicas. A meta deve ser sempre alcançar a posição planejada, com a estabilidade dos segmentos ósseos ${ }^{111,160}$.

Para a escolha do melhor método de fixação, o cirurgião freqüentemente considera a anatomia, o design da osteotomia, o movimento cirúrgico e seu vetor, a presença de fraturas indesejadas, o posicionamento condilar, a sua preferência cirúrgica e o custo do material ${ }^{111}$. Em geral, os profissionais apresentam nas suas casuísticas a predominância de um ou outro tipo de fixação (placas ou parafusos bicorticais) e, portanto, mais habilidade e afinidade com um destes métodos.

As características anatômicas mandibulares conferem ao procedimento de correção cirúrgica das DDFSs algumas dificuldades técnicas, e estruturas anatômicas nobres precisam ser respeitadas para melhores resultados $^{6,141}$. Além disso, outra dificuldade é a diferença posicional a ser alcançada após a osteotomia. A nova posição óssea faz com que todos os tecidos circundantes exerçam suas funções em nova posição, indicando cuidados especiais para que o sucesso do tratamento possa perpetuar ${ }^{6}$. 
O trajeto do feixe vásculo-nervoso mandibular influenciou $O$ desenvolvimento do desenho da OSBRM, e é determinante para a escolha e execução da osteossíntese $e^{49,66,149,158,180,181}$. Esta trajetória impõe ao cirurgião cuidados adicionais durante a osteotomia anterior com cinzel para separação dos segmentos ósseos, para que permaneça apenas a cortical óssea na parte anterior do segmento proximal. Outra limitação imposta pelo trajeto do canal mandibular é que ao ser seccionada a cortical vestibular em linha vertical anterior, esta osteotomia deve se estender até a base mandibular, sendo com terminações diferentes para fixação com placas e com parafusos bicorticais. Para fixar os segmentos com placas e parafusos monocorticais, o profissional pode e deve estender a osteotomia vertical anterior até a porção medial, a fim de facilitar a correta separação dos segmentos ${ }^{149}$. Já a fixação bicortical demanda alguns outros cuidados, isso porque em determinados pacientes a região de base mandibular é necessária para a fixação do terceiro parafuso ${ }^{180,181}$. Em casos onde é necessário avanço mandibular e o paciente apresenta pequena altura facial posterior combinado com ângulo goníaco aumentado, é comum faltar espaço para a instalação de três parafusos bicorticais em linha. Desta forma, para fixar a osteotomia propriamente faz-se necessária a instalação de fixação na região de base mandibular ${ }^{111}$.

Outro fator de complexidade imposto pela conformação anatômica é a forma do osso mandibular em "V". Esta característica confere aos procedimentos para aumento ou diminuição da dimensão mandibular anteroposterior dificuldade em manter o segmento proximal em posição similar ou, idealmente, na mesma posição pré-operatória ${ }^{6,141,145}$. Nos movimentos cirúrgicos anteroposteriores, a partir de técnicas que utilizam osteotomias sagitais, a fixação dos segmentos ósseos sem nenhum cuidado adicional para remoção de interferências ou, ainda, sem aplicar esta fixação de forma adequada, pode provocar uma alteração na distância entre os côndilos.

O design da osteotomia, já comentado no item 2.2, pode influenciar o desempenho do tratamento. A cortical anterior vestibular remanescente no segmento proximal, idealmente, deve ser totalmente separada das trabéculas ósseas e de todo o segmento distal, tanto para se evitar interferências ósseas como também fraturas indesejadas ${ }^{68,160,164,179}$. Para que ocorra esta correta separação das corticais, alguns autores sugerem que um desgaste 
perpendicular à linha sagital seja executado para se visualizar o exato local onde se inicia a cortical vestibular ${ }^{111}$. Algumas variações nos tipos de osteotomias potencializam a ação das fixações ao gerar maior contato entre os segmentos proximal e distal ${ }^{180}$. Além disso, na região de principal distribuição das forças mandibulares (linha oblíqua externa) o autor sugeriu que formas diferentes de inclinações e curvatura da osteotomia fossem atribuídas aos variados movimentos cirúrgicos.

O vetor do movimento cirúrgico deve ser estudado para que após a cirurgia a ação dos músculos da mastigação não prejudique os resultados. $A$ combinação de movimentos em direção horária e a falta de superfície de contato (sobreposição das corticais lingual e vestibular) com resistência para receber a fixação é a principal fonte de preocupação nos planejamentos com osteossíntese rígida ${ }^{6,8,12,124,128}$.

Nos casos onde ocorrem fraturas indesejadas, o profissional deve estabelecer a posição final planejada e tratar os fragmentos soltos do segmento proximal ou distal, e ainda, fixá-los de tal forma que permita sua integração à mandíbula como um enxerto livre ${ }^{68,111,160,164}$.

A fixação rígida inicialmente foi obtida através de parafusos bicorticais compressivos ${ }^{53,120,148}$. Introduzida por SPIESSL ${ }^{148}, 1974$, posteriormente foi reformulada e divulgada por PAULUS; STEINHAUSER ${ }^{120}$, 1982. Ela consistia de três parafusos bicorticais que atravessavam a cortical vestibular do segmento proximal, e se fixavam na cortical lingual do segmento distal. Inicialmente, as roscas dos parafusos apenas se prendiam à cortical lingual do segmento distal, mas devido aos resultados danosos aos côndilos mandibulares, os parafusos passaram a ser instalados passivos, com roscas travadas em ambos os segmentos (técnica posicional) $81,82,84,103,105$.

Assim, os autores que a utilizaram passaram a indicar o uso de parafusos posicionais ${ }^{145}$ (sem compressão óssea) para permitir maior estabilidade e segurança aos seus pacientes.

Variáveis como inclinação, posição, quantidade e tamanho dos parafusos bicorticais a serem utilizados como fixação de OSBRM estão amplamente discutidos na literatura científica ${ }^{53,68,71,74,110,145,163}$. As melhores posições para instalação dos parafusos posicionais em mandíbula são logo abaixo da linha oblíqua externa e próxima à base mandibular, ambas por 
vestibular ${ }^{110,111}$. A inclinação destes parafusos, sem que ocorra prejuízo para resistência da osteossíntese, é interessante para que a cirurgia ocorra somente com acesso transbucal. A angulação de $60^{\circ}$ e $90^{\circ}$ em relação à superfície vestibular do segmento proximal não apresenta resistência estatisticamente significante ${ }^{53,163}$. Há um consenso na literatura de que a opção três parafusos é a melhor quantidade para se fixar de forma rígida a mandíbula após OSBRM $^{28,44,53,65,71,81,105,110,111,144,145,163,180}$. Apesar de alguns autores indicarem o uso de parafusos de $2,4 \mathrm{~mm}$ de diâmetro e outros até $2,7 \mathrm{~mm}$, sabe-se que os de 2,0mm apresentam resistência suficiente para suportar as forças incididas neles após fixação, e são os mais utilizados ${ }^{110,111}$.

Algumas situações clínicas podem ser descritas como riscos e complicações decorrentes da utilização de fixação rígida, dentre elas: torque e compressão dos côndilos, lesões ao nervo alveolar inferior por transposição ou compressão e reabsorção imediata ou tardia dos côndilos ${ }^{6,11}$.

O conceito de osteossíntese semi-rígida representa um método bastante seguro e constitui um meio de fixação rígida o suficiente, e apenas 0 suficiente, para estabilizar os fragmentos ósseos e propiciar correto reparo ósseo pós-cirúrgico ${ }^{83,119}$. Com isso, a técnica de fixação semi-rígida deve propiciar resistência às forças a ele submetidas e, ao mesmo tempo, ser maleável para não transmiti-las integralmente às estruturas adjacentes. Outra vantagem seria a de apresentar a versatilidade de, por meio de elásticos intermaxilares, alterar a posição entre as bases ósseas após a cirurgia. Os autores que sugeriram pela primeira vez esta modalidade de fixação (semirígida) o fizeram recomendando a utilização de dois parafusos bicorticais posicionais para estabilizar os segmentos de cada lado ${ }^{119}$. Dependendo da placa utilizada, estas vantagens obtidas com dois parafusos posicionais podem ser alcançadas por meio de uma placa de seis ou de quatro furos, posicionada pela Técnica de Champy.

Os defensores da técnica de fixação por meio de placas com parafusos monocorticais ainda atestam a seu favor outras vantagens, como a isenção de incisões de pele, melhor acomodação condilar, segurança para evitar lesões do nervo alveolar inferior, reversibilidade posicional durante 0 procedimento, prática remoção e instrução de novos cirurgiões facilitada ${ }^{149}$. Em um recente trabalho de revisão de literatura, STOELINGA; BORSTLAP ${ }^{149}$, 
2003, foram bastante claros em suas conclusões, expondo o que consideram ser os motivos para se utilizar a técnica de fixação de OSBRM por meio de placas e parafusos monocorticais:

- Em pequena porcentagem da população existe uma tendência de cicatrizes se tornarem hipertróficas. Isso evidencia a importância de se manter a integridade da pele do paciente por meio da Técnica Champy, procedimento executado por via transbucal. Portanto, sem risco do paciente apresentar cicatriz na pele. Além disso, outra vantagem é a ausência de um risco remoto de lesão do nervo facial durante a instalação transcutânea da fixação bicortical;

- A maleabilidade da placa permite a dobra e o melhor ajuste às novas posições dos segmentos, sem que os côndilos sofram torções ou, ainda, sem que eles sofram alteração posicional além de suas capacidades adaptativas. Com o uso de parafusos compressivos ocorre freqüente mudança posicional dos côndilos. Mesmo com parafusos posicionais, podem ocorrer tais incorretos posicionamentos, principalmente quando associados aos enxertos em forma de cunha;

- Outro argumento para a utilização de placas e parafusos monocorticais é a segurança para se evitar lesões ao nervo alveolar inferior. Parafusos bicorticais, compressivos ou posicionais, podem na sua instalação acidentalmente atingir o canal mandibular e causar disestesias permanentes. A técnica utilizando os parafusos bicorticais de forma compressiva oferece um risco adicional de, ao apertar os dois segmentos ósseos, espremer o nervo alveolar inferior causando lesão permanente;

- A reversibilidade desta técnica é outra característica que favorece muito seu uso, pois qualquer falha em sua execução notada ainda em campo operatório pode ser facilmente corrigida. Ao perceber diferenças na oclusão obtida em relação à planejada, o profissional pode remover um dos pontos onde ele encontrou a discrepância, alterar a posição e fixar novamente. Isto muitas vezes é possível ainda que tenham se passado poucos dias após a cirurgia, com sedação e anestesia local; 
- Quando necessário este tipo de material é facilmente removido com anestesia local. Normalmente, quando ocorre infecção ou existe algum desconforto por parte do paciente;

- Um dos aspectos mais importantes é a praticidade de manuseio que permite facilidade de trabalho e de treinamento. Na etapa de formação do cirurgião é muito comum os residentes demonstrarem dificuldades de posicionar os côndilos corretamente nas fossas. Neste momento, mais uma vez, as características da reversibilidade em conjunto com o fácil manuseio geram condições favoráveis ao cirurgião em formação.

\subsection{Articulação Temporomandibular e Deformidades Dentofaciais Severas}

A ATM é uma estrutura complexa por meio da qual músculos da mastigação transmitem parte de suas forças da mandíbula para o crânio. Presentes na face como um tipo único de articulação do ser humano, as duas ATMs conectam e suportam um osso em forma de "V" com anexos especializados, os dentes. Os dentes devem estar posicionados em relação aos seus antagonistas presentes na maxila de tal forma a permitirem movimentos que conservem a eficiência mastigatória ${ }^{17,78,113}$.

Ainda que uma pessoa possua uma oclusão balanceada, com guias e movimentos dentro da normalidade, ela pode desenvolver DTM, devido à múltipla etiologia desta patologia ${ }^{78,113}$. Nos pacientes com DDFS, a oclusão é quase sempre severamente acometida, e freqüentemente associada à

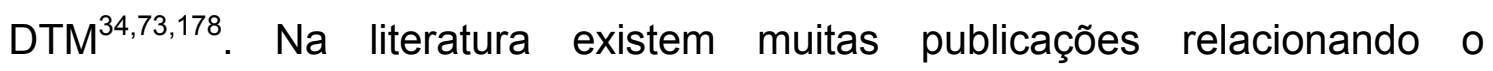
tratamento de pacientes com DDFS aos sinais de DTM. De maneira geral, estes trabalhos demonstram que o paciente, após os devidos tratamentos tanto para a DTM quanto para DDFS, rotineiramente relatam melhora dos sintomas de $\mathrm{DTM}^{20,41,56,106,172}$. Isto, porém, não é suficiente para oferecer este benefício como parte dos tratamentos das DDFSs ${ }^{7,43,182}$.

Pacientes que não apresentam sinais e sintomas de DTM podem, após tratamento cirúrgico para correção de DDFS, passar a relatar esses sintomas. GAGGL et al. ${ }^{56}, 1999$, utilizaram imagens de ressonância magnética do pré e pós-operatório de 25 pacientes para analisar a ATM. Eles encontraram um acréscimo do número de pacientes com doenças degenerativas ao nível condilar de $7 / 50$ para $9 / 50$, três meses após a realização de cirurgia 
ortognática. Não foi um resultado estatisticamente significante, mas chama atenção para um possível problema.

WESTERMARK; SHAYEGHI; THOR ${ }^{178}$, 2001, estudaram a prevalência de sintomas pré e pós-operatório de DTM em 1.516 pacientes. Em seus resultados demonstrou-se que a prevalência de distúrbios da ATM varia de $20 \%$ a $59 \%$ em indivíduos estudados. Em seu estudo foi encontrada uma prevalência de $43 \%$, sendo que $15 \%$ apresentavam sintomas avançados. Nos resultados pós-operatórios, o tratamento de retrognatia foi 0 de pior prognóstico, uma vez que no pré-operatório $41 \%$ dos prognatas apresentavam sintomas, contra $42 \%$ dos retrognatas, e diminuindo ambos para $24 \%$ e $34 \%$, respectivamente, após o tratamento. Isto evidencia um melhor prognóstico de DTM para os recuos mandibulares em relação aos avanços. Em geral, o reposicionamento das bases proporciona uma melhor condição ao paciente em relação à DTM, o que não significa que é um tratamento, uma vez que pacientes podem não apresentar DTM prévia e desenvolvê-la após uma cirurgia ortognática, assim como na população geral.

Considerando a abrangência que somente o assunto DTM pode gerar, decidimos direcionar nosso trabalho para a conduta de tratamento em pacientes sadios em relação à articulação temporomandibular.

\subsection{Posicionamento Condilar Transcirúrgico}

A estabilidade em tratamentos cirúrgicos de DDFS está diretamente relacionada à saúde dos côndilos mandibulares ${ }^{6,7,10}$. Procedimentos cirúrgicos devem ser idealmente realizados em mandíbulas que apresentam ATMs devidamente diagnosticadas como saudáveis ${ }^{6,8}$. Muito já foi mencionado na literatura sobre como obter resultados mais precisos e estáveis em relação ao posicionamento condilar. Alguns profissionais aventam a necessidade da utilização de dispositivos de posicionamento condilar para assegurar a posição adequada da cabeça dos côndilos na fossa glenóide, após a cirurgia $^{50,60,62,85,94,99,127,131,157,186}$. Estes dispositivos potencialmente estabilizam os côndilos em suas posições pré-cirúrgicas em relação à maxila, ao osso zigomático, a a outra estrutura estável de referência.

ROTSKOFF et al. ${ }^{131}$, 1991, compararam casos de Osteotomia Sagital Bilateral e FIR com e sem o uso de um dispositivo para 
reposicionamento condilar proximal utilizado no momento da cirurgia. Vinte pacientes foram tratados $\mathrm{e}$ as tomografias computadorizadas obtidas foram analisadas a partir de reconstruções. Foram realizados traçados na área das ATMs comparando as tomografias obtidas antes da cirurgia e um dia após a intervenção cirúrgica. As sobreposições dos traçados foram realizadas a partir da sobreposição da fissura escamotimpânica, fossa glenóide, eminência articular, aspecto posterior do côndilo e ramo ascendente. Foram realizadas medidas diretas do espaço superior da articulação, para verificar o deslocamento vertical do côndilo. O posicionamento horizontal e a rotação do côndilo foram avaliados com base no deslocamento condilar, a partir da posição inicial. Os resultados mostraram que houve um deslocamento dos côndilos no sentido posterior inferior, com rotação anterior. O deslocamento foi menor no grupo em que o posicionador condilar proximal foi utilizado.

Apesar de ser um conceito interessante, este dispositivo consome muito tempo, não é prático, e não foram demonstrados resultados consistentes a partir do seu uso. Outro problema dos posicionadores de côndilo é a limitação de alterações de plano oclusal e de rotações transcirúrgicas, muitas vezes necessárias para melhor resolver algumas condições em tratamentos de DDFS $^{45,76}$. ELLIS $1 \mathrm{II}^{45}$, 1994, afirmou que sua conduta era posicionar os côndilos sem qualquer tipo de dispositivo de fixação transcirúrgica; dentre seus mais de duzentos pacientes operados com a técnica de osteotomia sagital bilateral, nenhum paciente precisou ser re-operado ou sofreu cirurgia na ATM por mau posicionamento pós-cirúrgico dos côndilos $^{45}$. Em sua seqüência de publicações, ARNETT et al. ${ }^{6}, 1993$, demonstraram com exemplos clínicos os reflexos de procedimentos cirúrgicos em avanços e recuos de mandíbula, apresentando as causas e efeitos sobre os côndilos ${ }^{6}$.

\subsubsection{Posicionamento Condilar e Estabilidade do Tratamento de DDFS}

Dentre os problemas que podem estar relacionados ao posicionamento condilar transcirúrgico, com reflexos pós-operatórios imediatos ou tardios, estão a recidiva do movimento cirúrgico, o desvio dos côndilos por interferência ou por falta de contato, e a compressão condilar gerando alterações morfológicas ${ }^{6}$. 
A recidiva óssea (slippage $=$ quantidade de desvio ou escorrego) em avanços cirúrgicos mandibulares ocorre antes da consolidação óssea em resposta à distensão dos tecidos moles adjacentes aos segmentos seccionados. Os tecidos conectivos paramandibulares são compostos de periósteo, músculos, subcutâneo conectivo e pele. Quando são esticados pelo movimento cirúrgico, eles tendem a retornar à posição inicial. Contrários a esta força, estão o material de fixação, o bloqueio maxilomandibular ou a suspensão óssea (quando adotados) e os côndilos (se corretamente assentados na fossa mandibular). Se a fixação não suportar as forças, a recidiva irá ocorrer para posterior e, possivelmente, para inferior. Grandes avanços, rotação anti-horária do complexo maxilomandibular (incisivos movimentados para cima e para anterior) e ângulo do plano mandibular aumentado estão em graus variados associados à recidiva de avanços mandibulares ${ }^{6}$.

A acomodação dos côndilos ocorre quando a fixação não atinge os objetivos de permitir que os segmentos ósseos sejam consolidados na posição planejada, mantendo os côndilos em posição estável e fisiológica. Esta acomodação existe em duas formas, a acomodação condilar com (ACCC) ou sem (ACSC) contato entre côndilo e fossa mandibular ${ }^{6}$.

Outra reação à falha no posicionamento condilar passível de ocorrer é a remodelação condilar por compressão. A compressão pode ser originada por deslocamentos para posterior, medial ou lateral dos côndilos. Tanto a remodelação por compressão posterior dos côndilos como por compressão medial ou lateral pode ocorrer no período de 9 a 18 meses após a cirurgia, causando recidiva dentária e no ponto $\mathrm{B}^{6}$.

STROSTER et al. ${ }^{150}, 1994$, compararam casos em que foi realizada a FIR a casos em que se realizou a fixação com fios de aço inoxidável. Foram utilizadas radiografias transcranianas para analisar mudanças nas dimensões sagital e vertical. Estes autores seguiram o método desenvolvido por PULLINGER; HOLLENDER ${ }^{126}, 1985$, para analisar a posição condilar por meio do acesso anterior e posterior dos espaços articulares. Eles encontraram diferenças significantes entre as duas técnicas de fixação após a cirurgia. $O$ espaço articular posterior havia diminuído mais nos casos em que fora realizada a fixação com fios de aço inoxidável. Mas ao final do tratamento ortodôntico, não era possível observar diferenças estatisticamente significantes 
entre os dois grupos. Estes resultados sugerem pequeno deslocamento posterior do côndilo, com ausência de significância clínica. Além disso, os autores consideraram a radiografia transcraniana muito útil na determinação das variações condilares, mas não necessariamente o método mais preciso para avaliar o real posicionamento do côndilo na fossa articular.

ALDER et al. ${ }^{2}, 1999$, avaliaram mudanças condilares em curto prazo após a realização de Osteotomia Sagital Bilateral e FIR. Foram observados 25 pacientes por meio de tomografias computadorizadas, realizando um estudo duplo-cego. Foram realizadas tomografias computadorizadas antes e 8 semanas após o procedimento cirúrgico. No plano sagital, $67 \%$ dos pacientes tiveram seus côndilos deslocados no sentido posterior. Não houve diferenças estatisticamente significantes entre os lados direito e esquerdo. Não houve diferença estatisticamente significante entre as imagens do pré e do pósoperatório.

Segundo PROFFIT; WHITE JR.;SARVER ${ }^{125}$, 2003, a recuperação dos movimentos mandibulares foi bastante facilitada quando o paciente fora submetido à terapia fisioterápica e à limitação do tempo de imobilização. Ainda assim, é quase impossível executar uma cirurgia de osteotomia sagital de ramo sem alterar a posição do côndilo em relação à fossa mandibular. Mesmo que o centro do côndilo permaneça em posição (o que é possível, apesar de pequenas mudanças de 1a $2 \mathrm{~mm}$ em uma dos três planos do espaço serem prováveis), freqüentemente ele rotaciona em dois planos: ao redor e através do eixo condilar.

A remodelação da ATM pode ocorrer em resposta à cirurgia de avanço mandibular. A remodelação condilar local caracteriza-se por alterações morfológicas limitadas, altura estável do ramo, oclusão estável e crescimento normal. Esta condição local não é limitante e, por isso, é denominada de remodelação funcional. Por outro lado, a remodelação condilar total caracteriza-se por envolver alterações morfológicas significativas. Quando presente, reduz a altura do ramo, cria retrusão mandibular progressiva e diminui a taxa de crescimento. O significado da remodelação total é que a oclusão se altera lentamente para Classe II, com sobressaliência após o tratamento oclusal, na medida em que o tamanho e a forma dos côndilos forem 
se alterando. Desta forma é também conhecida como remodelação não funcional $^{9}$.

\subsection{Métodos de análise da ATM}

Os exames possíveis para estudo da ATM baseiam-se em dados clínicos subjetivos e objetivos, além de exames complementares de imagem ou da análise de líquidos ${ }^{1,63,136,154,156}$ ou tecidos colhidos do local ${ }^{20}$. Os exames disponíveis e que, rotineiramente, são utilizados são a anamnese e o exame físico e, dentre os exames complementares, a ressonância magnética $56,135,172,182$ para analisar tecidos moles e a tomografia computadorizada ${ }^{72,79,91,135,141}$ para analisar tecidos duros. Além destes exames, o profissional pode realizar a análise dos tecidos por meio de biópsias em casos de patologias ou pesquisas em animais, e a análise do líquido sinovial quando necessitar saber quais substâncias prevalecem naquele meio.

ELLIS III; HINTON ${ }^{47}$ 1991, pesquisaram em macacos as alterações em articulações temporomandibulares decorrentes avanço mandibular fixados com técnicas rígida e não rígida (fios de aço inoxidável). Os animais foram operados pela técnica OSBRM e foram sacrificados após 6 semanas. Foi analisada a espessura da cartilagem articular e correlacionada à mudança posicional dos côndilos. Animais com bloqueio maxilomandibular (fixação não rígida) mostraram tendência para migração anterior dos côndilos; ao contrário, os animais com fixação rígida mostraram tendência de movimento posterior dos côndilos. A espessura da cartilagem articular estava aumentada nos animais com fixação não rígida. O grupo com fixação rígida quando havia migração dos côndilos para posterior também possuía reabsorção na superfície posterior desses côndilos e na superfície anterior da espinha posterior do osso esfenóide adjacente a ele. Houve relação significante entre a posição horizontal e a espessura da cartilagem posterior dos côndilos. O autor afirmou que seus resultados indicam que as alterações na posição condilar podem induzir a reabsorção condilar.

SCHULTES et al. ${ }^{141}$, 1998, utilizaram tomografias para criar modelos de mandíbulas antes e seis meses após a realização de cirurgia ortognática. As dimensões dos côndilos foram medidas diretamente nos modelos usando paquímetros. Estas medidas revelaram a ausência de mudanças na largura e 
altura dos processos condilares. A contribuição principal deste trabalho foi a utilização de tomografia computadorizada para a criação de modelos para verificar mudanças morfológicas.

GAGGL et al. ${ }^{56}$, 1999, ainda utilizando imagens de ressonância magnética de 25 pacientes, realizaram estudo estático e ativo das ATMs. A posição do disco articular e a degeneração do disco foram analisadas por métodos subjetivos. Na fase pré-cirúrgica, $54 \%$ dos pacientes apresentavam-se com deslocamento anterior do disco articular e 44\% apresentavam degeneração do disco articular. Na fase pós-cirúrgica, os autores não encontraram alterações significantes na quantidade de pacientes com deslocamento anterior ou degenerações ao nível do disco articular.

TOMINAGA et al. ${ }^{156}, 2004$, executaram teste ELISA em amostras de líquido sinovial colhido por artrocentese de pacientes sadios e portadores de sinais e sintomas de DTM. Os resultados revelaram tendências de aumento de atividade pró-inflamação, por meio da quantificação de marcadores fotossensíveis, no líquido sinovial dos pacientes portadores de DTM. Recentemente, outros pesquisadores ${ }^{1,75,107,136,154}$ também fizeram análises quantitativas de substâncias presentes no líquido sinovial, assim como da pressão por ele exercida. Estes estudos mostraram-se bastante precisos para detectar alterações no líquido sinovial, por meio de mediadores químicos.

\subsection{O minipig como modelo experimental}

A pesquisa médico-odontológica tem se desenvolvido com uma importante contribuição dos estudos em animais. Essa prática continua sendo largamente empregada com o intuito de se desenvolver métodos e técnicas que possam gerar instrumentos de "cura" ou alívio para os males que acometem o homem e outros animais ${ }^{89}$.

Dentre várias espécies utilizadas em experimentação biomédica destaca-se o suíno doméstico (Sus scrofa domesticus). Originário da Europa e Ásia, foi introduzido na América por Colombo em 1493. Descendente do javali, o suíno é um mamífero onívoro, de tamanho médio e corpo robusto, sendo explorado em cativeiro há mais de cinco mil anos. Atinge a puberdade em média entre os 5 e 6 meses de idade, quando então está pronto para a reprodução. É um animal sociável que vive em grupo ${ }^{88,146}$. 
O uso do suíno em pesquisas científicas é uma prática antiga ${ }^{151,153}$. No ano de 1540, VERSALIUS, em sua famosa obra De Humani Corporis Fabrica, em que tentava descrever os mecanismos que regem o corpo humano, desenhou um suíno sendo utilizado em experimentação da maneira como o médico grego Galeno o fizera há mais de mil anos. Segundo o autor, essa deve ser a mais antiga ilustração do uso desses animais nas diferentes áreas da ciência.

HAVEY, em 1628, ao descrever os mecanismos que regem a circulação sangüínea, também utilizou o suíno como animal de experimentação para melhor compreender a fisiologia humana. Os estudos de Versalius e Havey contribuíram para que Claude Bernard escrevesse mais tarde as normas da medicina experimental, que regem os procedimentos experimentais em biologia e medicina em nossos dias ${ }^{89}$.

Apesar dessas evidências, bem como daquelas que mostram a utilização de suínos de longa data na experimentação animal, o uso desta espécie como modelo experimental pela comunidade científica foi acanhado até os anos $70^{89}$.

A restrição do uso de suínos se prendeu à elevada capacidade de conversão alimentar com conseqüente ganho de peso desses animais, limitando o planejamento de experimentos em longo prazo. Por essa razão, suínos com essas características eram utilizados apenas em experimentos agudos ou de curta duração. Ainda, a utilização de animais muito jovens (leitões desmamados) induz a resultados não comparáveis à fisiologia de humanos adultos ${ }^{89}$.

As limitações descritas acima levaram cientistas a desenvolver linhagens de suínos com dimensões compatíveis com a utilização dos mesmos em laboratório, facilitando assim o emprego destes animais como modelo de experimentação em diversas áreas da pesquisa médico-biológica. Esses animais foram denominados de miniporcos (minipigs) ou, dependendo das dimensões dos mesmos, suínos miniatura (miniature pigs). A partir do desenvolvimento dos minipigs, as principais desvantagens dos estudos em suínos foram eliminadas, como o rápido crescimento e ganho de peso, além do alto custo para manutenção dos animais ${ }^{89}$, favorecendo 0 início do desenvolvimento de diversas pesquisas ${ }^{92,173,174}$. 
O estudo programado para o desenvolvimento de uma população de suínos miniatura iniciou-se no Instituto Homel, da Universidade de Minesota, em 1949 ${ }^{48}$. Resultados apresentados em 1965 e estudos nos 20 anos subseqüentes substanciaram os objetivos de se produzir um animal de tamanho reduzido, anatômica e fisiologicamente normal. Publicações recentes indicam que a seleção genética para um tamanho reduzido continua em várias linhagens de suíno miniatura, incluindo o suíno Kangaroo Island, do sul da Austrália; o Yucatan, originário do sul do México; o Minesota e o Sinclair, produzidos nos Estados Unidos; e o Goettinger, produzido na Dinamarca ${ }^{89}$.

É importante salientar que o plano de desenvolvimento do minipig foi feito para produzir animais que, mesmo em idade adulta, sejam suficientemente pequenos para permitir sua utilização como animal de laboratório em pesquisas biomédicas. Portanto, a única diferença entre o suíno doméstico e o minipig é o tamanho, não existindo diferenças entre os aspectos fisiológicos e anatômicos normais na sua similaridade com o homem ${ }^{23}$.

Segundo MARIANO ${ }^{89}, 2003$, a literatura referente ao uso do minipig em pesquisa biomédica mostra citação deste animal em mais de 5.000 publicações nos últimos 30 anos. Realizamos uma busca bibliográfica na base de dados internacional PubMed, utilizando os seguintes descritores: "miniature swine or minipig or minipigs or miniature pig", e encontramos entre janeiro de 1950 e dezembro de 2006, 4.517 trabalhos indexados. Como ilustra o gráfico, a utilização desses animais como modelo experimental nas diferentes áreas da biomedicina era pouco expressiva nas décadas de 50 e 60 . A partir da década de 70 , o número de publicações utilizando minipigs apresenta um crescimento significante e contínuo (Figura 1). 


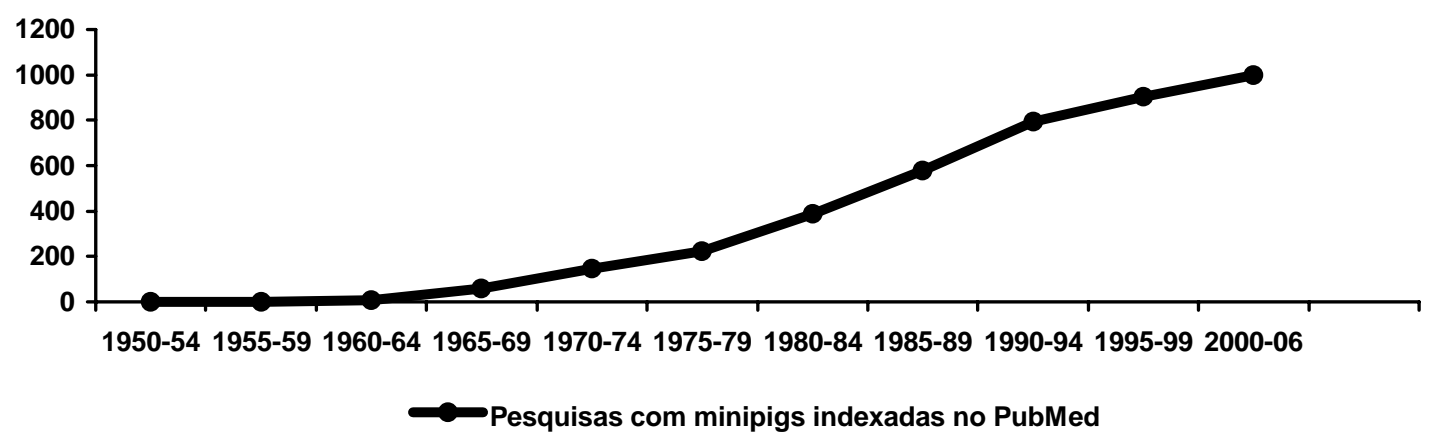

Figura 1 - Gráfico ilustrando a crescimento do número de pesquisas indexadas no PubMed utilizando o minipig como modelo experimental nas diferentes áreas da biomedicina

Estão hoje amplamente estabelecidas na literatura as semelhanças entre os suínos e o homem. O desenvolvimento embriológico do suíno tem sido reconhecido como muito similar ao encontrado em humanos, razão pela qual embriões de suínos têm sido utilizados para o estudo da embriologia humana. As semelhanças se estendem à anatomia ${ }^{24,48,64,89,92,118,174,176}$, fisiopatologia ${ }^{24,48,174,176}$ e estrutura molecular ${ }^{24,48,173,175,176}$, as quais são muito menores quando a fisiologia do homem é comparada à do cão, rato, camundongo e outras espécies utilizadas em experimentação.

Os suínos, incluindo o minipig, apresentam semelhanças com o homem no que diz respeito a aspectos ligados à Odontologia ${ }^{24}$. WEAVER; MCKEAN $^{175}$, 1965, complementam que os minipigs possuem atributos de um animal ideal para pesquisas na área odontológica: padrão de crescimento semelhante ao do homem; quantidade de crescimento rápida o bastante, para permitir a realização de estudos em determinado período de tempo, e lenta o bastante, que permite a diferenciação de determinadas etapas de um estudo; fisiologia semelhante à do homem, incluindo mastigação e movimentos da mandíbula; acesso aos dentes e glândulas para a realização de procedimentos clínicos e baixo custo de manutenção. Além disso, pesquisas direcionadas à Odontologia são facilitadas pela grande abertura bucal ${ }^{176}$.

Os suínos são animais difiodontes, sendo a dentadura decídua formada por 32 dentes: 12 incisivos, 4 caninos e 16 molares; e a dentadura permanente formada por 44 dentes: 12 incisivos, 4 caninos, 16 pré-molares e 12 molares $^{88,146}$. Para a determinação da idade durante os 12 primeiros meses de vida do suíno o melhor procedimento é a identificação de alguns dentes 
específicos que só irrompem após certa idade ${ }^{88}$, o que foi estudado por alguns autores $^{88,146}$.

A seqüência e cronologia de erupção dos dentes em minipigs foram estudadas por WEAVER; JUMP; MCKEAN ${ }^{173,174}$, 1966 e 1969, para PitmanMoore Minipigs. Esta seqüência foi confirmada para Minipigs BR-1 por OLTRAMARI et al. ${ }^{116}$, 2006, um estudo radiográfico, com acompanhamento dos animais dos 3 aos 15 meses de idade. Segue a seqüência descrita pelos autores para Minipigs BR-1:

- 3 meses: estão irrompidos todos os incisivos, caninos e molares decíduos, com exceção do primeiro molar decíduo que já exfoliou e será substituído em breve pelo primeiro pré-molar. Já é possível visualizar radiograficamente os germes dos seguintes dentes permanentes: primeiros e terceiros incisivos, caninos, primeiros pré-molares e primeiros molares.

- 5 meses: Os primeiros e terceiros incisivos e os caninos decíduos já se apresentam com bastante desgaste na coroa e raiz bastante reabsorvida; os segundos incisivos, que irromperam por último, apresentam-se praticamente intactos. Por volta dos 5 meses irrompem os primeiros pré-molares. Radiograficamente é possível visualizar os germes dos seguintes dentes permanentes: primeiros e terceiros incisivos, caninos, terceiros e quartos prémolares, primeiros e segundos molares permanentes.

- 7 meses: início do irrompimento dos primeiros molares permanentes. Radiograficamente é possível visualizar os seguintes germes dentários permanentes: primeiros e terceiros incisivos, caninos, terceiros e quartos prémolares e segundos molares.

- 9 meses: caninos decíduos quase totalmente reabsorvidos e caninos permanentes prontos para iniciar irrupção. Início da irrupção dos terceiros incisivos permanentes. Radiograficamente é possível visualizar os seguintes germes dentários permanentes: primeiros e segundos incisivos, caninos, segundos, terceiros e quartos pré-molares, segundos molares permanentes e o início da formação dos terceiros molares.

- 12 meses: primeiros incisivos decíduos apresentam suas raízes bastante reabsorvidas e radiograficamente visualizam-se os primeiros incisivos permanentes prontos para irromper. Início do irrompimento dos segundos molares permanentes. Os caninos mostram-se em irrupção. Radiograficamente 
é possível visualizar os germes dentários dos seguintes dentes permanentes: segundos incisivos, segundos, terceiros e quartos pré-molares, segundos molares permanentes (aqueles que ainda não iniciaram o processo de irrupção) e terceiros molares permanentes (ainda em estágio precoce de formação).

- 14 a 15 meses: encontram-se irrompidos os terceiros incisivos, caninos, primeiros pré-molares, primeiros e segundos molares permanentes. Os primeiros e segundos incisivos decíduos ainda estão presentes, mas já se pode visualizar os sucessores permanentes em estágio avançado de desenvolvimento. Os terceiros pré-molares na maxila e os quartos pré-molares na mandíbula estão em estágio de irrupção, e verifica-se radiograficamente a presença dos germes dos demais pré-molares. Os germes dos terceiros molares encontram-se em estágio um pouco mais avançado de desenvolvimento.

As DTMs têm sido estudadas em suínos ${ }^{171}$. Isso porque as características da ATM humana não podem ser adequadamente simuladas por animais comuns de laboratório, uma vez que para testar a função normal da ATM o modelo deve possuir anatomia, oclusão, movimento mandibular e biomecânico comparáveis ao humano. Alguns desses critérios são violados por primatas não humanos, e todos são violados por roedores (ratos, camundongos e cobaias) e alguns animais da ordem dos carnívoros (gatos e cachorros) $)^{64}$.

A variação na morfologia e função da ATM em mamíferos é surpreendente, até mesmo com relação à presença ou não do disco articular ${ }^{64}$. As formas de todos os componentes da ATM variam e esta diferença está relacionada aos movimentos que ocorrem ao nível articular. Nos carnívoros, a ATM permite pouco ou nenhum movimento de protrusão. Assim, as superfícies que se articulam são congruentes e simulam uma dobradiça, e o disco articular é pouco espesso em toda sua extensão. Os roedores apresentam movimento protrusivo do côndilo. Porém, esse movimento de protrusão é muito mais extenso em relação ao que acontece nos humanos. Nas ovelhas e cabras, os côndilos apresentam-se côncavos, ao contrário dos humanos, nos quais os côndilos são convexos. Além disso, a mastigação nos coelhos e nos ungulados difere sobremaneira da mastigação em humanos. Nesses animais, os molares 
formam planos inclinados que controlam a direção do movimento de força. Nos humanos, as cúspides dos dentes inferiores são muito menos importantes, sendo a força da mastigação controlada pela musculatura ${ }^{64}$.

Com relação à morfologia e movimentos mastigatórios, a semelhança mais próxima à condição humana é encontrada nos primatas superiores não humanos (macacos) e, surpreendentemente, nos suínos. Os suínos são muito semelhantes, talvez mais parecidos com os humanos que os macacos quando se destacam os detalhes da anatomia do disco articular ${ }^{64}$.

Além da morfologia e movimentos mastigatórios, há que se considerar a participação dos músculos da mastigação. A direção e a magnitude da carga na ATM são produtos da ação dos músculos mandibulares. Nos roedores e coelhos, a força muscular possui resultante anterior, que coincide com a força resultante de mordida, anulando a carga sobre a ATM. Nos cães, a força muscular possui resultante bastante posterior em relação à ATM, resultando em carga muito acentuada na articulação. Já nos humanos, a força muscular apresenta resultante pouco posterior à ATM, excedendo a força de mordida e fazendo com que a ATM receba carga suave ${ }^{64}$.

Os primatas superiores e suínos são anatomicamente e funcionalmente mais semelhantes aos humanos e, considerando-se custo, tamanho e cooperação, recomenda-se a utilização dos suínos como modelos experimentais para desenvolver pesquisas nessa área ${ }^{64}$.

$O$ suíno tem sido indicado como um bom modelo para pesquisas em Ortodontia ${ }^{24,25,109,168,176}$. BUCK; WEAVER ${ }^{23}, 1965$, avaliaram a movimentação dentária em minipigs utilizando um aparelho que promovia a mesialização do terceiro pré-molar para a área do segundo pré-molar previamente extraído. Após ter ministrado tetraciclina via endovenosa, analisaram as peças por microscopia de fluorescência e comprovaram a ocorrência de movimento de inclinação dos terceiros pré-molares.

NOGUCHI; KURODA; NAKAMURA ${ }^{109}$, 1976, relataram os aspectos de semelhança entre o homem e o suíno num trabalho de caracterização da linhagem Ohmini Minipigs. Afirmaram que a semelhança se refere à anatomia e fisiologia, e destacaram especialmente as similaridades relacionadas às estruturas bucais, o que permite o desenvolvimento de pesquisas científicas 
ligadas à Odontologia, inclusive estudos que envolvam Ortodontia, como a movimentação dentária e o crescimento e desenvolvimento craniofacial.

VERNA et al. ${ }^{168}$, 2004, utilizaram 25 suínos (landrace pigs) com três meses de idade para avaliar a presença de microrrachaduras no osso alveolar após a movimentação dentária. Concluíram que a presença de microrrachaduras próximas à área de reabsorção durante a movimentação ortodôntica é um indício de que elas podem ser o primeiro dano que será causado e reparado ao início da movimentação dentária.

$\mathrm{Na}$ Implantologia, os minipigs têm sido freqüentemente utilizados para pesquisa $22,95,102,108,129,140$. Nestes vários estudos, o minipig demonstrou ser um bom modelo experimental, apresentando recuperação rápida e eficiente após procedimentos cirúrgicos, mesmo quando estes foram extremamente invasivos.

Na área de Cirurgia, os minipigs têm sido utilizados com sucesso como modelo experimental ${ }^{54,63,133,134,159,162}$. TUXEN; KIRKEBY ${ }^{162}$, 1990, estudaram as fibras que compõem o músculo masséter de diversos animais, como ratos, camundongos, gatos, cães, vacas e suínos. O único animal a demonstrar maior semelhança às características do masséter humano foi o suíno que, portanto, foi considerado um animal adequado para pesquisas experimentais, como por exemplo, na investigação da distribuição e diâmetro dos tipos de fibras nos músculos mastigatórios antes e após procedimentos de cirurgia ortognática.

Em outro estudo, FREEMAN et al. ${ }^{54}$, 1997, investigaram em minipigs o grau para qual uma placa reta (linear plaque) imobiliza segmentos ósseos separados. O estudo revelou que placas retas não imobilizam suturas ósseas.

TROULIS et al. ${ }^{159}, 2000$, demonstraram a possibilidade da realização de um procedimento minimamente invasivo, a exposição endoscópica, dissecção e osteotomia vertical do ramo mandibular (EVRO), para posterior recuo mandibular. Neste trabalho os autores concluíram que o procedimento foi realizado com sucesso em minipigs.

SAKA et al. ${ }^{134}, 2002$, estudaram o suprimento sangüíneo da cortical mandibular em minipigs. Os autores concluíram que a cortical mandibular pode ser dividida em três partes, cada uma com diferentes tipos de suprimento sanguíneo. Os resultados deste estudo puderam contribuir com significância 
para os procedimentos em humanos e facilitaram a compreensão de algumas desordens patológicas da mandíbula.

Os mesmos autores ${ }^{133}, 2002$, compararam os estudos com relação ao suprimento sangüíneo realizados em minipigs a resultados obtidos em humanos. Os autores concluíram que os resultados obtidos em minipigs são aplicáveis em humanos e há três diferentes tipos de suprimento sangüíneo evidentes na cortical mandibular das duas espécies.

Ainda nesta área, HERFORD et al. ${ }^{63}, 2005$, compararam a pressão exercida sobre o líquido sinovial da ATM após avanço imediato e avanço gradual da mandíbula em minipigs. Concluíram que este modelo animal era útil para a medição direta da pressão exercida sobre o côndilo. Além disso, os resultados demonstraram que o avanço gradual da mandíbula, por meio da distração osteogênica, produz menos pressão e causa menor reabsorção condilar que o avanço imediato estabilizado com fixação rígida.

Objetivando a utilização de minipigs para pesquisa odontológica no Brasil, NAVARRO et al. ${ }^{101}$, 2006, desenvolveram seis técnicas para padronização radiográfica em Minipigs BR-1: técnica para avaliação da região posterior na maxila, técnica para avaliação dos dentes posteriores na mandíbula, técnica para avaliação dos dentes posteriores e anteriores na maxila, técnica para avaliação dos dentes posteriores na mandíbula (lateral oblíqua), técnica para avaliação dos dentes anteriores na maxila e técnica para avaliação dos dentes anteriores na mandíbula. Foram testados diferentes ângulos de incidência, distâncias focais e tempos de exposição aos raios $X$. A partir de então, foram confeccionados posicionadores específicos para as técnicas, na tentativa de facilitar a realização das radiografias e garantir a padronização dos resultados em estudos que envolvessem o controle radiográfico de vários animais, em longo prazo.

As estruturas bucais, em especial a cronologia de erupção dos dentes, foram avaliadas em exemplares da colônia brasileira de minipigs BR$1^{101,114,116}$. Doze minipigs machos, com idades de 3 a 15 meses, foram anestesiados e submetidos a exames físico e radiográfico. Considerando estruturas bucais, presença de dentes e cronologia de erupção, semelhante ao relatado na literatura, o trabalho indica possibilidade da utilização dos minipigs BR-1 em pesquisas na área odontológica. 
Em função da extensa literatura à cerca da utilização de minipigs como modelos experimentais para pesquisas na área médico-odontológica, optamos por utilizar este animal para nosso estudo investigativo. 


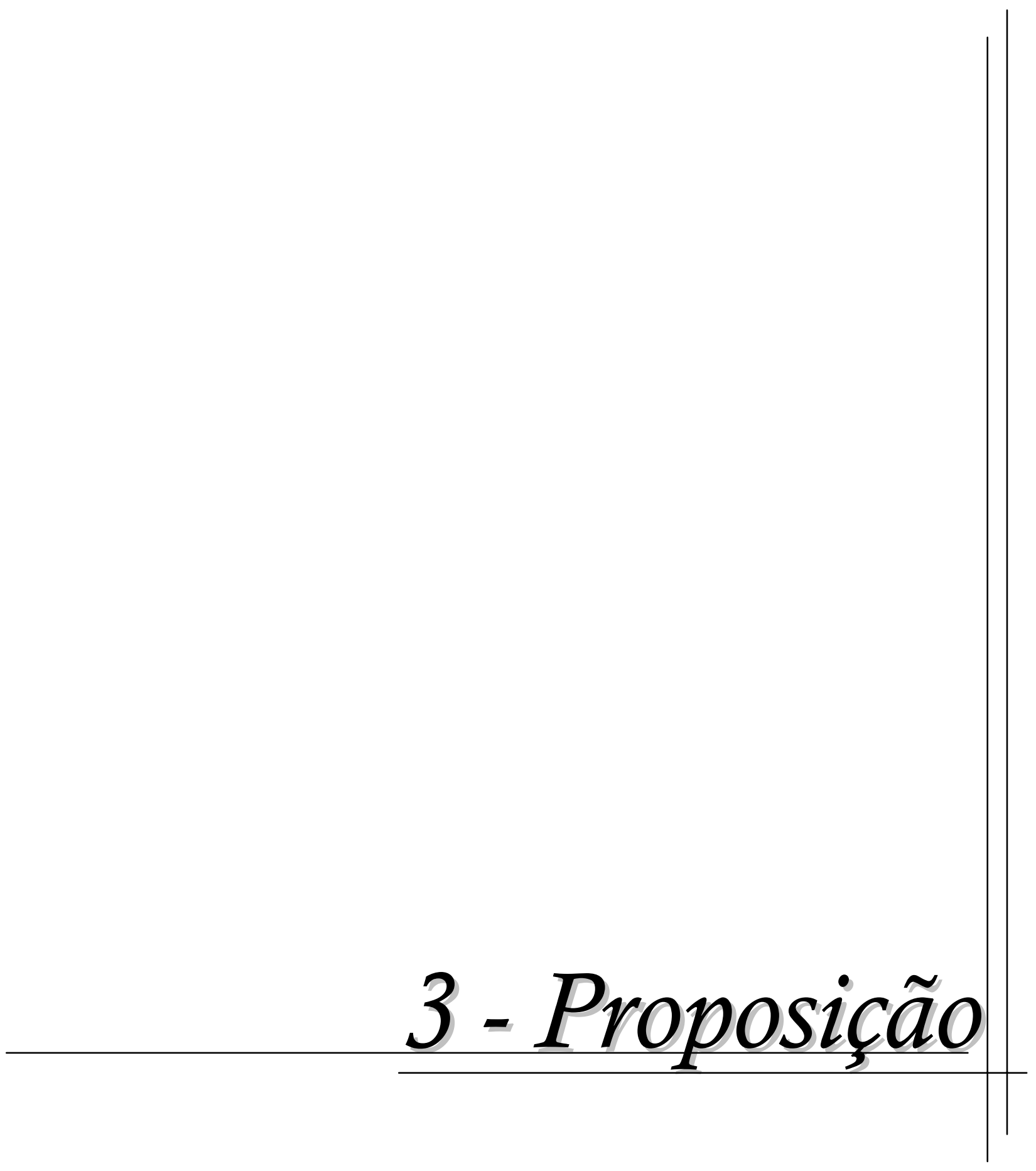




\section{3 - Proposição}

O objetivo deste trabalho foi testar a seguinte hipótese nula: "Não há alterações na forma dos côndilos e não há diferença entre o nível de mediadores do processo inflamatório nas ATMs dos grupos 1 (controle), 2 (fixação rígida) e 3 (fixação semi-rígida). Para tanto, a quantidade de mediadores presentes, os índices de alteração do côndilo e o aspecto histológico dos mesmos, nestes três protocolos, foram comparados.

Ainda, como objetivos secundários foram avaliados:

1- A metodologia proposta para futuros estudos sobre ATM, Cirurgia Ortognática e fixações ósseas;

2- O potencial do minipig BR-1 como modelo experimental em pesquisas odontológicas e para treinamento na área de Cirurgia e Traumatologia Bucomaxilofacial. 


$$
\begin{array}{r}
4 \text { - Material e } \\
\text { Métodos }
\end{array}
$$




\section{4 - Material e Métodos}

A execução desta pesquisa foi aprovada pela Comissão de Ética no Ensino e Pesquisa em Animais (CEEPA), da Faculdade de Odontologia de Bauru - USP, em 05 de dezembro de 2003, processo número 41/2003.

\subsection{Amostra}

Para a realização deste estudo utilizaram-se 18 minipigs (Minipig BR-1), machos, adultos jovens, apresentando peso médio de $30 \mathrm{Kg}$ e 15 meses de idade. Os animais foram adquiridos da empresa Minipig Comércio e Desenvolvimento (Campina do Monte Alegre-SP-Brasil) e transportados para o Biotério da Faculdade de Odontologia de Bauru - USP, onde permaneceram até o final do experimento.

Manteve-se a numeração original de cada animal, seguindo o "Sistema Australiano" ${ }^{\text {", }}$, no qual o assinalamento é feito por mossas nas orelhas com alicates especiais. Neste sistema, dependendo da posição na orelha, a mossa tem um valor convencional e assim se formam os números (Figura 2).

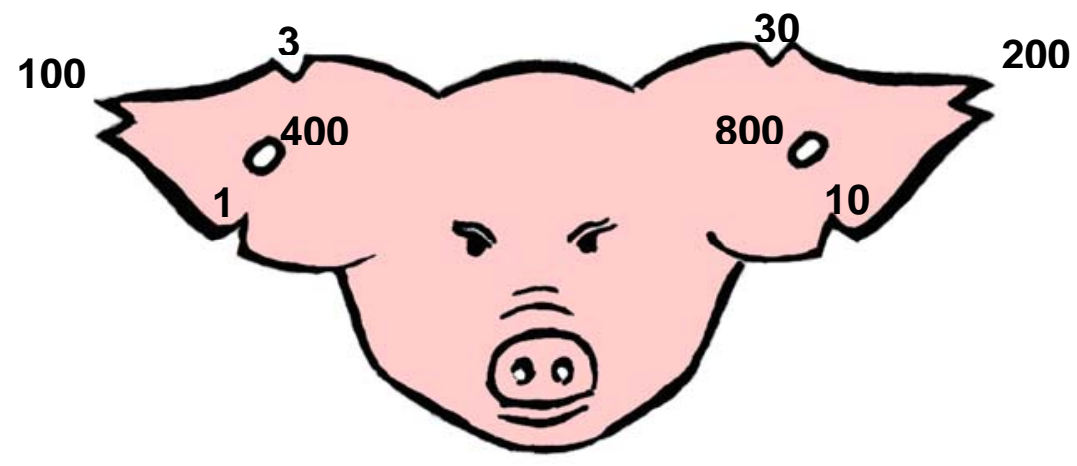

Figura 2 - Diagrama do "Sistema Australiano" para assinalamento de suínos. Vista frontal do animal $^{88}$

Durante o período experimental, os animais receberam água sem restrições e foram alimentados com ração própria para suínos (S4®, Bravisco, Bastos-SP-Brasil), numa quantidade diária equivalente a $2 \%$ do peso de cada animal, dividida em duas porções, uma pela manhã e outra à tarde. No período 
pós-cirúrgico, misturou-se a ração com água para que adquirisse consistência pastosa antes de ser ingerida pelos animais, para facilitar a alimentação. Os animais foram mantidos em baias com dimensões de $1,5 \mathrm{~m} \times 5 \mathrm{~m}$, sendo dois em cada baia (Figuras 3 A e B).
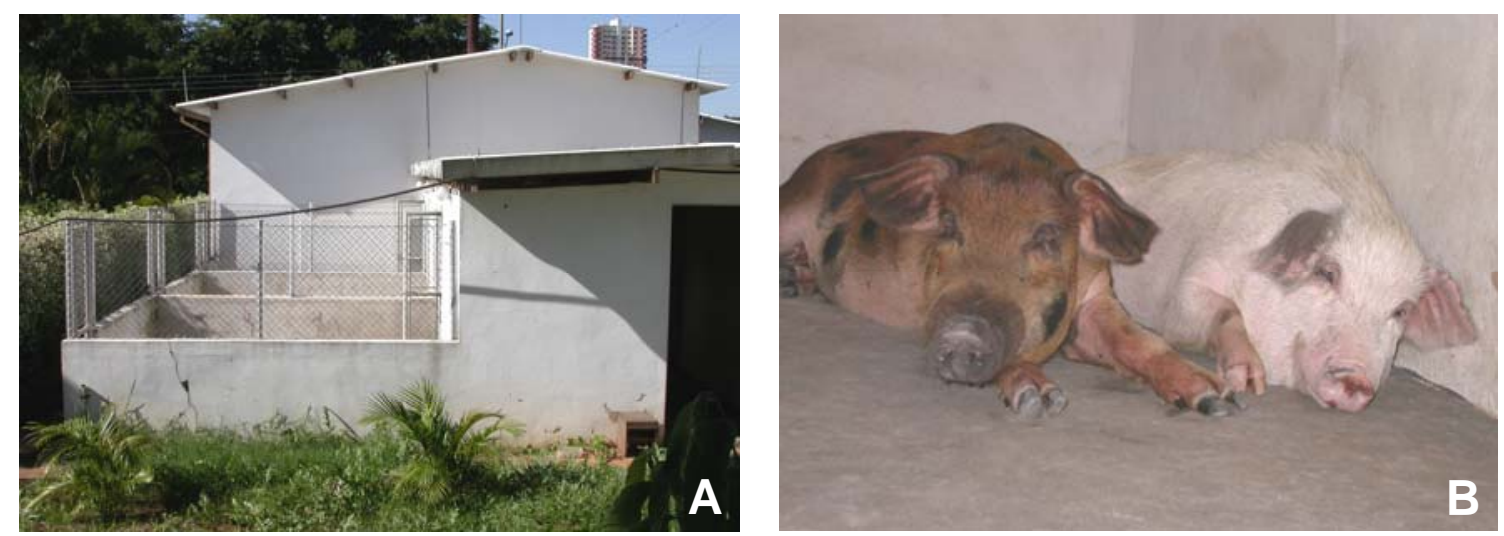

Figuras 3 A e B - Vista do Biotério da Faculdade de Odontologia de Bauru - USP, mostrando o setor das baias, no qual os animais permaneceram durante a pesquisa. Foram mantidos dois animais em cada baia durante a realização dos experimentos

O local manteve-se sob iluminação natural e temperatura ambiente, exceto após as intervenções, quando, então, a baia em que os animais estavam era aquecida por meio de um aquecedor elétrico, até que os mesmos se recuperassem da anestesia geral. As baias eram higienizadas duas vezes ao dia e mantidas arejadas, permitindo total controle e observação dos animais.

\subsection{Contenção dos Animais}

Nesta pesquisa a contenção utilizada foi o cachimbo, recomendada para suínos ${ }^{88,90}$, ela é composta por uma corda que envolve a maxila do animal. Ao apertar a maxila, o animal sente um desconforto e se mantém imobilizado (Figuras 4 A e B). 


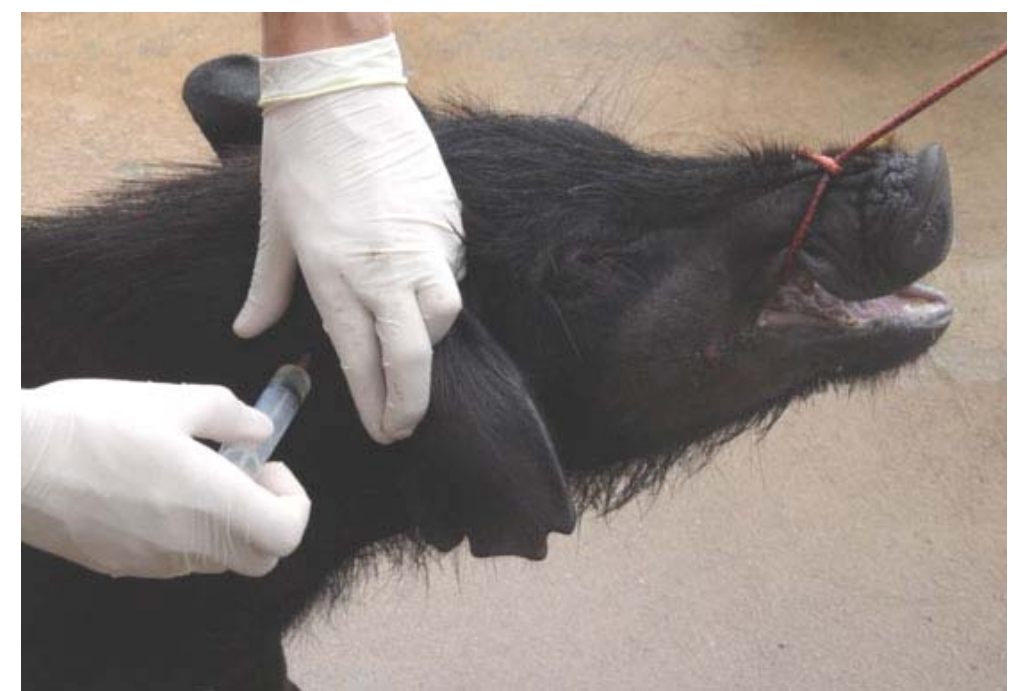

Figuras 4 A e B - Figura ilustrando o procedimento para contenção do animal, utilizando o cachimbo

\subsection{Anestesia dos Animais}

$\mathrm{Na}$ realização de todas as intervenções, os animais estavam sob anestesia geral. Para isso, eles permaneceram em jejum alimentar de 12 horas e jejum hídrico de 6 horas previamente aos procedimentos anestésicos ${ }^{90,152}$.

Após a contenção do animal, utilizou-se a combinação de préanestésico específico para suínos Azaperone (Destress® ${ }^{\circledR}$ - Des-Vet, São Paulo-SP-Brasil), ministrando-se via intramuscular $1 \mathrm{mg} / \mathrm{Kg}$ de peso. Após 20 minutos, aplicou-se a dose inicial de anestésico geral Quetamina (Dopalen $®$ Vetbrands, Jacareí-SP-Brasil), com dosagem de $5 \mathrm{mg} / \mathrm{Kg}$ de peso, também por via intramuscular. Estes dois medicamentos foram aplicados enquanto o animal estava na rede de contenção.

Aproximadamente após 10 minutos da aplicação do anestésico geral, ocorria o aprofundamento da anestesia e o animal era levado ao laboratório de pesquisa, onde foram realizadas as cirurgias. No laboratório, iniciavam-se os procedimentos para dar continuidade à anestesia, por via endovenosa (veia marginal da orelha) (Figuras 5 A-D). 

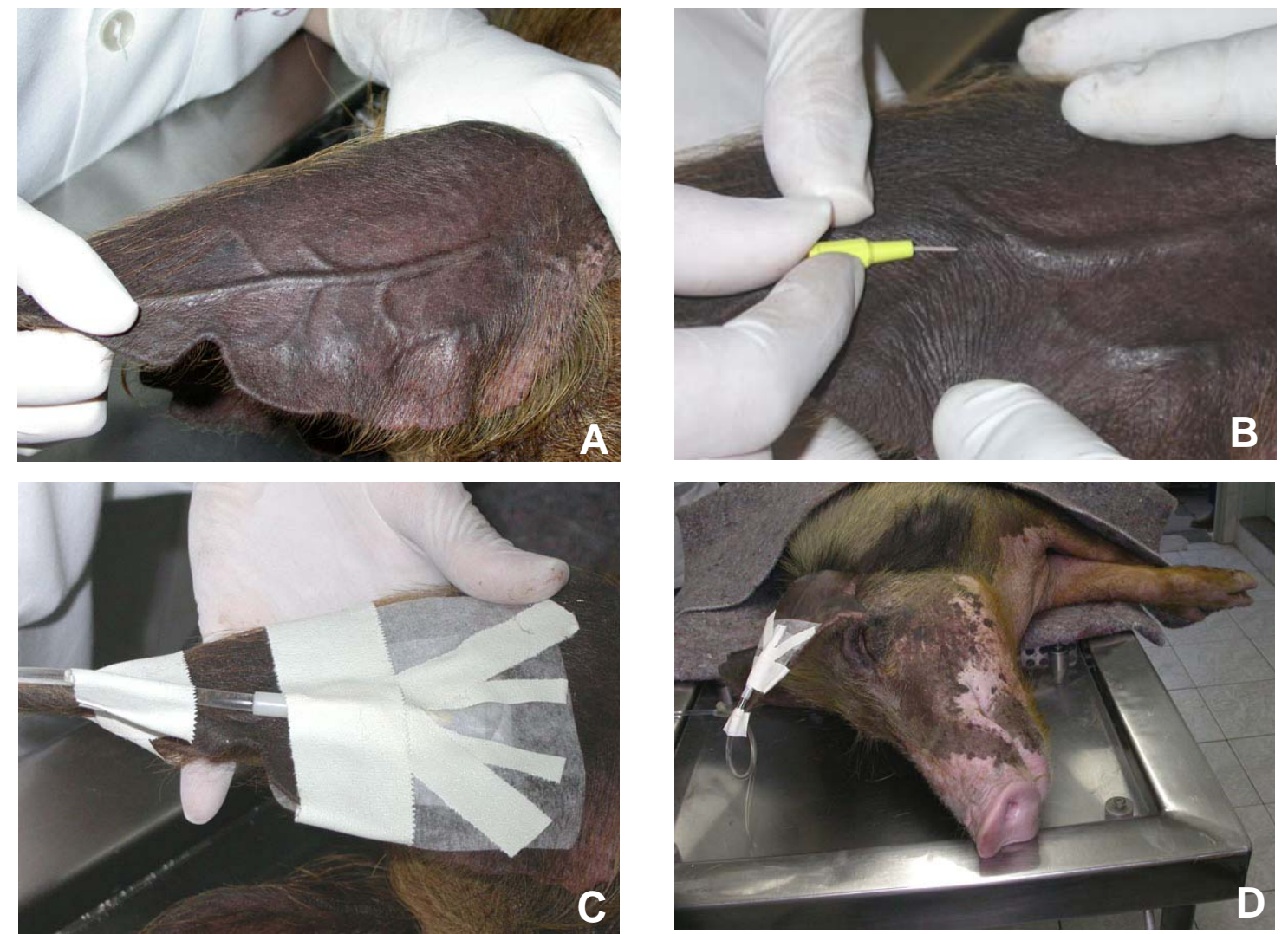

Figuras 5 A-D: A) Veia marginal da orelha após tricotomia na região; B) Introdução do catéter; C) Catéter em posição e estabilizado; D) Animal na fase pré-cirúrgica em venóclise

A dose inicial permitiu um tempo de trabalho de aproximadamente 1 hora, quando então se iniciavam as reaplicações, que corresponderam à $5 \mathrm{mg} / \mathrm{Kg}$ de peso de Quetamina, realizadas a cada 45 minutos, enquanto durasse a intervenção - em média 5 horas. Durante todo o período em que o animal permaneceu sob anestesia geral, monitoraram-se os batimentos cardíacos, a freqüência respiratória e a temperatura, além do controle dos reflexos palpebrais, interdigitais e intestinais. Os animais foram mantidos com cobertas para controle da temperatura.

\subsection{Divisão dos Grupos}

Grupo 1 (Controle): seis animais não operados;

Grupo 2 (Fixação Rígida): seis animais submetidos à cirurgia de avanço mandibular e osteossíntese com parafusos bicorticais;

Grupo 3 (Fixação Semi-Rígida): seis animais submetidos à cirurgia de avanço mandibular e osteossíntese com mini-placas. 


\subsection{Preparo dos animais e procedimentos cirúrgicos}

A equipe era composta por um cirurgião, um anestesista, dois assistentes e um instrumentador (Figura 6).

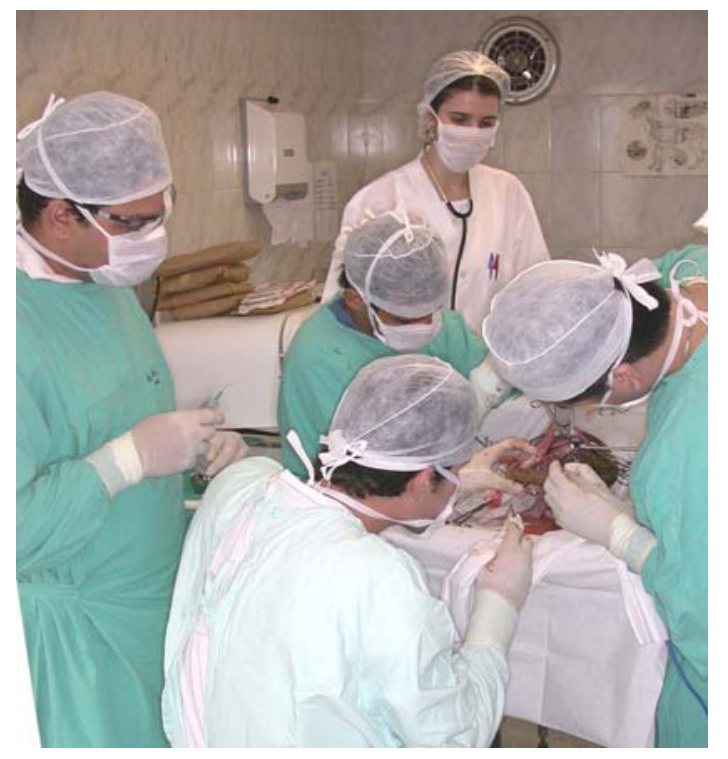

Figura 6 - Foto mostrando a equipe atuando durante as intervenções

Em todos os animais manteve-se a mesma seqüência operatória. Inicialmente, os animais foram contidos e então mantidos sob anestesia geral conforme descrito anteriormente. Quando levados ao laboratório de pesquisa, os animais eram colocados sobre uma mesa cirúrgica, na qual permaneceram em posição lateral para o início da intervenção.

Em função das diferenças anatômicas e condições do animal, foram necessárias algumas modificações na técnica realizada em humanos, como por exemplo, a incisão da comissura labial. O mesmo cirurgião (RLN) executou todas as intervenções, durante 11 dias sucessivos.

Realizaram-se anti-sepsia intra (Figura 7A) e extrabucal (Figura 7B) com PVPI tópico (Polivinil Pirrolidona-lodo), seguidas pela irrigação com soro fisiológico. Os animais foram cobertos com campo operatório estéril, para o início do ato operatório (Figura 7C). Para anestesia local, realizou-se a técnica terminal infiltrativa, com solução anestésica à base cloridrato de lidocaína $2 \%$ e epinefrina 1:100.000 (Anestésico L® - Pearson, São Paulo-SP-Brasil) (Figura 7D), objetivando a ausência de dor e reflexos do animal e, também, a hemostasia local.

Utilizando-se bisturi com lâmina no 20, realizou-se a incisão da comissura labial (Figura 7E), para facilitar o acesso à região posterior da 
mandíbula. Neste momento, foram utilizados pinças Halstead e fios reabsorvíveis para ligar os pequenos vasos sagüíneos locais. Apesar da grande abertura bucal do animal, a dimensão antero-posterior de sua mandíbula fez com que utilizássemos este acesso, adaptando a técnica aplicada em humanos.

Iniciou-se a incisão intrabucal utilizando-se bisturi com lâmina $\mathrm{n}$ ำ 15 (Figura 7G). O descolamento se estendeu da região dos pré-molares até próximo à borda posterior da mandíbula, por vestibular (Figura $7 \mathrm{H}$ ). $\mathrm{O}$ descolamento lingual foi executado à semelhança da técnica em humanos, expondo a língula mandibular e o início do processo coronóide (Figura 7I).

As cirurgias iniciavam-se pelo lado direito e anteriormente à fixação deste lado o animal era virado para o lado esquerdo, para que então fosse finalizado o protocolo de avanço mandibular cirúrgico do lado oposto. Somente após os dois lados liberados era executada a fixação.

A osteotomia sagital foi executada baseada na técnica descrita por TRAUNER; OBWEGESER ${ }^{158}$ e revisada por DAL PONT ${ }^{40}$, HUNSUCK $^{66}$ e BELL; SCHENDEL ${ }^{15}$. Esta técnica consiste em separar o segmento do corpo mandibular dos dois ramos ascendentes, por meio de osteotomias executadas paralelas entre si de cada lado da mandíbula. Foram executadas algumas adaptações devido a variações anatômicas do animal.

A linha de osteotomia iniciou-se 3 a $5 \mathrm{~mm}$ acima da língula e forame mandibular, na borda medial do ramo mandibular, com profundidade de $4 \mathrm{~mm}$ (Figura 7J). Esta linha seguiu em direção à tábua óssea mandibular vestibular, logo abaixo ao colo dos molares, cruzando obliquamente a linha oblíqua externa. Ao alcançar a posição do primeiro molar, um ângulo de 90 graus foi executado, e seguiu-se em direção à borda inferior da mandíbula (Figura 7K). É muito importante que, ao alcançar esta estrutura, estivesse feito o contorno quase total da base mandibular. As linhas de osteotomias estavam definidas. Neste ponto, era importante ter certeza de que em sua extensão a osteotomia havia atravessado toda a cortical mandibular(Figura $7 L$ ).

Utilizando cinzéis, seguiu-se com a separação dos segmentos ósseos proximais e distais (Figura 7M). Primeiro, introduziu-se uma distância de $10 \mathrm{~mm}$ em toda extensão da osteotomia, seguindo com introdução posterior maior (20 a 35mm). Por meio de dois cinzéis inseridos na linha de osteotomia, 
seguiu-se com a separação óssea, agora realmente com movimentos antagonistas dos cinzéis, abrindo uma fenda por toda extensão da osteotomia. Neste momento, a partir da visualização direta, era importante confirmar se a fratura havia se completado da forma desejada (Figura 7N). Depois de confirmada a separação, era feita uma hiper-mobilização do fragmento distal para liberar a musculatura, e a seqüência de fixação se iniciava.

Para atingir um avanço padrão de $6 \mathrm{~mm}$, dois cinzéis desta espessura foram utilizados (Figura 70). Um dos auxiliares estabilizava o segmento proximal a ser fixado durante o tempo necessário para completa instalação das fixações. As perfurações foram feitas sob irrigação abundante e utilizando as brocas indicadas pelo fabricante (MDT, Rio Claro,SP, Brasil). No grupo 2, foram utilizados sempre três parafusos em disposição de " $L$ " invertido e parafusos de extensão compatível com medidas feitas no momento da perfuração (Figura 7Q). No grupo 3, foram utilizadas duas placas do sistema de $2 \mathrm{~mm}$, uma de seis furos e outra de quatro furos, ambas com ponte média (Figura 7R).

Após a fixação, os movimentos excursivos mandibulares foram testados para verificar a resistência da fixação, o posicionamento ósseo e a oclusão.

Em área de mucosa, utilizou-se a sutura festonada contínua, adicionando alguns pontos simples sobre a sutura contínua, porque se caso algum ponto soltasse, o retalho não abriria além daquele ponto (Figura 7S). Utilizou-se Vycryl 4.0 (Ethicon - Johnson \& Johnson, Piscataway-NJ-EUA) em todas as suturas de mucosa e em pontos internos, principalmente nos lábios. Nestes, a sutura sempre começou da posição mais interna da mucosa jugal até a comissura labial, seguindo-se com a sutura por planos (Figura $7 \mathrm{~T}$ e U). A sutura externa foi executada com fio nylon 2.0 (Ethicon - Johnson \& Johnson, Piscataway-NJ-EUA), devido à pele do animal ser muito espessa (Figura $7 \mathrm{~V}$ ).

No período de recuperação da anestesia, o animal era posicionado em um dispositivo de contenção adaptado a partir de um equipamento para uso em eqüinos (cabresto). Posicionavam-se as patas dianteiras e a cabeça dentro do dispositivo e o animal era suspenso. Tanto a suspensão como a fixação inferior deste dispositivo eram feitas em quatro pontos, não permitindo 
que o animal pudesse causar ferimentos a si mesmo durante o pós-operatório imediato (Figura $7 \mathrm{X}$ e $\mathrm{Y}$ ).

Após o procedimento cirúrgico, administraram-se via intramuscular: antibiótico (Florfenicol - Nuflor $®$, Schering-Plough, Cotia-SP-Brasil, $1 \mathrm{~mL}$ para cada $20 \mathrm{~kg}$ de peso, duas aplicações, com intervalo de 48 horas); corticosteróide (Triclorometiazida e Dexametasona - Naquasone ${ }^{\circledR}$ Injetável, Schering-Plough, Cotia-SP-Brasil, $5 \mathrm{ml}$ por dia, durante 2 dias); antiinflamatório não esteroidal (Flunixin meglumine - Banamine® Injetável, Schering-Plough, Cotia-SP-Brasil, $2 \mathrm{~mL}$ para cada 45 quilos de peso por dia, durante 3 dias); analgésico (dipirona sódica - D500, Pfizer, Guarulhos-SP-Brasil, 5ml por dia, durante 3 dias). 

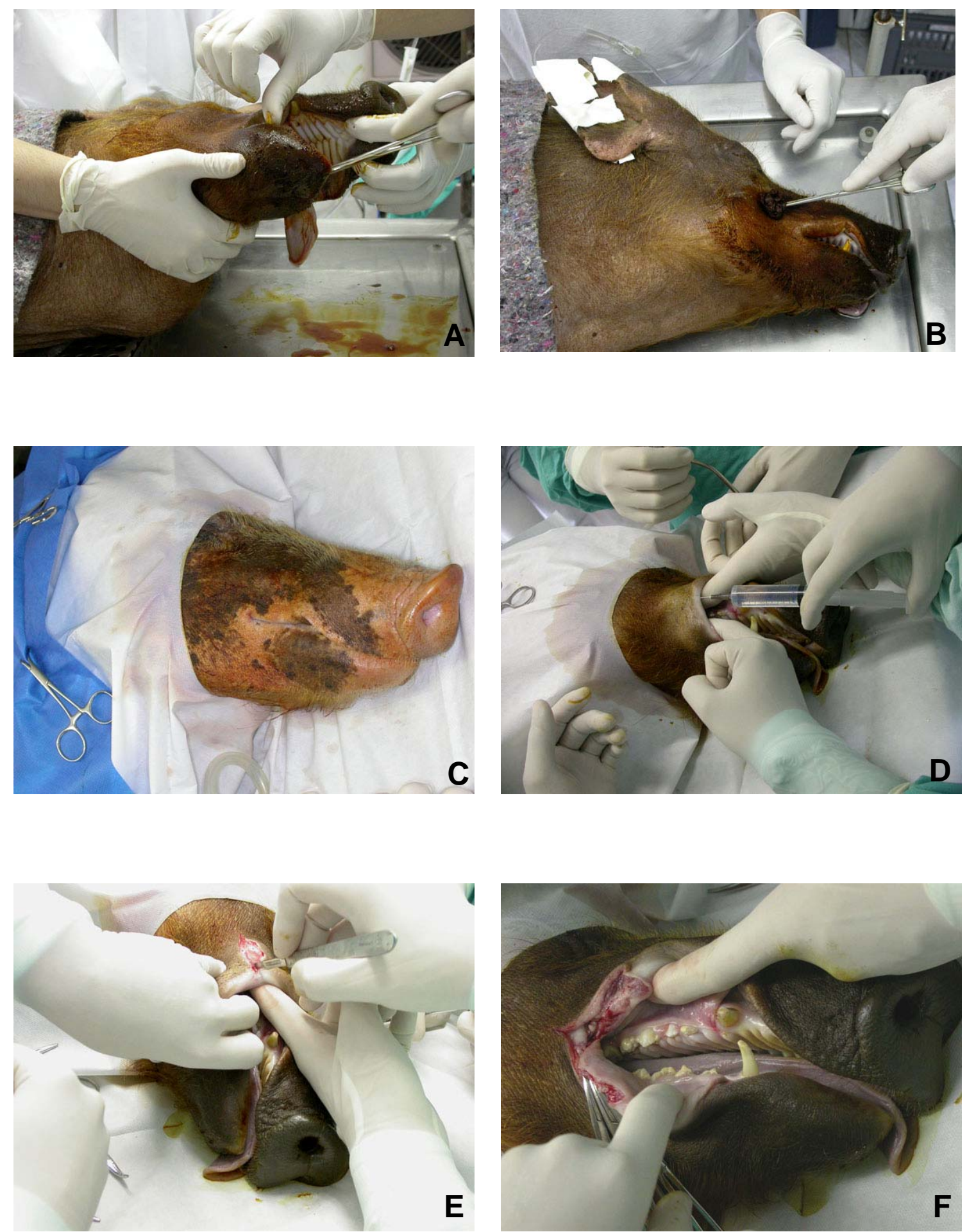

Figuras 7 A-F: A e B) Anti-sepsia intra e extrabucal com PVPI tópico; C) Animais cobertos com campos operatórios estéreis; D) Anestesia local; E e F) Incisão da comissura labial 

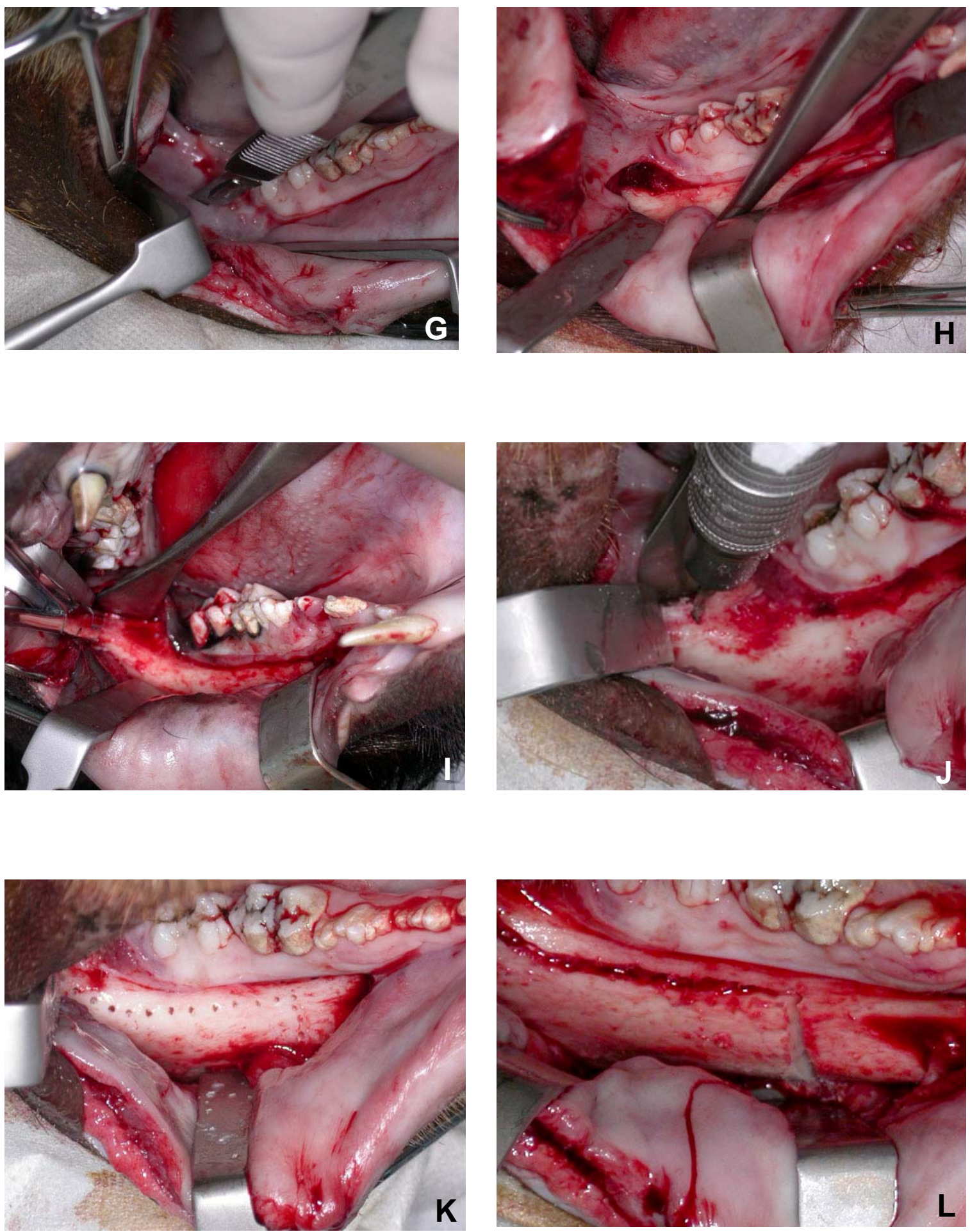

Figuras 7 G-L: G) Incisão intrabucal; H e I) Descolamento mucoperiostal; J) Início da osteotomia com broca esférica; K) Demarcação da extensão da osteotomia; L) Osteotomia sagital da mandíbula 

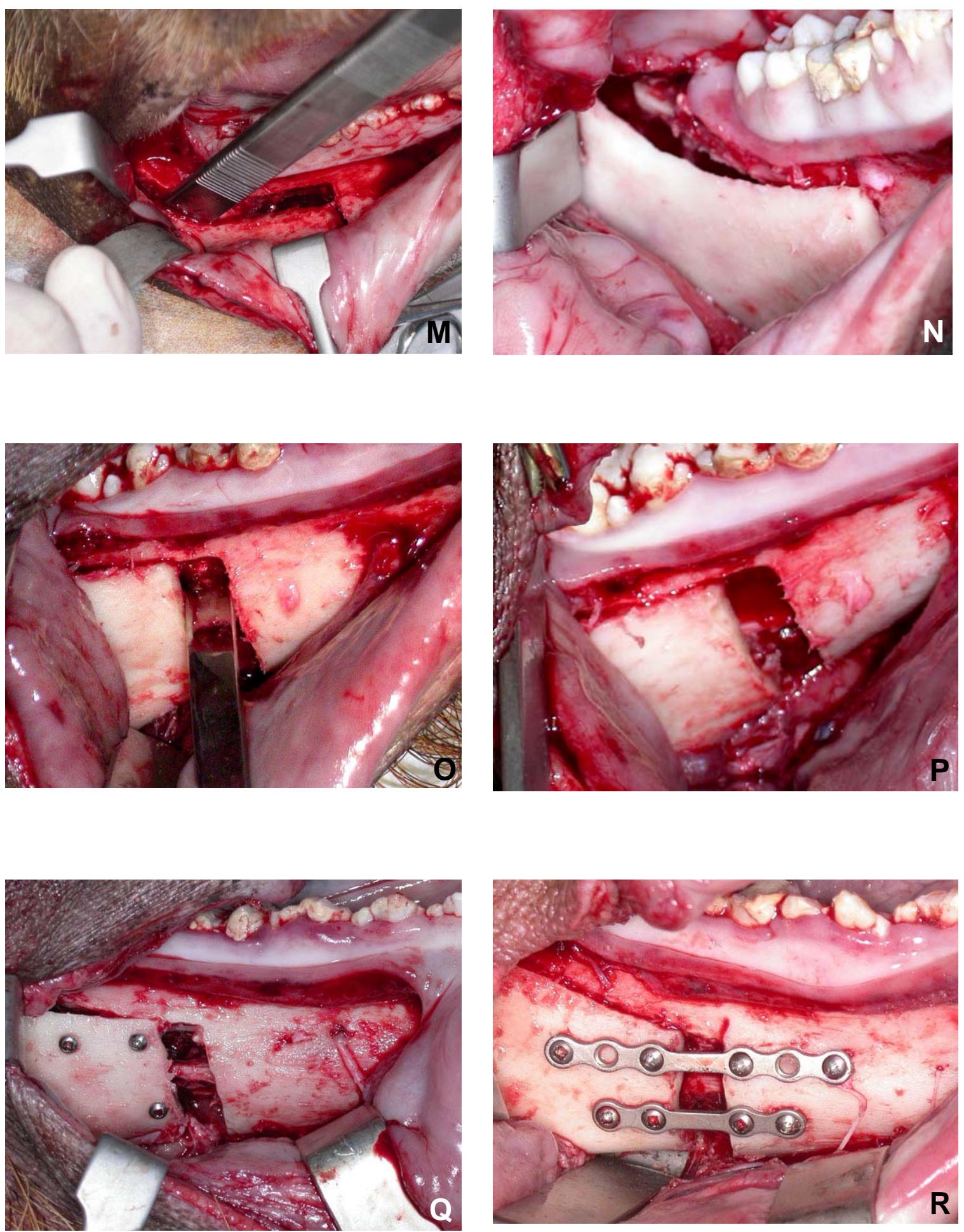

Figuras 7 M-R: M e N) Finalização da osteotomia com cinzel e separação dos cotos; $\mathbf{O}$ e P) Medição da quantidade de avanço mandibular (6mm); Q) Osteossíntese com fixação rígida; R) Osteossíntese com fixação semi-rígida 

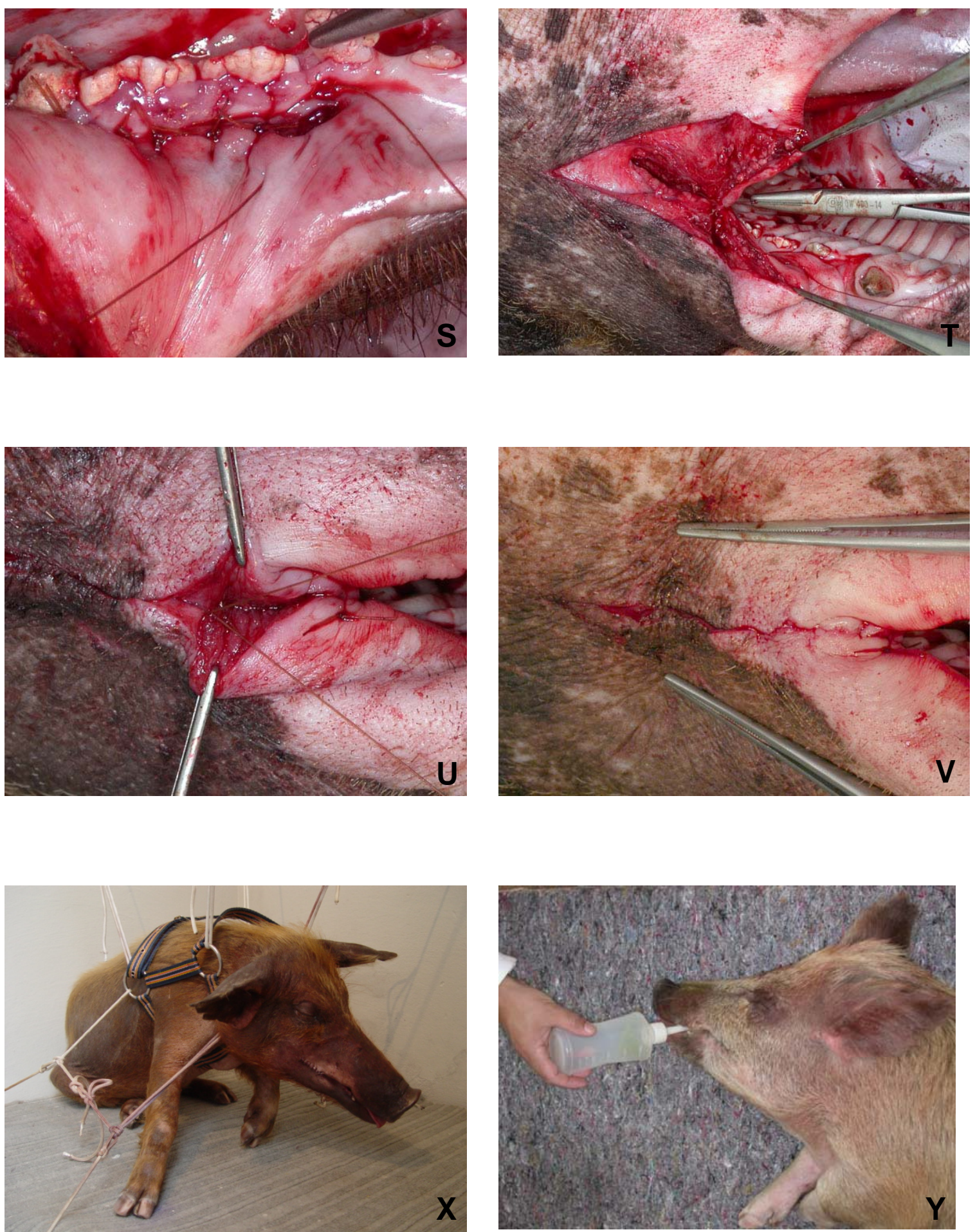

Figuras 7 S-Y: S) Sutura intrabucal; T-V) Sutura da comissura labial por planos; X) Pósoperatório imediato: animal estabilizado em um dispositivo para não se machucar; Y) Alimentação pastosa na fase pós-cirúrgica 


\subsection{Coleta do líquido sinovial, realização do Teste ELISA e obtenção das biópsias}

Decorrido o período experimental (120 dias), os animais foram mortos e realizou-se imediatamente a coleta do líquido sinovial das ATMs direita e esquerda de cada animal. As ATMs foram dissecadas até a região próxima à cápsula articular (Figuras 8 A-C), e a coleta do líquido sinovial foi realizada com o auxílio de uma seringa de $3 \mathrm{~mL}$ e agulha de 0,15 x $20 \mathrm{~mm}$ (Figuras 8 D-F). O líquido coletado foi centrifugado (Centrífuga Heraeus Sepatech Biofuge $15 \mathrm{R}$, a $10.000 \mathrm{~g}$, por 10 minutos em temperatura de $4^{\circ} \mathrm{C}$ ) com o objetivo de separar o sobrenadante do material sólido indesejável (Figuras $8 \mathrm{E}$ e F). A amostra foi armazenada em temperatura de $-80^{\circ} \mathrm{C}$, até a realização do teste ELISA.

Terminada a coleta do líquido sinovial, os animais foram decapitados e removeram-se as ATMs e regiões anexas de interesse para fixação em solução de formol 10\% em tampão fosfato, por um período de sete dias.

O fluido separado foi analisado pelo teste ELISA para quantificar a presença de mediadores do processo inflamatório Interleucina-6 (IL-6), um mediador pró-inflamatório, e Interleucina-10 (IL-10), um mediador antiinflamatório. As amostras foram descongeladas e, após serem diluídas em concentrações crescentes, foram adicionadas a uma placa própria (de 96 poços). Uma série de reações imunosensíveis foi realizada para identificar a quantidade de cada marcador presente no líquido sinovial dos côndilos.

A placa utilizada para os testes ELISA foi preparada previamente com anticorpos primários específicos. Desta forma, estes anticorpos são empregados para aderir às paredes dos poços presentes na placa. Esta etapa é bem delicada e, se a placa utilizada não vier preparada da fábrica, a pessoa que executar a técnica deve ter experiência, pois pouco anticorpo nas paredes pode deixar espaço para outras moléculas, induzindo a um resultado falso positivo. Por outro lado, se muito anticorpo for utilizado, o excedente irá se ligar à proteína a ser estudada e nas lavagens subseqüentes será eliminado.

Após o preparo adequado da placa com os anticorpos primários, foi realizada a diluição do líquido a ser estudado, para que de um amplo espectro de concentrações, pelo menos em uma delas pudesse ser encontrada a 
quantificação desejada. Os líquidos com as diluições fracionadas foram pipetados em poços previamente identificados em um mapa de referência.

As concentrações de IL-6 e IL-10 no líquido sinovial foram determinadas pelo teste ELISA com duplo ligante ${ }^{37}$. Sua seqüência se inicia com a incubação de uma placa de 96 poços, previamente preparada com $100 \mu \mathrm{l} /$ poço de anticorpo específico (Pharmingen, Saint Louis, MO, EUA) para as citocinas mencionadas, em concentração de $2 \mathrm{mg} / \mathrm{ml}$ (IL-6) e $1 \mathrm{mg} / \mathrm{ml}$ (IL-10) de solução tamponada. A placa foi armazenada em $4^{\circ} \mathrm{C}$ durante 12 horas (overnight). Foi imprescindível neste momento a lavagem cuidadosa com solução tamponada, seguida por incubação durante duas horas em $37^{\circ} \mathrm{C}$, em solução de soro bovino $1 \%$ a fim de inviabilizar eventuais ligantes de anticorpos ainda ativos.

Curvas padrão foram construídas utilizando quantidades padronizadas de citocinas recombinantes IL-6 e IL-10 (Pharmingen). Amostras e controle foram aplicadas nos respectivos poços e incubadas overnight em $4^{\circ} \mathrm{C}$. As placas foram lavadas arduamente e os anticorpos secundários biotilinizados policlonais ou monoclonais anti-citocina (Pharmingen) foram adicionados. Após 1 hora, a placa foi lavada cinco vezes com a solução tamponada, seguida da aplicação do complexo avidinaperoxidase (Sigma) diluído 1:5000. Após incubação por 15 min, nova lavagem árdua foi executada.

Finalmente, o substrato cromogênico 0-fenilenediamina (OPD Dako, Dinamarca) em concentração de 0,4 mg de OPD em 0,4 $\mathrm{ml}$ de $\mathrm{H}_{2} \mathrm{O}_{2}$ para cada $1 \mathrm{ml}$ de solução tamponada foi adicionado. Após $15 \mathrm{~min}$, a reação foi interrompida com solução de $\mathrm{H}_{2} \mathrm{SO}_{4} 1 \mathrm{M}$. A intensidade da cor revelada pelo processo foi mensurada em espectrofotômetro regulado em $490 \mathrm{~nm}$, utilizando um Scanner para placas de ELISA (Spectra Max 250 - Molecular Devices, USA). Os resultados foram expressos na grandeza de picograma (pg) de citocina por $\mathrm{ml}$ de líquido sinovial. 

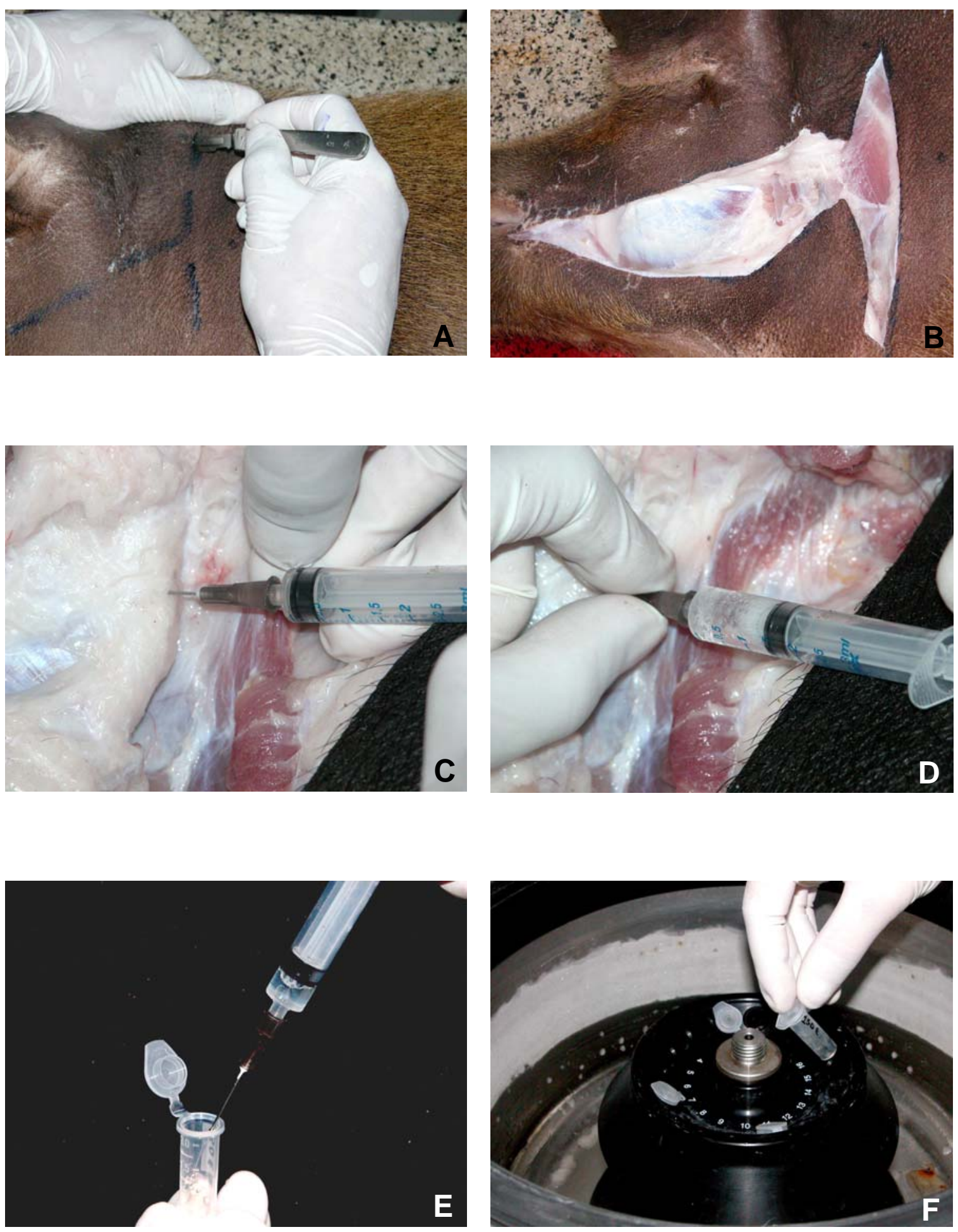

Figuras 8 A-F: A e B) Dissecção das ATMs até a região próxima à cápsula articular $\mathbf{C}$ e D) Coleta do líquido sinovial; E e F) Centrifugação do líquido coletado para separar o sobrenadante do material sólido indesejável 


\subsection{Realização dos exames de Tomografia Computadorizada}

Durante o período de fixação em solução de formol 10\%, os côndilos foram escaneados num tomógrafo helicoidal (Auklet, Toshiba Medical Systems, Japão) (Figura 9A). As peças, cortadas em pequenos blocos, foram posicionadas em paralelepípedos de espuma por meio de elásticos, imitando sua posição original (Figura 9B). Ajustou-se na mesa do tomógrafo a posição das peças, bem próximo do que seria o natural (Figura 9C), e o ajuste fino de foi obtido com a inclinação do gantry (Figura 9D).

Para cada ATM, obtiveram-se reconstruções de $1 \mathrm{~mm}$ de espessura, com distância de $1 \mathrm{~mm}$ entre eles (Figuras 9E-F). Cada côndilo foi documentado com oito cortes tomográficos, mas para fins de padronização da análise, foram selecionados o primeiro corte de anterior para posterior com projeções bilaterais e os quatro cortes subseqüentes.
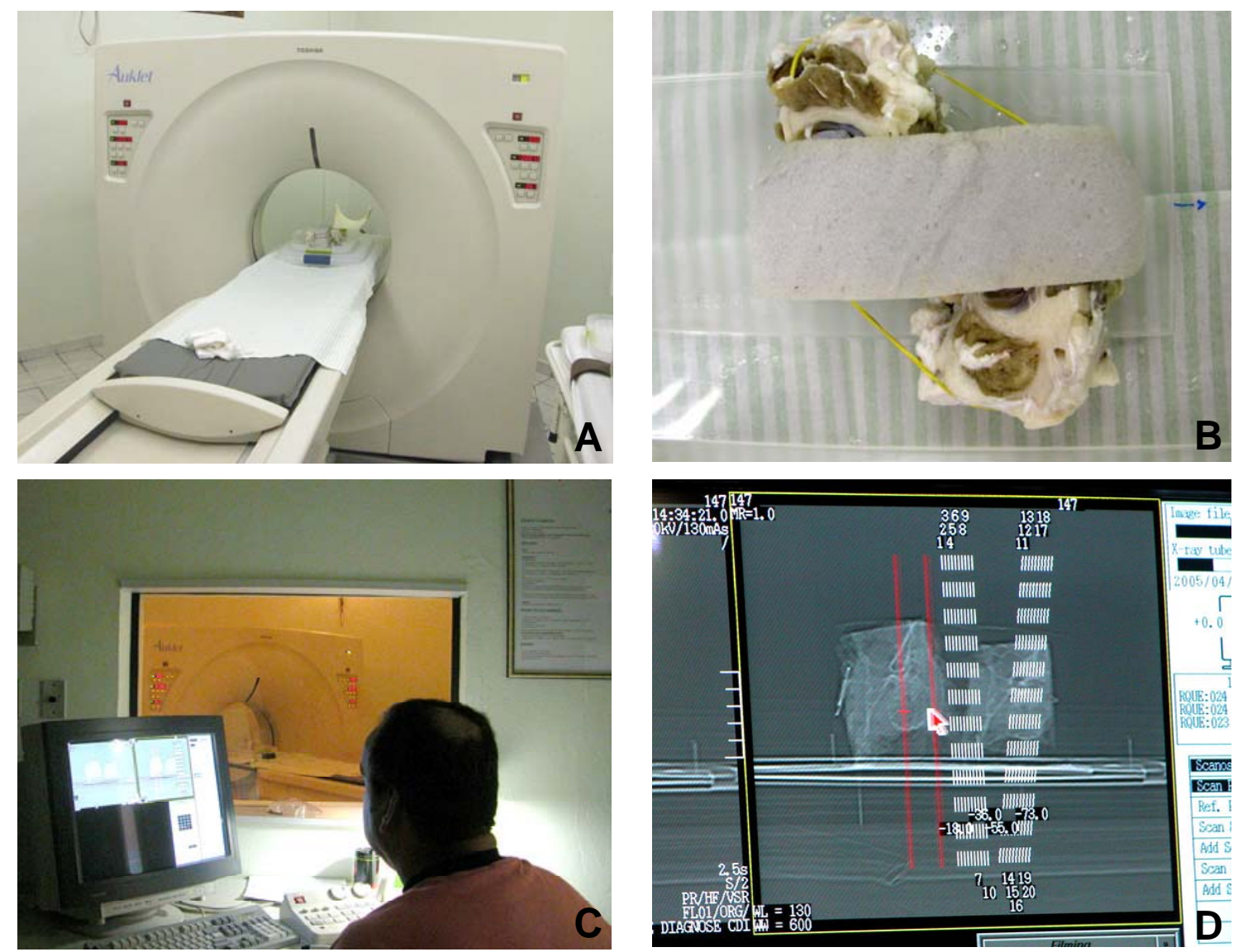

Figuras 9 A-D: A e B) ATMs posicionadas no tomógrafo; C e D) Ajuste da inclinação das peças 

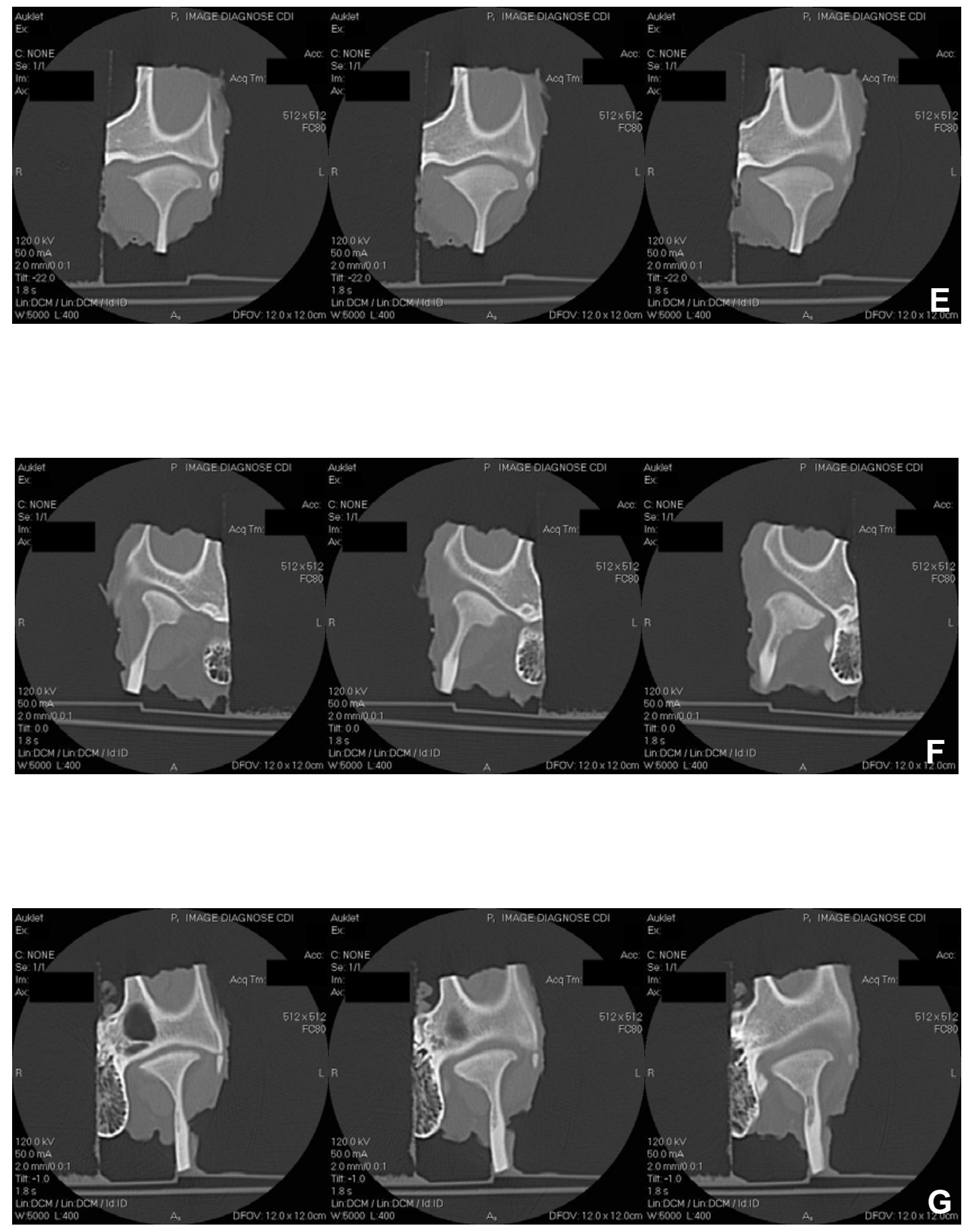

Figuras 9 E-G: E) Série de cortes coronais do grupo controle; F) Série de cortes coronais do grupo com fixação rígida; G) Série de cortes coronais do grupo com fixação semi-rígida

Estas imagens foram avaliadas pelo mesmo examinador (RLN) duas vezes, com intervalo de 30 dias, para comprovar a reprodutibilidade da metodologia. Para a avaliação, considerou-se a presença ou não de alterações 
de forma do côndilo (erosão, osteófito e achatamento). Escores de 0 ou 1 (presente ou ausente) foram atribuídos a cada côndilo, referente a cada alteração.

Para considerar as alterações presentes (escore 1), foram estabelecidos os seguintes critérios: para erosão, descontinuidade da cortical óssea visível a olho nu em dois ou mais cortes seqüenciais ou, em três ou mais intercalados; para achatamento, o côndilo em nenhum corte deveria assumir a forma convencional elíptica, podendo apresentar achatamento superior total ou parcial e, ainda, lateral; para osteófito, na região medial dos côndilos alguma projeção aparecendo em dois ou mais cortes tomográficos, podendo ser visível na fossa mandibular ou no próprio côndilo.

\subsection{Preparo histotécnico}

Após a realização dos exames tomográficos, as biópsias foram lavadas em água corrente por 24 horas. Em seguida, foram imersas em solução desmineralizadora de etileno diamino tetracetato dissódico (EDTA) pH 7,2 (solução contendo 4,13\% de Titriplex III Merck® e 0,44\% de hidróxido de sódio), à temperatura de 2 a $8^{\circ} \mathrm{C}$, com trocas a cada sete dias da solução desmineralizadora, até que pudesse ser constatada, por meio radiográfico, a completa desmineralização das ATMs (período aproximado de 300 dias).

Em seguida, as peças foram lavadas em água corrente por 24 horas e processadas histotecnicamente, com desidratação em concentrações crescentes de etanol, diafanização em xilol e inclusão em Histosec Merck® (parafina + resina sintética). Obtiveram-se cortes semi-seriados de $5 \mu \mathrm{m}$ de espessura em um micrótomo Jung RM 2045 (Leica ${ }^{\circledR}$, Alemanha), os quais foram corados pela técnica da Hematoxilina e Eosina ${ }^{86}$ para a análise histológica.

\subsection{Forma de análise dos resultados}

Os resultados foram avaliados sob três aspectos: 1) histológico, 2) molecular e 3) tomográfico. 


\subsubsection{Análise Histológica}

Os cortes histológicos foram analisados em um microscópio óptico Axioskop 2 (Zeiss, Alemanha). Durante a análise morfológica procuramos observar os seguintes fenômenos nos cortes corados pela Hematoxilina/Eosina:

a) Presença de infiltrado inflamatório crônico;

b) Reabsorção e remodelação do tecido ósseo;

c) Integridade dos tecidos capsulares, quando presentes;

d) Trabeculado ósseo condilar;

e) Cartilagem da superfície condilar.

\subsubsection{Análise Molecular}

Os resultados da análise molecular, valores obtidos a partir do ELISA, foram avaliados por meio do teste ANOVA, seguido pelo teste de TUKEY. Realizaram-se os testes no programa SigmaStat ${ }^{\circledR}$ (Sigmastat for Windows versão 2.0 - Jandel Corporation, USA). Os resultados foram considerados estatisticamente significantes para $\mathrm{P}<0,05$.

\subsubsection{Análise Tomográfica}

Para avaliação do erro intra-examinador, 30 dias após a primeira medição realizaram-se novamente todas as avaliações por escores nas imagens tomográficas dos 36 côndilos. Os escores das duas avaliações realizadas foram comparados por meio do teste Kappa ${ }^{52}$.

Como o teste Kappa apresentou concordância substancial ${ }^{77}$, apenas os valores da primeira avaliação foram considerados para análise estatística. A comparação entre os escores obtidos para os diferentes grupos foi realizada por meio do teste Kruskal-Wallis. Realizaram-se os testes no programa SigmaStat ${ }^{\circledR}$ (Sigmastat for Windows versão 2.0 - Jandel Corporation, USA). Os resultados foram considerados estatisticamente significantes para $\mathrm{P}<0,05$. 


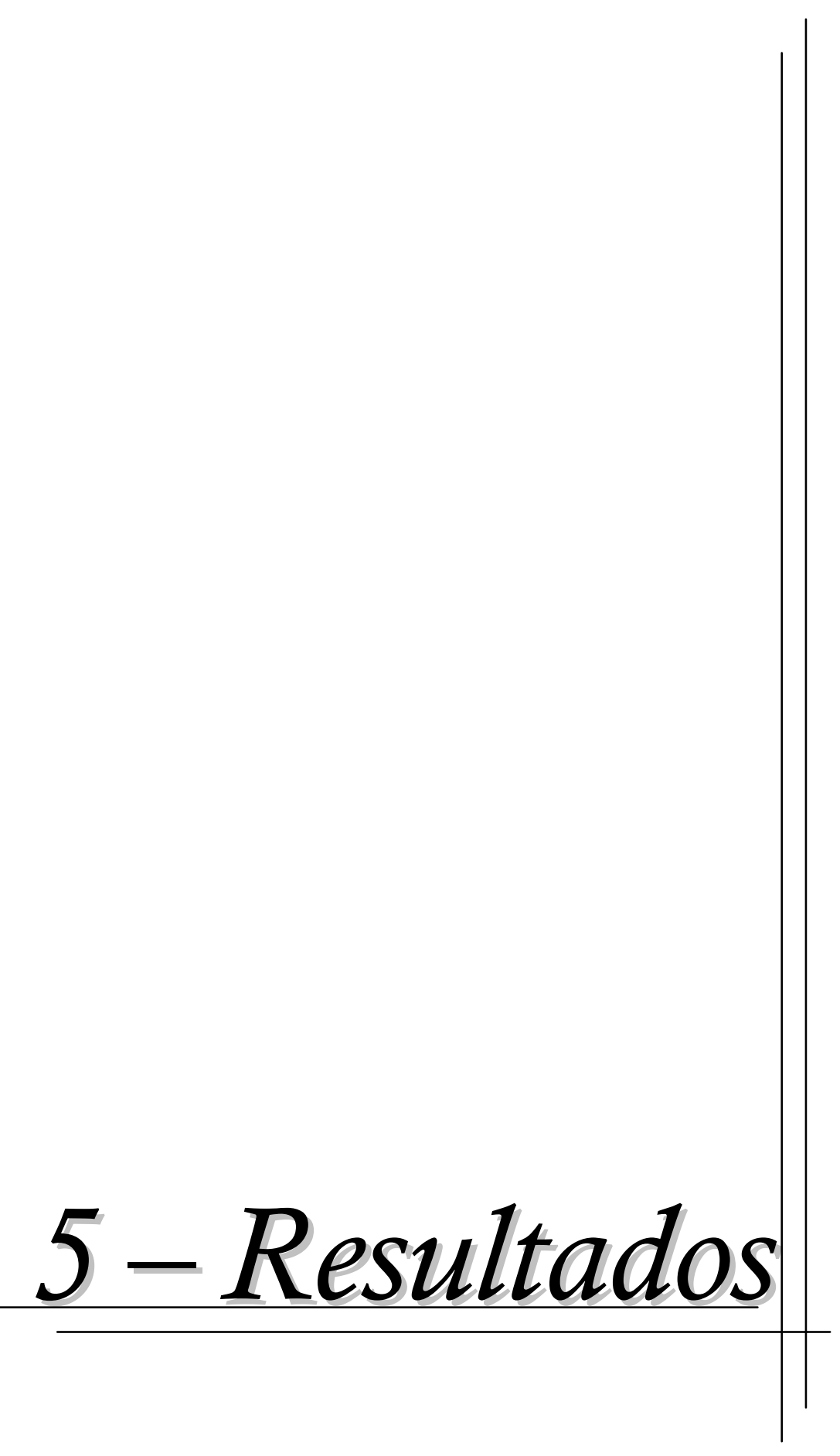




\section{5 - Resultados}

Para efeito de melhor compreensão, este capítulo foi dividido em quatro partes. Na primeira parte, abordaram-se os aspectos histológicos, descrevendo-se as características histológicas dos côndilos para os três diferentes grupos. Numa segunda parte, relataram-se os aspectos moleculares obtidos a partir do teste ELISA, realizado nas amostras de líquido sinovial das ATMs dos três grupos. Outro aspecto avaliado foi o resultado obtido a partir dos exames de tomografia computadorizada nos côndilos. No último tópico, avaliaram-se brevemente os aspectos da utilização dos minipigs como modelo experimental para pesquisas na área odontológica, especificamente para pesquisas em Cirurgia e Traumatologia Bucomaxilofacial.

\subsection{Aspectos Histológicos}

\section{Grupo 1 (Controle)}

O grupo controle apresentou características de normalidade e está representado pelas Figuras 10-14. O disco articular era composto por tecido conjuntivo denso, rico em fibras colágenas, e mais delgado na região central; fibras colágenas correndo principalmente na direção antero-posterior; fibroblastos esparsamente distribuídos; aspecto avascular, com exceção da cavidade superior do disco intra-articular. Nas porções anterior e posterior, as fibras colágenas apresentaram-se mais espessas, com feixes de fibras proeminentes percorrendo transversalmente e com orientação médio-lateral, bem como superior e inferior, dando às fibras uma aparência muito mais enrolada. Os feixes de fibras colágenas, na periferia do disco, mostraram-se arranjados circunferencialmente e apresentaram inúmeros vasos sanguíneos. A membrana sinovial revestiu a superfície interna da cápsula fibrosa da ATM e as margens do disco articular.

O côndilo apresentou formato mais regular e simétrico em relação aos grupos experimentais (comparar as imagens da Figura 11A com 15A). Pela presença de regiões com cartilagem condilar secundária (Figura 11B), os 
animais encontravam-se em fase final de crescimento no período de abate. $O$ côndilo (Figuras 11 e 12) mostrou-se revestido por uma camada de tecido fibroso, abaixo do qual se encontrava uma camada proliferativa de células indiferenciadas, que provavelmente davam origem aos condrócitos, os quais formavam a cartilagem articular secundária. Ao contrário dos condrócitos em um disco de crescimento típico, os condrócitos da cartilagem condilar não estão alinhados em colunas (observar Figuras 11B e 12B-C). Como se tratava de animais adulto-jovens, o côndilo não se mostrava totalmente revestido por uma camada distinta de osso compacto como ocorre no adulto, apresentando na região central (Figuras 11B e 12B-C) todas as fases de mineralização da matriz cartilaginosa, invasão vascular com presença de células gigantes multinucleadas, osteoclastos, degeneração dos condrócitos e síntese de tecido ósseo na estrutura cartilaginosa mineralizada. Na região lateral do côndilo (Figuras 13B), a superfície articular do côndilo não exibia articulação secundária, porém, o tecido ósseo apresentava-se ainda na forma de trabéculas ósseas. Mais posteriormente (Figura 14B) o tecido ósseo exibia característica de osso compacto, com superfície irregular devido ao processo de reabsorção decorrente do crescimento articular. Na região medial (Figura 10B), inúmeras áreas exibiam reabsorção óssea com células osteoclásticas. 

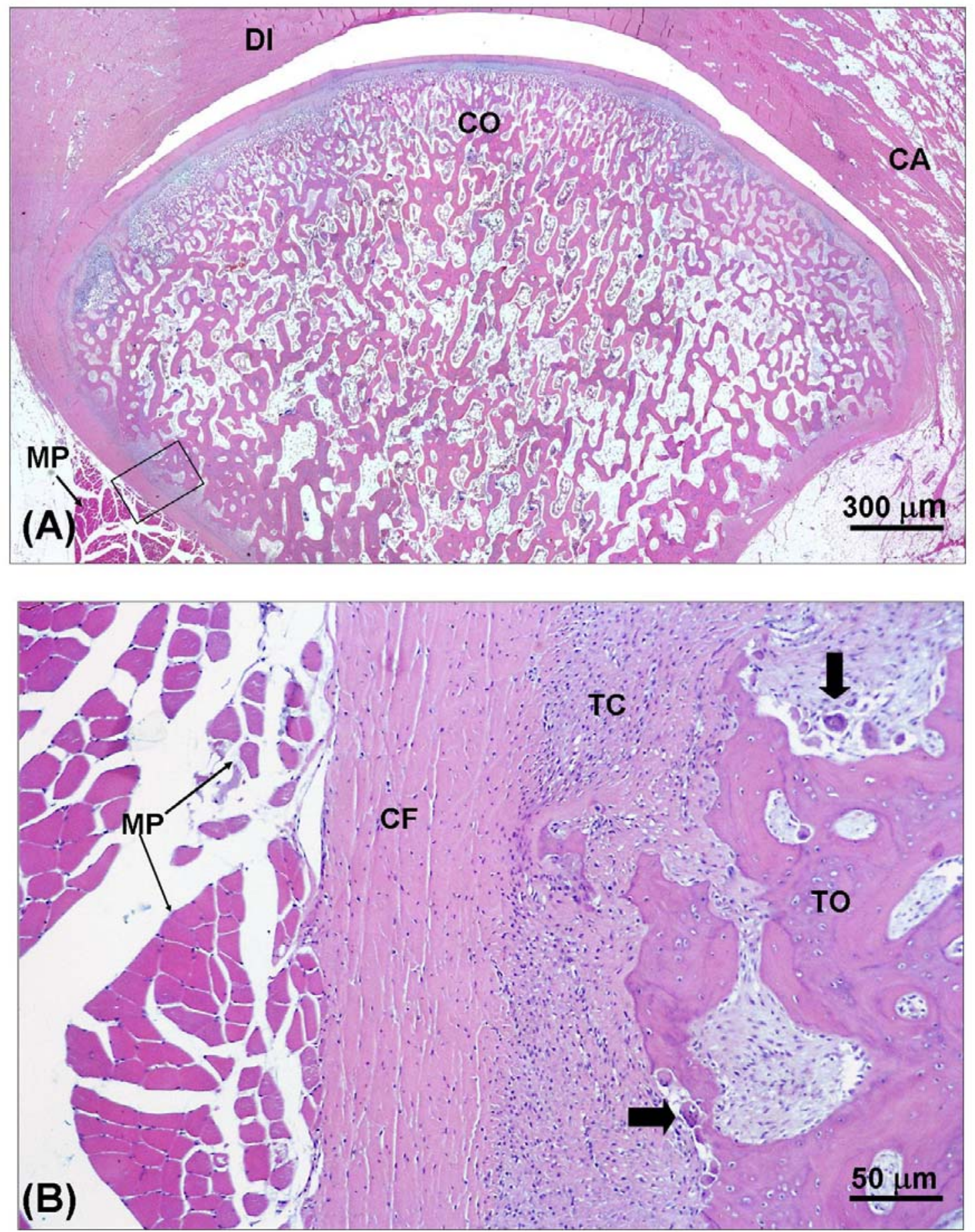

Figuras 10 A e B: Corte sagital do côndilo mandibular do grupo controle. A) Visão panorâmica mostrando a distribuição dos tecidos: disco intra-articular (DI), côndilo mandibular (CO), cápsula articular (CA), músculo pterigóideo lateral (MP); B) Detalhe da região medial: músculo pterigóideo (MP), superfície do tecido ósseo (TO) demonstrando áreas de reabsorção por osteoclastos (setas), espessa camada de tecido conjuntivo (TC) ricamente celularizada recobrindo o tecido ósseo, cápsula fibrosa (CF) na região mais externa. Hematoxilina-eosina 

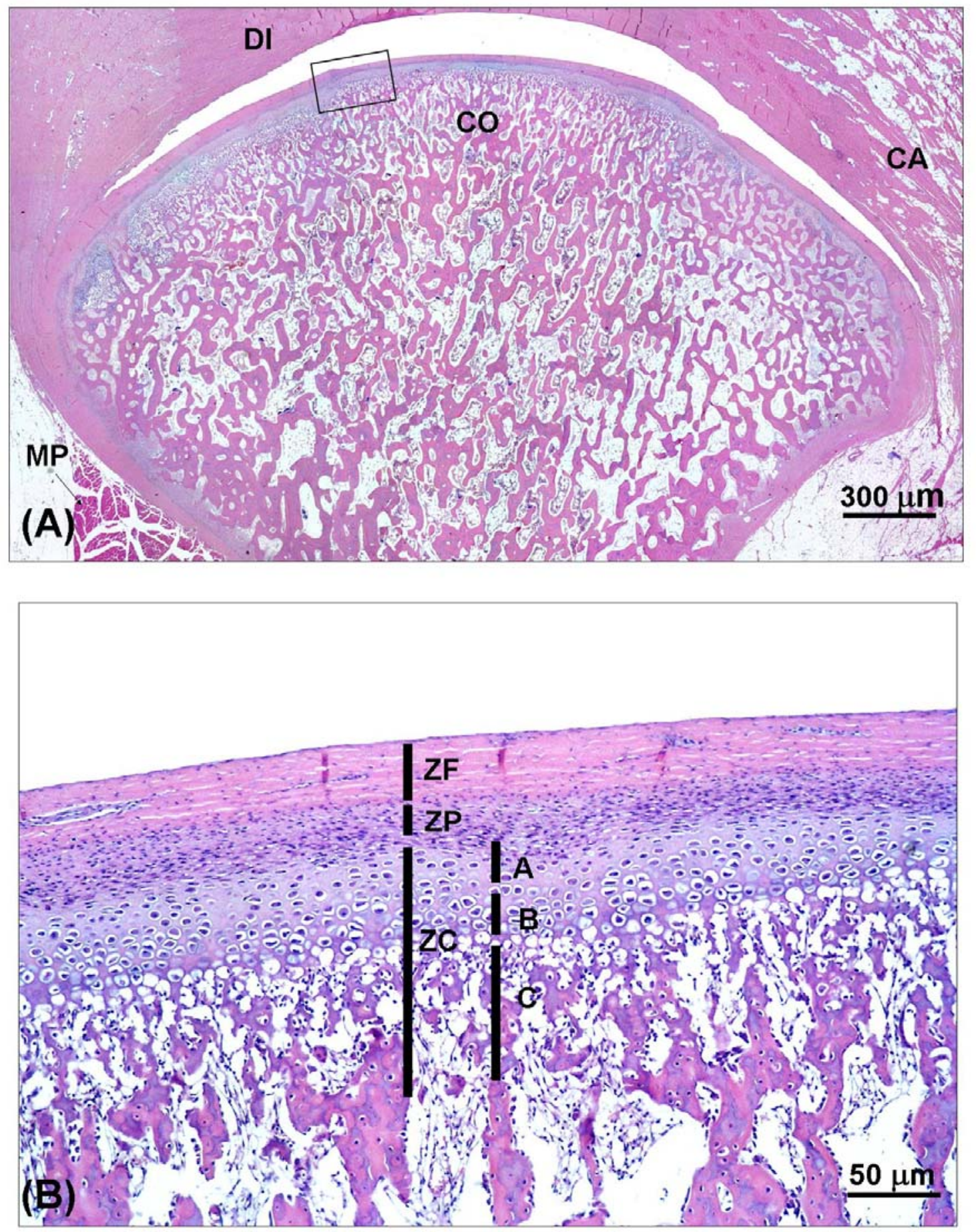

Figuras 11 A e B: Corte sagital do côndilo mandibular do grupo controle. A) Visão panorâmica mostrando a distribuição dos tecidos: disco intra-articular (DI), côndilo mandibular (CO), cápsula articular (CA), músculo pterigóideo lateral (MP); B) Detalhe da região central mostrando: zona de superfície articular fibrosa (ZF), zona proliferativa (ZP) e zona da cartilagem condilar secundária $(Z C)$. A ZC é formada por áreas de diferenciação e proliferação dos condrócitos $(A)$, área de hipertrofia dos condrócitos $(B)$ e área de mineralização da cartilagem, degeneração dos condrócitos e ossificação (C). Hematoxilina-eosina 

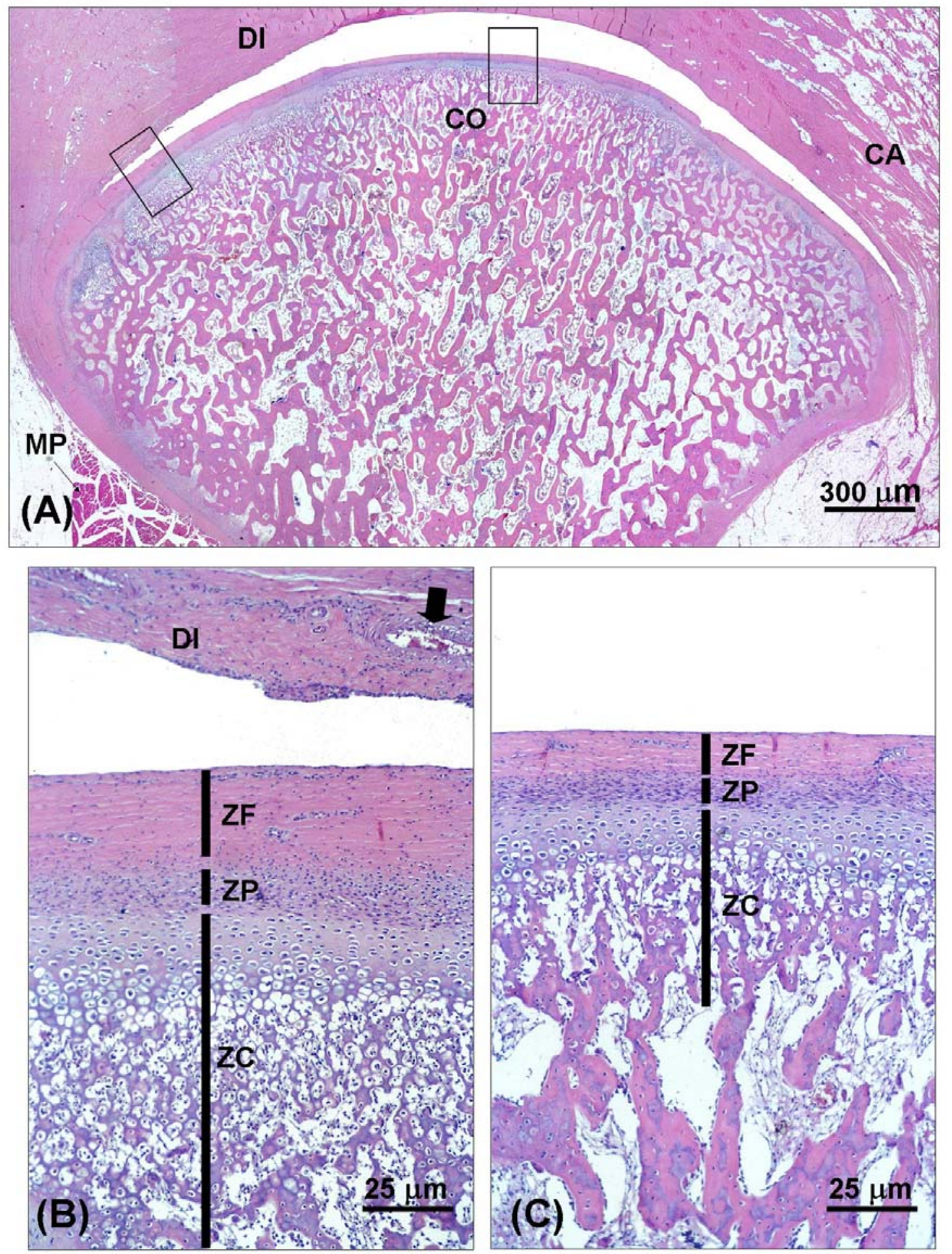

Figuras 12 A-C: Corte sagital do côndilo mandibular do grupo controle. A) Visão panorâmica mostrando a distribuição dos tecidos: disco intra-articular (DI), côndilo mandibular (CO), cápsula articular (CA), músculo pterigóideo lateral (MP); B-C) Detalhes das regiões lateral (Figura B) e central (Figura C) do côndilo, mostrando diferença na espessura das superfícies articular fibrosa (ZF), zona proliferativa (ZP) e zona condilar secundária (ZC). Observar, ainda, as fibras colágenas na periferia do disco intra-articular (DI), ricamente celularizado e vascularizado (seta vazada). Hematoxilina-eosina 

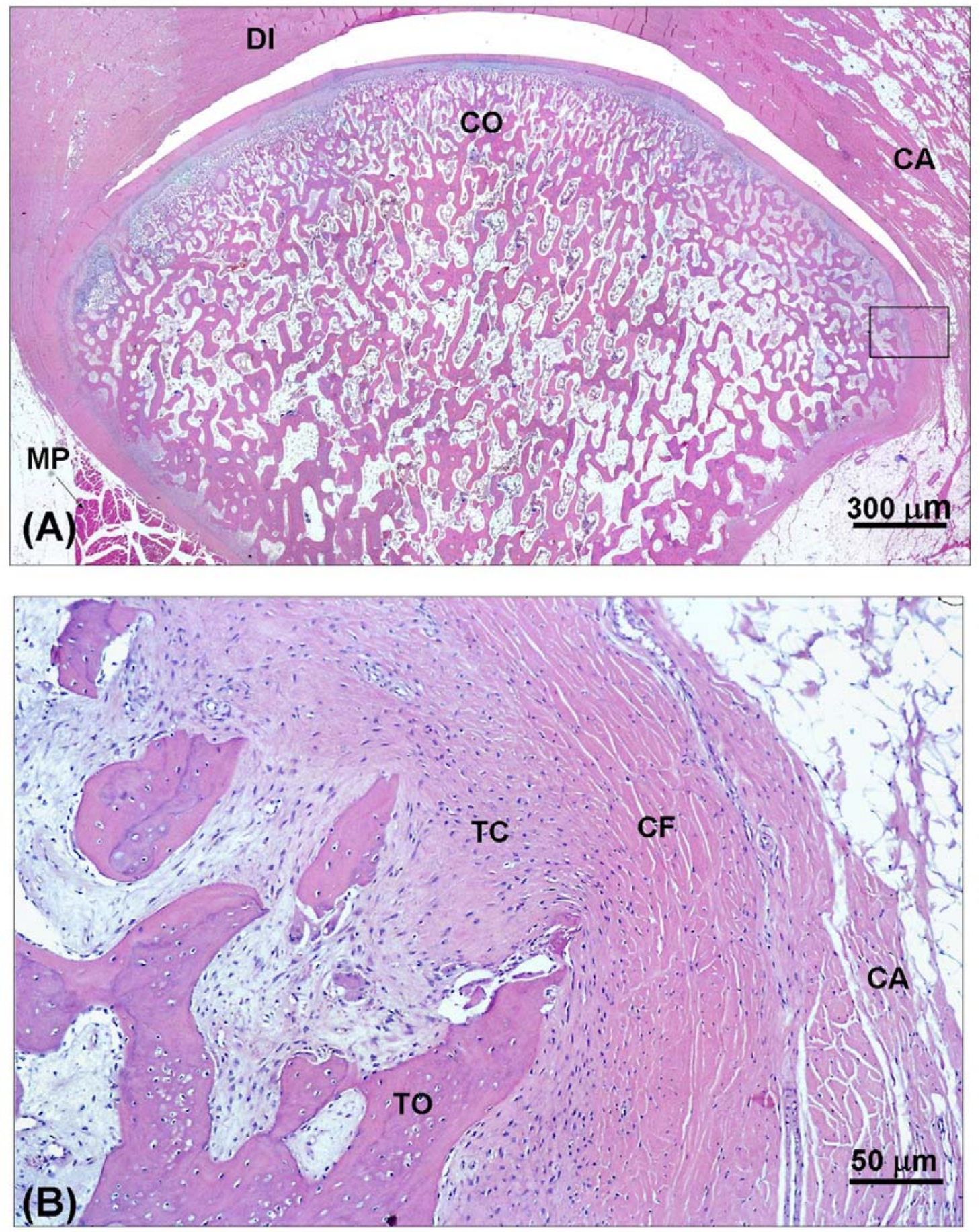

Figuras 13 A e B: Corte sagital do côndilo mandibular do grupo controle. A) Visão panorâmica mostrando a distribuição dos tecidos: disco intra-articular (DI), côndilo mandibular (CO), cápsula articular (CA), músculo pterigóideo lateral (MP); B) detalhes da região lateral, exibindo tecido ósseo (TO) recoberto por tecido conjuntivo ricamente celularizado (TC) e superficialmente pela cápsula fibrosa (CF). Observar mais externamente a cápsula articular. Hematoxilina-eosina 

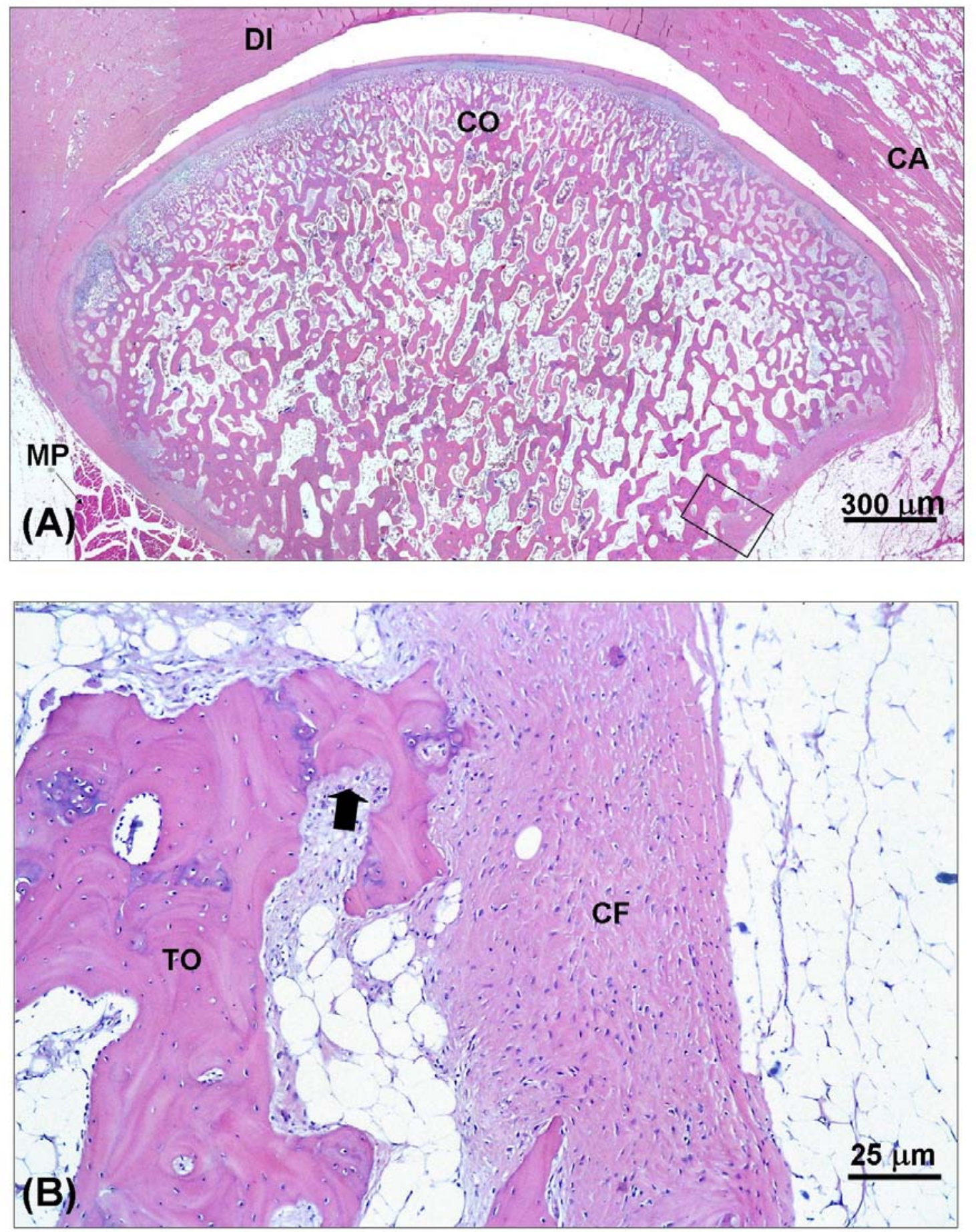

Figuras 14 A e B: Corte sagital do côndilo mandibular do grupo controle. A) Visão panorâmica mostrando a distribuição dos tecidos: disco intra-articular (DI), côndilo mandibular (CO), cápsula articular (CA), músculo pterigóideo lateral (MP); B) detalhes da região lateral: na porção mais posterior, observa-se tecido ósseo (TO) de arranjo mais compacto, com sinais de reabsorção (seta vazada) na porção mais externa envolta por cápsula fibrosa (CF), decorrente do crescimento articular. Hematoxilina-eosina 


\section{Grupo 2 (Fixação Rígida)}

O grupo 2 está representado pelas Figuras 15-19. Neste grupo, o côndilo apresentou formato irregular e mais assimétrico em relação aos grupos controle e experimental 3 (comparar as imagens da Figura 15A com 11A e 20A). O disco articular apresentou características similares ao do grupo controle exceto na região medial onde se mostrou mais desorganizado e menos denso.

Já o côndilo, apresentou superfície bastante irregular com cartilagem condilar secundária (Figura 16B) descontínua. Mostrou-se, ainda, revestido por uma camada de tecido fibroso de espessuras variadas e áreas de descontinuidade (Figuras 17). Abaixo da cápsula fibrosa, apresentava a camada proliferativa seguida pela cartilagem articular secundária, que estava ausente na porção medial (Figura 16B), presente na porção central (Figura 17B) e mais espessa e desorganizada na porção lateral (Figuras 17C e 18B). Associado à cartilagem articular, o tecido ósseo apresenta-se compacto. $\mathrm{Na}$ região lateral (Figura 19), a porção mais posterior apresentou aumento em espessura da tábua óssea, com neoformação de tecido ósseo de arranjo trabecular, que acompanhava toda extensão da região condilar da porção central à lateral. Associado a este espessamento na região lateral, a região medial apresentou-se mais compacta em relação ao grupo controle, com extensas áreas de reabsorção por osteoclastos, recoberto por tecido fibroso, semelhante à fibrocartilagem, com algumas áreas acidofílicas e células dispersas aleatoriamente. 

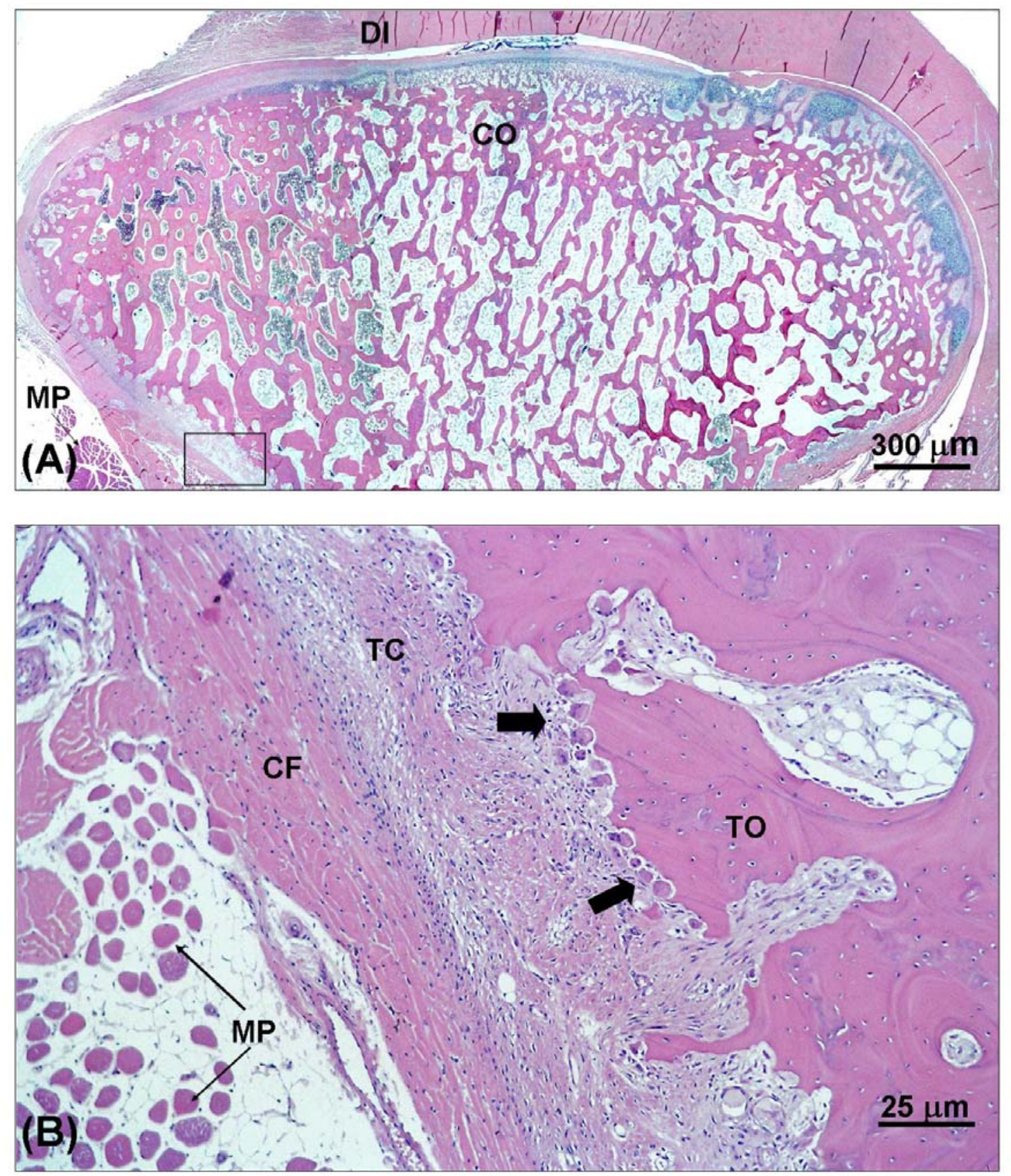

Figuras 15 A e B: Corte sagital do côndilo mandibular do grupo 2 (Fixação Rígida). A) Visão panorâmica mostrando a distribuição dos tecidos: disco intra-articular (DI), côndilo mandibular (CO), músculo pterigóideo lateral (MP); B) Detalhes da região medial na porção posterior, exibindo tecido ósseo (TO) com áreas de reabsorção por osteoclastos (setas), recoberto por tecido fibroso (CF) semelhante à fibrocartilagem, com algumas áreas acidofílicas (cabeça de seta) e células (seta vazada) dispersas aleatoriamente. Hematoxilina-eosina 

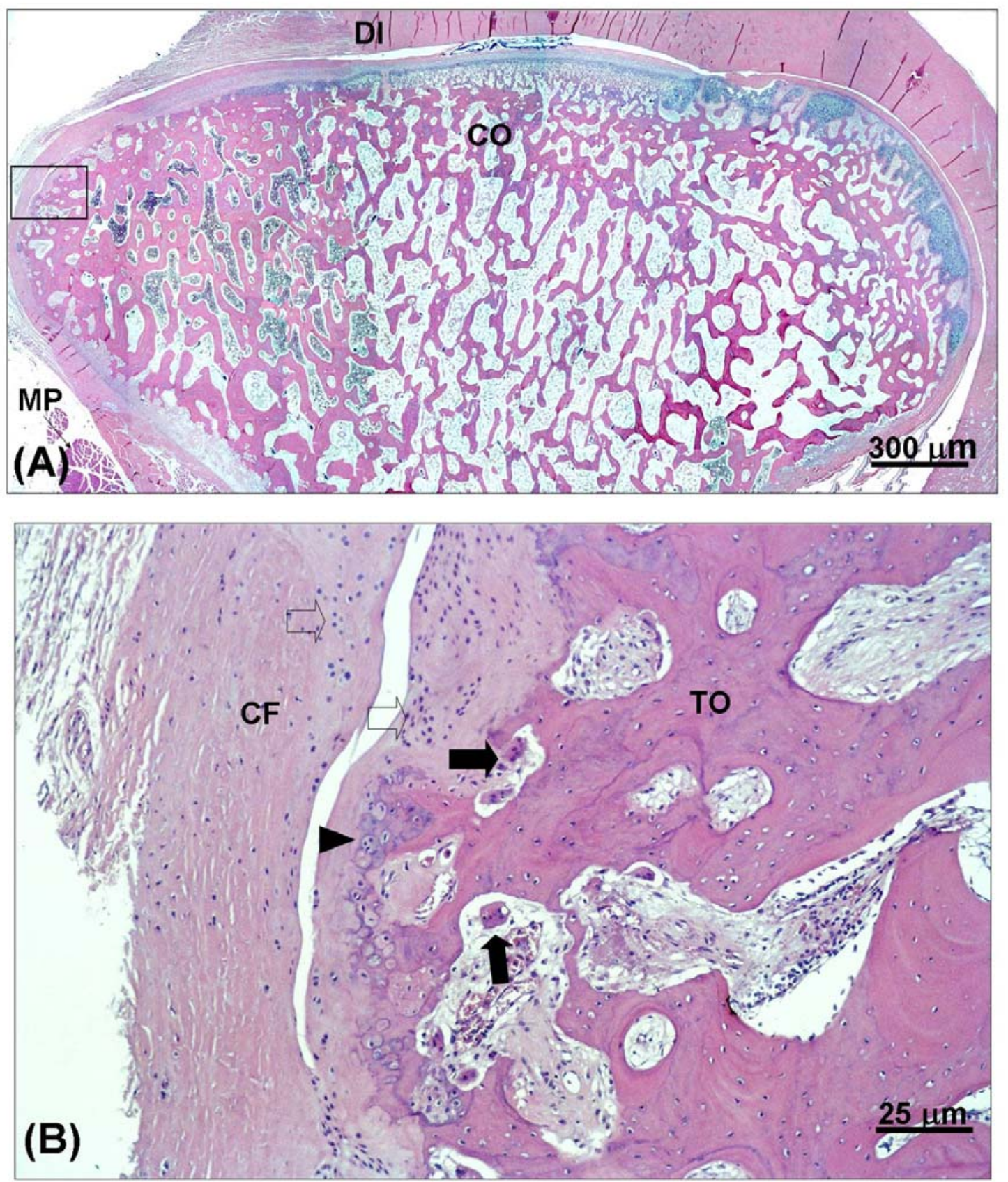

Figuras 16 A e B: Corte sagital do côndilo mandibular do grupo 2 (Fixação Rígida). A) Visão panorâmica mostrando a distribuição dos tecidos: disco intra-articular (DI), côndilo mandibular (CO) e músculo pterigóideo lateral (MP); B) detalhe da região medial: músculo pterigóideo (MP), superfície do tecido ósseo (TO) apresentando áreas de reabsorção por osteoclastos (setas), espessa camada de tecido conjuntivo (TC) ricamente celularizada recobrindo o tecido ósseo, cápsula fibrosa (CF) na região mais externa. Hematoxilina-eosina 

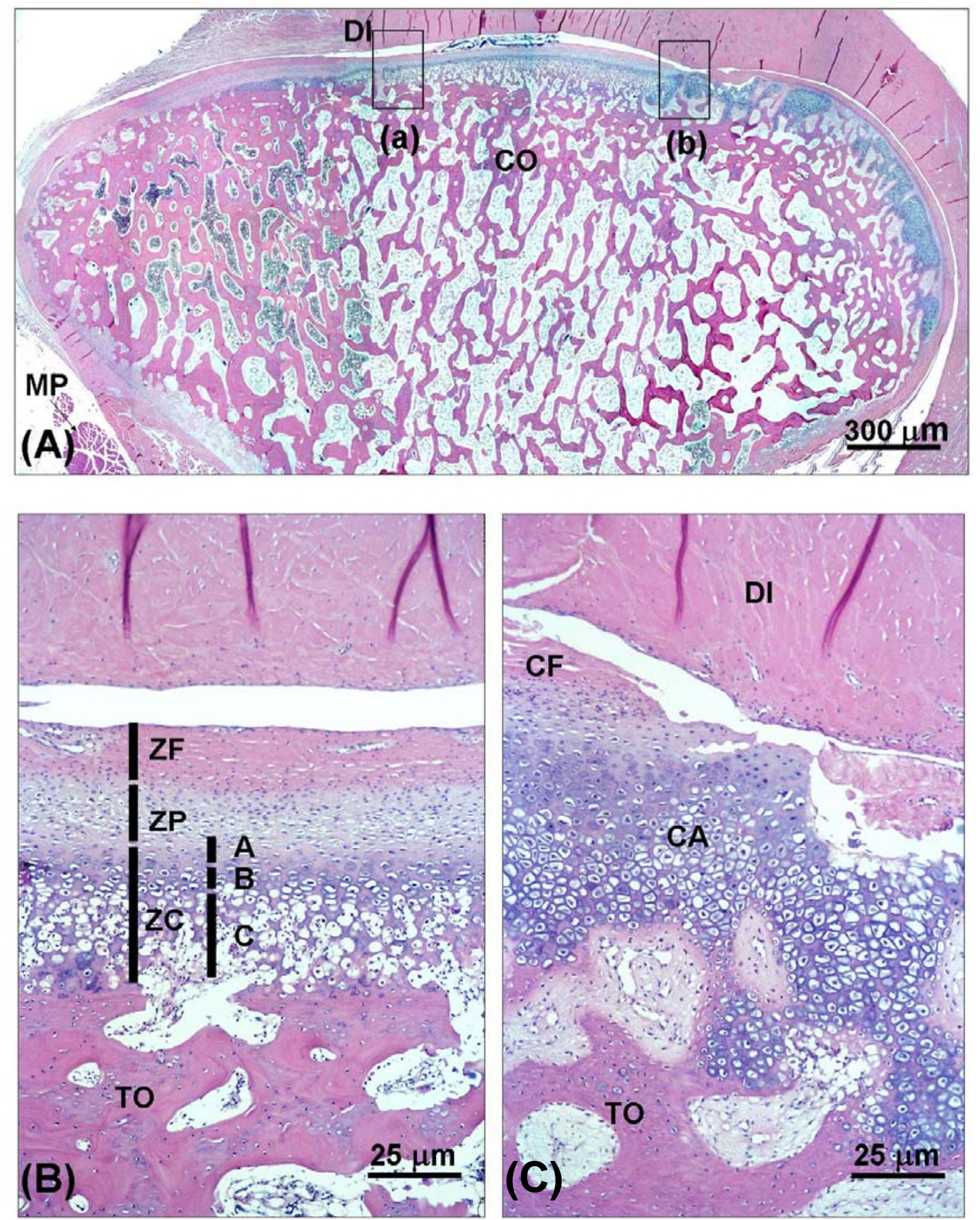

Figuras 17 A-C: Corte sagital do côndilo mandibular do grupo 2 (Fixação Rígida). A) Visão panorâmica mostrando a distribuição dos tecidos: disco intra-articular (DI), côndilo mandibular (CO), músculo pterigóideo lateral (MP); B) detalhe da região central: zona de superfície articular fibrosa (ZF), zona proliferativa (ZP) e zona da cartilagem condilar secundária (ZC). A ZC é formada por áreas de diferenciação e proliferação dos condrócitos (A), área de hipertrofia dos condrócitos (B) e área de mineralização da cartilagem, degeneração dos condrócitos e ossificação (C), C) Região do côndilo apresentando descontinuidade da cápsula fibrosa, desorganização e espessamento da cartilagem articular secundária. $\mathrm{DI}=$ disco intercalar, TO = tecido ósseo. Hematoxilina-eosina 

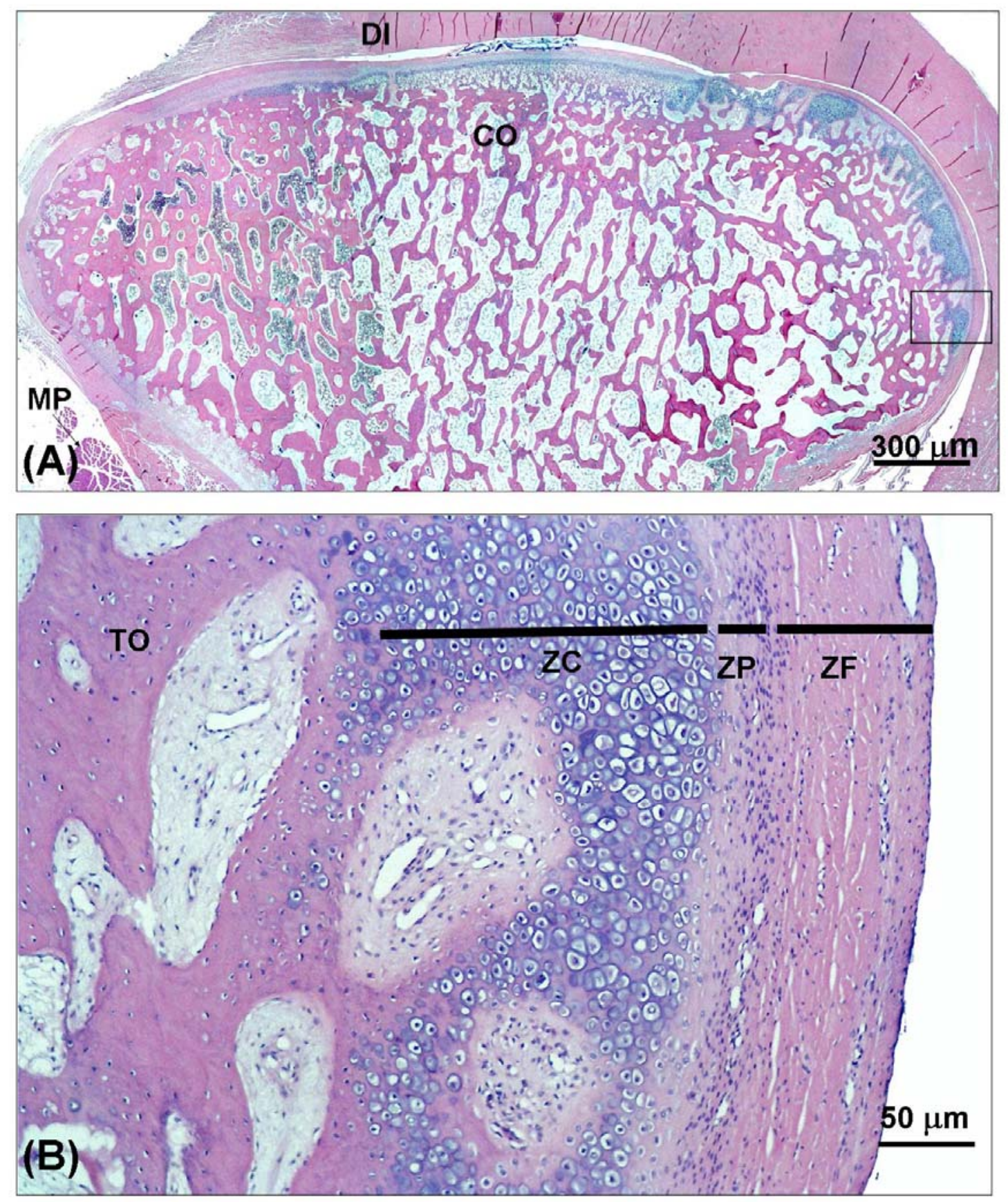

Figuras 19 A e B: Corte sagital do côndilo mandibular do grupo 2 (Fixação Rígida). A) Visão panorâmica mostrando a distribuição dos tecidos: disco intra-articular (DI), côndilo mandibular (CO) e músculo pterigóideo lateral (MP); B) Detalhes da região lateral: zona de superfície articular fibrosa (ZF), zona proliferativa (ZP) e zona da cartilagem condilar secundária de espessura variada associada ao tecido ósseo (TO). Hematoxilina-eosina 

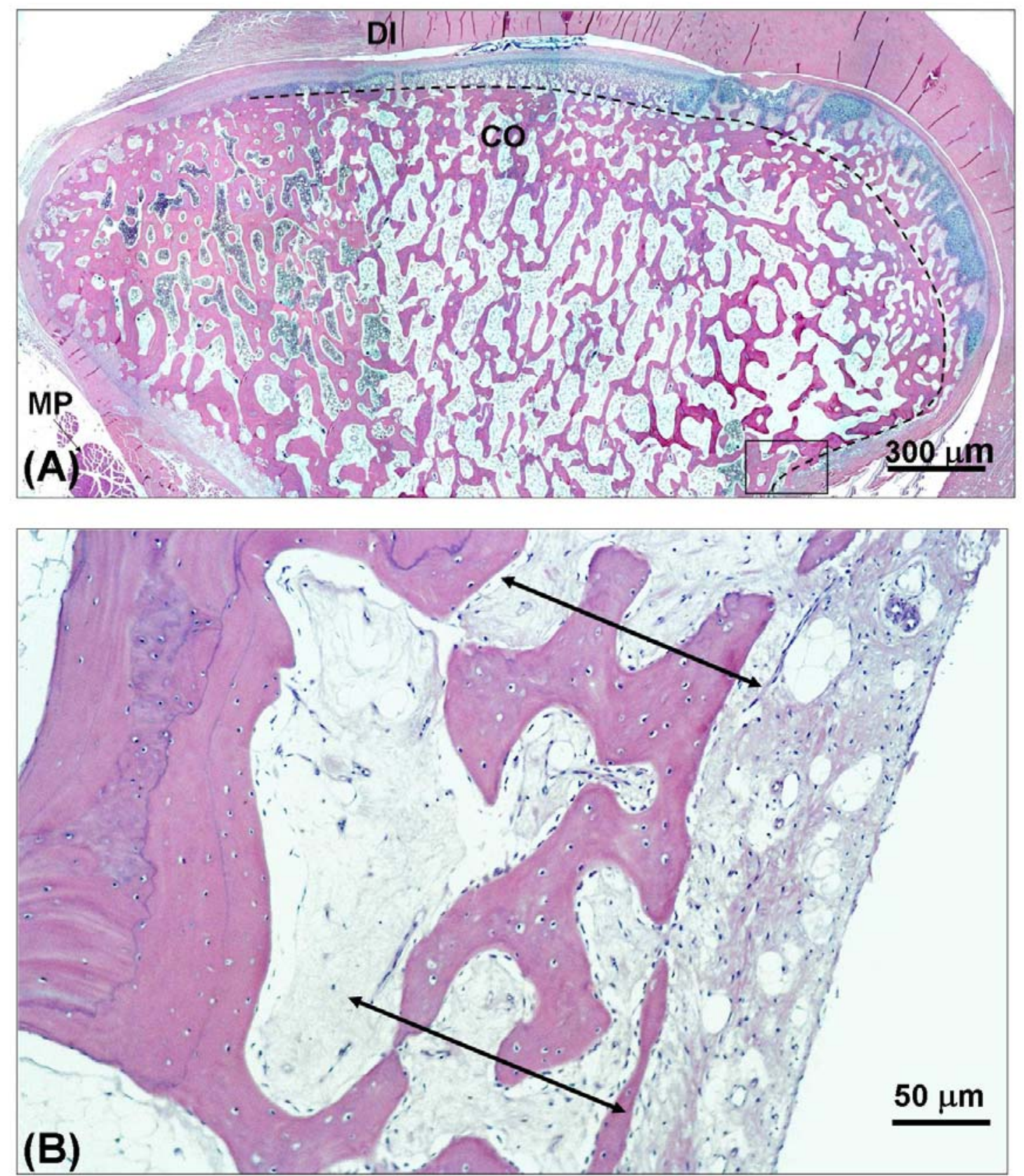

Figuras 19 A e B: Corte sagital do côndilo mandibular do grupo 2 (Fixação Rígida). A) Visão panorâmica mostrando a distribuição dos tecidos: disco intra-articular (DI), côndilo mandibular (CO) e músculo pterigóideo lateral (MP); B) Detalhes da região lateral na porção mais posterior: aumento em espessura da tábua óssea (seta) acompanhado por toda extensão da região condilar, da porção central à lateral (ver linha tracejada na Figura 19A). Hematoxilina-eosina 
Grupo 3 (Fixação Semi-Rígida)

O grupo 3 está representado pelas Figuras 20-22. Neste grupo, o côndilo apresentou formato semelhante ao grupo controle (comparar as imagens da Figura 20A com 11A). O disco articular também apresentou características similares ao do grupo controle.

A região do côndilo apresentou áreas distintas: na região medialcentral (Figura 21B), mostrou-se revestido por uma camada de tecido fibroso, abaixo do qual encontrava uma camada proliferativa, seguida pela cartilagem articular secundária; na porção central-lateral (Figura 21B), não apresentou cartilagem articular secundária e apresentou tecido ósseo de arranjo trabecular, associado externamente ao tecido conjuntivo ricamente celularizado e, mais superficialmente, à cápsula fibrosa. Na porção lateral (Figura 22B), a cortical óssea mostrou-se compacta e revestida por tecido conjuntivo ricamente celularizado e, mais superficialmente, pela cápsula fibrosa.

Da porção central para a lateral, ocorreu aumento em espessura da tábua óssea, com neoformação de tecido ósseo de arranjo trabecular, que acompanhava toda extensão da região condilar. Associado a este espessamento na região lateral, a região medial (Figura 20B) apresentou extensas áreas de reabsorção por osteoclastos. Recobrindo o tecido ósseo, uma espessa camada de tecido conjuntivo ricamente celularizado e vascularizado e, mais externamente, a cápsula fibrosa (CF) mostrou-se desorganizada, com alguns feixes de tecido conjuntivo denso, indicando remodelação da mesma. 

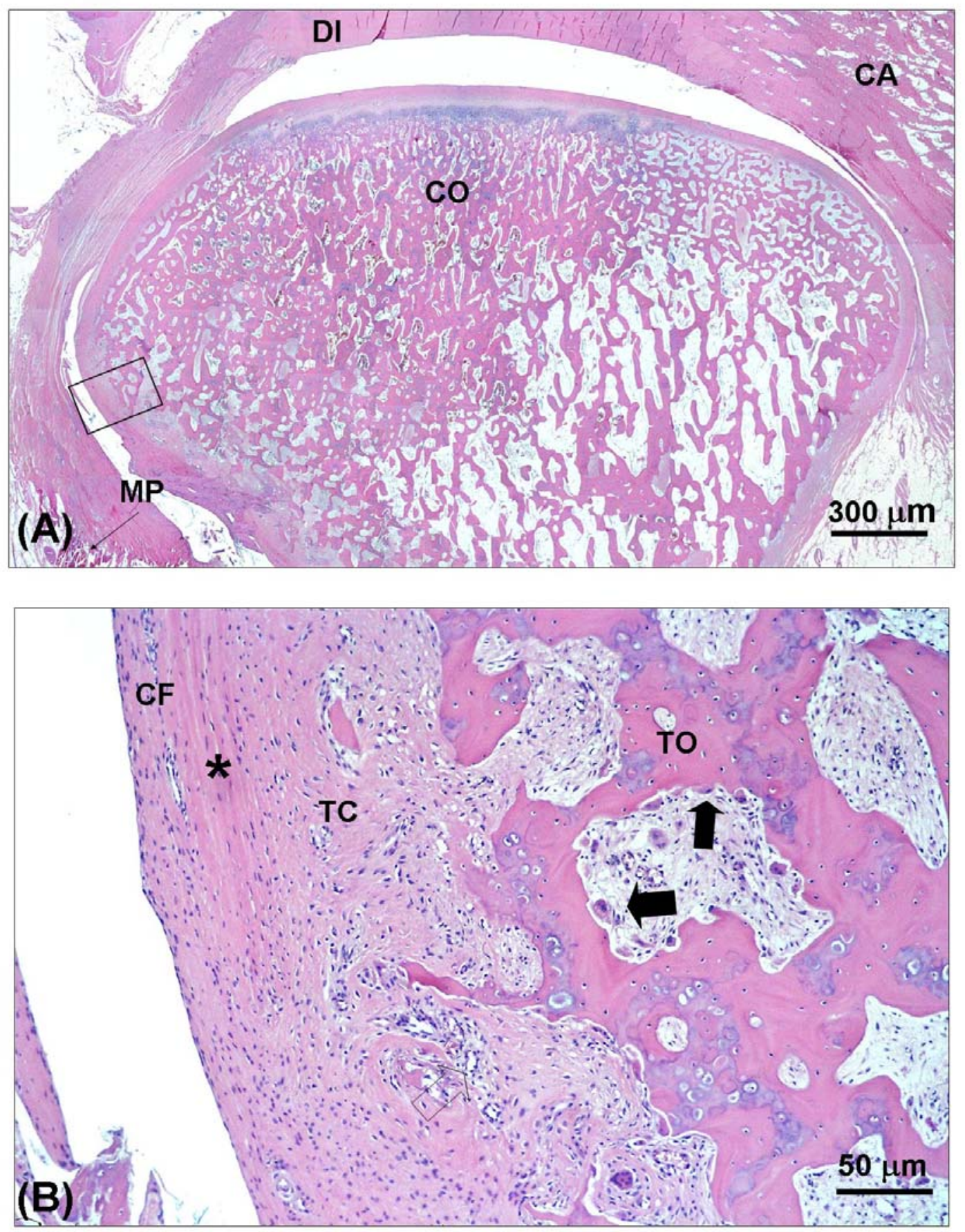

Figuras 20 A e B: Corte sagital do côndilo mandibular do grupo 3 (Fixação Semi-rígida). A) Visão panorâmica mostrando a distribuição dos tecidos: disco intra-articular (DI), côndilo mandibular (CO), cápsula articular (CA) e músculo pterigóideo lateral (MP); B) Detalhe da região medial mostrando o tecido ósseo (TO) com extensas áreas de reabsorção por osteoclastos (setas). Recobrindo o tecido ósseo, uma espessa camada de tecido conjuntivo (TC) ricamente celularizado e pequenos vasos sanguíneos (seta vazada). Mais externamente, a cápsula fibrosa (CF) desorganizada, com alguns feixes remanescentes (asteriscos), indicando remodelação da cápsula. Hematoxilina-eosina 

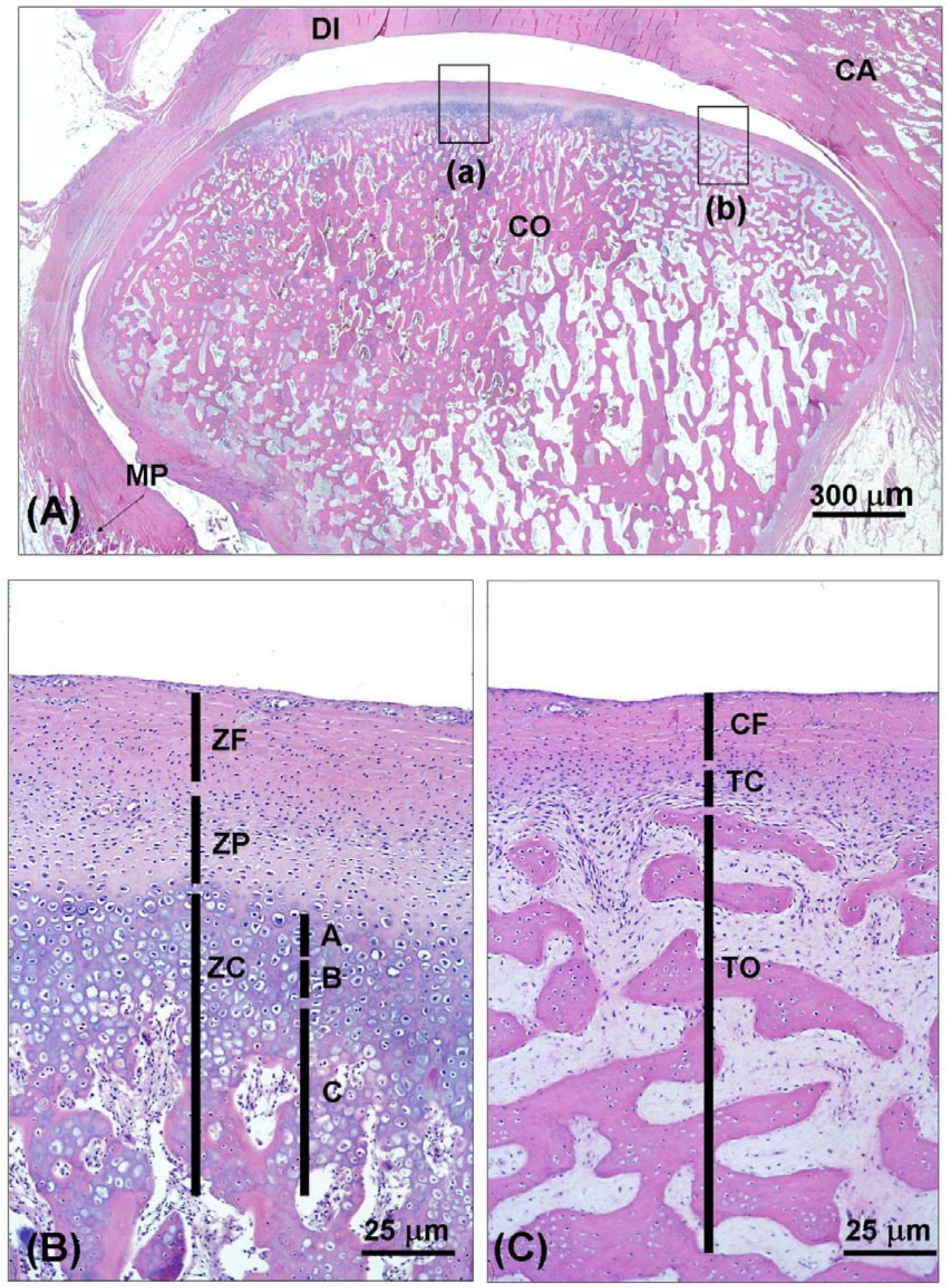

Figuras 21 A-C: Corte sagital do côndilo mandibular do grupo 3 (Fixação Semi-rígida). A) Visão panorâmica mostrando a distribuição dos tecidos: disco intra-articular (DI), côndilo mandibular (CO), cápsula articular (CA) e músculo pterigóideo lateral (MP); B) detalhe da região central: zona de superfície articular fibrosa (ZF), zona proliferativa (ZP) e zona da cartilagem condilar secundária (ZC). A ZC é formada por áreas de diferenciação e proliferação dos condrócitos (A), área de hipertrofia dos condrócitos (B) e área de mineralização da cartilagem, degeneração dos condrócitos e ossificação (C); C) Região do côndilo mais lateral, apresentando tecido ósseo (TO) de arranjo trabecular, associado externamente ao tecido conjuntivo ricamente celularizado e, mais superficialmente, a cápsula fibrosa (CF). Hematoxilina-eosina 

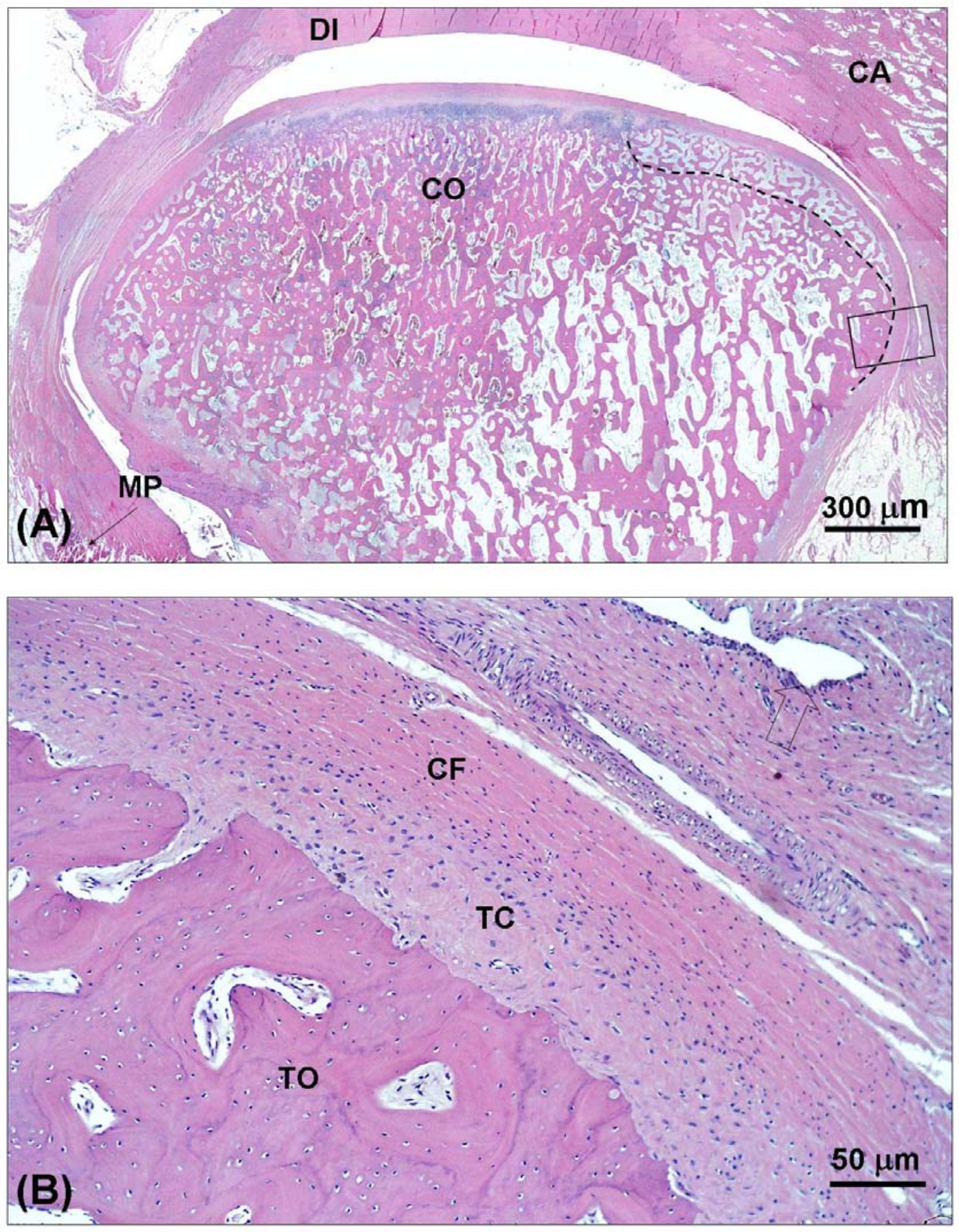

Figuras 22 A e B: Corte sagital do côndilo mandibular do grupo 3 (Fixação Semi-rígida). A) Visão panorâmica mostrando a distribuição dos tecidos: disco intra-articular (DI), côndilo mandibular (CO), cápsula articular (CA), músculo pterigóideo lateral (MP); B) Detalhes da região lateral: cortical óssea (TO) compacta, camada de tecido conjuntivo ricamente celularizado e superficialmente a cápsula fibrosa (CF). Observar também a membrana sinovial (seta vazada) revestindo as margens da cavidade articular inferior. Aumento em espessura está representado pela linha tracejada na Figura A. Hematoxilina-eosina 


\subsection{Aspectos Moleculares}

Os resultados serão apresentados sob a forma de tabelas e gráfico.

Os resultados em destaque $\left(^{*}\right)$ são estatisticamente significantes para $\mathrm{P}<0,05$.

Tabela 1 - Quantificação da IL-6 em picogramas $(\rho g) / m L$ nos grupos 1, 2 e 3: média, erro-padrão, teste ANOVA

\begin{tabular}{c|c|c|c}
\hline IL-6 & Média & Erro Padrão & $\boldsymbol{P}$ \\
\cline { 1 - 3 } Grupo 1 & 83,21630000 & 14,65200000 & \multirow{2}{*}{$\mathrm{P}=0,4960$} \\
\cline { 1 - 2 } Grupo 2 & 103,52400000 & 38,23100000 & \\
\cline { 1 - 2 } Grupo 3 & 140,05408333 & 37,65200000 & \\
\hline
\end{tabular}

Tabela 2 - Quantificação da IL-10 pg/mL nos grupos 1, 2 e 3: média, erropadrão, teste ANOVA

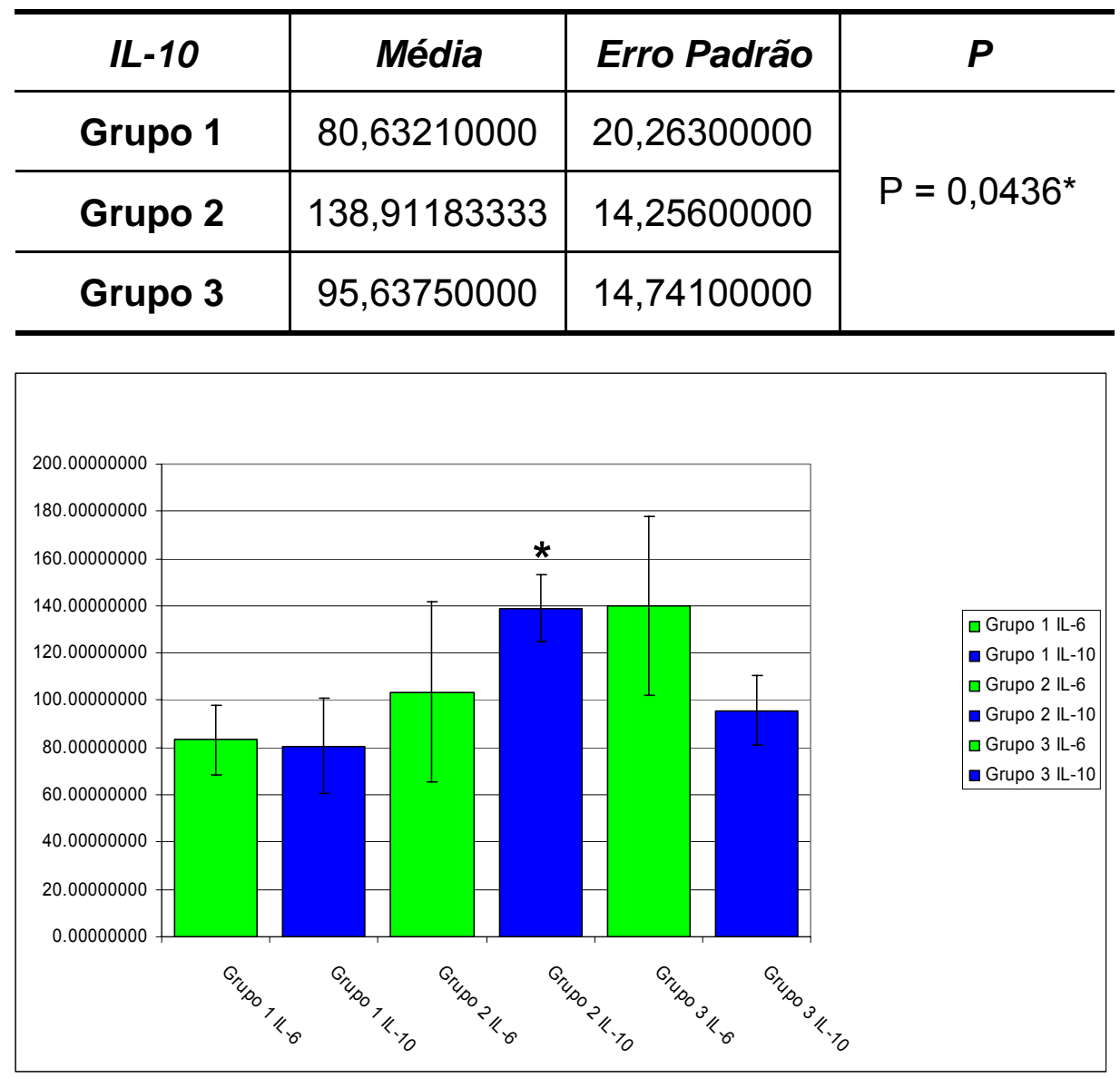

Figura 23: Gráfico a quantidade de IL-6 e IL-10 no líquido sinovial das amostras dos grupos 1, 2 e 3 . Destaque para a quantidade de IL-10 no grupo 2 significantemente maior $\left({ }^{*}\right)$ em relação ao grupo 1 


\subsection{Aspectos Tomográficos}

Os resultados serão apresentados sob a forma de tabelas. Na tabela 1 , estão dispostos os resultados da avaliação intra-examinador e os valores do teste Kappa para erosão, achatamento e osteófito e valor total, nos grupos 1, 2 e 3. Este teste possui a função de comprovar a reprodutibilidade da metodologia utilizada. Como o teste Kappa apresentou concordância substancial (valor de $\mathrm{K}$ entre 0,61 e 0,80$)^{77}$, apenas os escores da primeira avaliação foram considerados para análise estatística.

Tabela 3 - Escores obtidos nas duas avaliações ( $1^{\mathrm{a}}$ e $\left.2^{\mathrm{a}}\right)$ para erosão, achatamento e osteófito, nos grupos 1, 2 e 3 e teste Kappa (K)

\begin{tabular}{|c|c|c|c|c|c|c|c|c|}
\hline \multirow[b]{2}{*}{ Grupo } & \multicolumn{2}{|c|}{ Erosão } & \multicolumn{2}{|c|}{ Achatamento } & \multicolumn{2}{|c|}{ Osteófito } & \multicolumn{2}{|c|}{ TOTAL } \\
\hline & $1^{a}$ & $2^{a}$ & $1^{a}$ & $2^{a}$ & $1^{a}$ & $2^{a}$ & $1^{a}$ & $2^{a}$ \\
\hline 1 & 1 & 0 & 0 & 0 & 0 & 1 & 1 & 1 \\
\hline 1 & 0 & 0 & 0 & 0 & 0 & 0 & 0 & 0 \\
\hline 1 & 0 & 0 & 0 & 0 & 0 & 0 & 0 & 0 \\
\hline 1 & 0 & 1 & 0 & 0 & 1 & 0 & 1 & 1 \\
\hline 1 & 0 & 0 & 1 & 1 & 0 & 0 & 1 & 1 \\
\hline 1 & 0 & 0 & 0 & 0 & 0 & 0 & 0 & 0 \\
\hline 1 & 0 & 0 & 0 & 0 & 0 & 0 & 0 & 0 \\
\hline 1 & 0 & 0 & 0 & 0 & 0 & 0 & 0 & 0 \\
\hline 1 & 0 & 0 & 0 & 0 & 0 & 1 & 0 & 1 \\
\hline 1 & 1 & 0 & 0 & 1 & 0 & 0 & 1 & 1 \\
\hline 1 & 0 & 0 & 0 & 0 & 0 & 0 & 0 & 0 \\
\hline 1 & 0 & 0 & 0 & 0 & 1 & 1 & 1 & 1 \\
\hline 2 & 1 & 1 & 1 & 1 & 0 & 0 & 2 & 2 \\
\hline 2 & 0 & 0 & 0 & 0 & 1 & 1 & 1 & 1 \\
\hline 2 & 0 & 1 & 1 & 0 & 1 & 1 & 3 & 2 \\
\hline 2 & 0 & 1 & 1 & 0 & 1 & 1 & 3 & 2 \\
\hline 2 & 0 & 0 & 1 & 1 & 1 & 1 & 2 & 2 \\
\hline 2 & 0 & 1 & 1 & 1 & 1 & 1 & 3 & 3 \\
\hline 2 & 0 & 1 & 1 & 1 & 1 & 1 & 3 & 3 \\
\hline 2 & 0 & 1 & 1 & 1 & 1 & 1 & 3 & 3 \\
\hline 2 & 0 & 1 & 1 & 1 & 0 & 0 & 2 & 2 \\
\hline 2 & 1 & 0 & 1 & 1 & 1 & 1 & 2 & 2 \\
\hline 2 & 0 & 0 & 1 & 1 & 0 & 1 & 2 & 2 \\
\hline 2 & 0 & 1 & 1 & 0 & 0 & 0 & 2 & 2 \\
\hline 3 & 1 & 0 & 0 & 0 & 0 & 0 & 0 & 0 \\
\hline 3 & 0 & 0 & 0 & 0 & 1 & 1 & 1 & 1 \\
\hline 3 & 0 & 0 & 0 & 1 & 1 & 1 & 1 & 2 \\
\hline 3 & 0 & 0 & 0 & 0 & 1 & 1 & 1 & 1 \\
\hline 3 & 0 & 0 & 0 & 0 & 1 & 1 & 1 & 1 \\
\hline 3 & 0 & 0 & 0 & 0 & 0 & 0 & 0 & 0 \\
\hline 3 & 0 & 0 & 1 & 0 & 0 & 1 & 1 & 1 \\
\hline 3 & 0 & 0 & 0 & 0 & 1 & 1 & 2 & 1 \\
\hline 3 & 0 & 0 & 0 & 0 & 1 & 1 & 1 & 1 \\
\hline 3 & 1 & 0 & 0 & 0 & 0 & 1 & 0 & 1 \\
\hline 3 & 0 & 0 & 0 & 0 & 1 & 1 & 1 & 1 \\
\hline 3 & 0 & 0 & 0 & 0 & 1 & 1 & 1 & 1 \\
\hline $\mathrm{K}$ & & & & & & & & \\
\hline
\end{tabular}


Para as comparações utilizando o teste Kruskal-Wallis, os resultados em destaque $\left(^{*}\right)$ são estatisticamente significantes para $P<0,05$.

Tabela 4 - Escores obtidos para erosão, nos grupos 1, 2 e 3: média, mediana, desvio-padrão e teste Kruskal-Wallis

\begin{tabular}{c|c|c|c}
\hline EROSÃO & G 1 & G 2 & G3 \\
\hline \multirow{4}{*}{} & 1 & 1 & 0 \\
\cline { 2 - 4 } & 0 & 0 & 0 \\
\cline { 2 - 4 } & 0 & 1 & 0 \\
\cline { 2 - 4 } & 0 & 1 & 0 \\
\cline { 2 - 4 } & 0 & 0 & 0 \\
\cline { 2 - 4 } & 0 & 1 & 0 \\
\cline { 2 - 4 } & 0 & 1 & 0 \\
\cline { 2 - 4 } & 0 & 1 & 0 \\
\cline { 2 - 4 } & 0 & 0 & 0 \\
\cline { 2 - 4 } & 0 & 1 & 0,08 \\
\hline Média & 0,17 & 0,75 & 0,00 \\
\hline Mediana & 0,00 & 1,00 & 0,29 \\
\hline DP & 0,39 & 0,45 & $\mathbf{0 , 0 0 1 0 *}$ \\
\hline P & & \multicolumn{2}{|c}{} \\
\hline
\end{tabular}

Tabela 5 - Escores obtidos para achatamento, nos grupos 1, 2 e 3: média, mediana, desvio-padrão e teste Kruskal-Wallis

\begin{tabular}{c|c|c|c}
\hline \multirow{2}{*}{ ACHATAMENTO } & G 1 & G 2 & G3 \\
\hline \multirow{5}{*}{} & 0 & 1 & 0 \\
\cline { 2 - 4 } & 0 & 0 & 0 \\
\cline { 2 - 4 } & 0 & 1 & 0 \\
\cline { 2 - 4 } & 0 & 1 & 0 \\
\cline { 2 - 4 } & 1 & 1 & 0 \\
\cline { 2 - 4 } & 0 & 1 & 0 \\
\cline { 2 - 4 } & 0 & 1 & 0 \\
\cline { 2 - 4 } & 0 & 1 & 0 \\
\cline { 2 - 4 } & 0 & 1 & 0 \\
\cline { 2 - 4 } & 0 & 1 & 0,0833 \\
\hline Média & 0,0833 & 0,9167 & 0,00 \\
\hline Mediana & 0,00 & 1,00 & \\
\hline DP & 0,29 & 0,29 & 0,29 \\
\hline P & & $<0,0001^{*}$ & \\
\hline
\end{tabular}


Tabela 6 - Escores obtidos para osteófito, nos grupos 1, 2 e 3: média, mediana, desvio-padrão e teste Kruskal-Wallis

\begin{tabular}{c|c|c|c}
\hline \multirow{2}{*}{ OSTEÓFITO } & G 1 & G 2 & G3 \\
\hline \multirow{5}{*}{} & 0 & 0 & 0 \\
\cline { 2 - 4 } & 0 & 1 & 1 \\
\cline { 2 - 4 } & 0 & 1 & 1 \\
\cline { 2 - 4 } & 1 & 1 & 1 \\
\cline { 2 - 4 } & 0 & 1 & 1 \\
\cline { 2 - 4 } & 0 & 1 & 0 \\
\cline { 2 - 4 } & 0 & 1 & 1 \\
\cline { 2 - 4 } & 0 & 0 & 0 \\
\cline { 2 - 4 } & 0 & 1 & 1 \\
\cline { 2 - 4 } & 1 & 0 & 0,6667 \\
\hline Média & 0,1667 & 0,6667 & 1,00 \\
\hline Mediana & 0,00 & 1,00 & 0,49 \\
\hline DP & 0,39 & 0,49 & $\mathbf{0 , 0 2 0 5 *}$ \\
\hline P & & \multicolumn{3}{|c}{} \\
\hline
\end{tabular}

Tabela 7 - Soma dos escores obtidos para todas as alterações (erosão, achatamento e osteófito), nos grupos 1, 2 e 3: média, mediana, desvio-padrão e teste Kruskal-Wallis

\begin{tabular}{c|c|c|c}
\hline \multirow{2}{*}{ TOTAL } & G 1 & G 2 & G3 \\
\hline \multirow{5}{*}{} & 1 & 2 & 0 \\
\cline { 2 - 4 } & 0 & 1 & 1 \\
\cline { 2 - 4 } & 0 & 3 & 1 \\
\cline { 2 - 4 } & 1 & 3 & 1 \\
\cline { 2 - 4 } & 0 & 2 & 1 \\
\cline { 2 - 4 } & 0 & 3 & 0 \\
\cline { 2 - 4 } & 0 & 3 & 2 \\
\cline { 2 - 4 } & 0 & 3 & 1 \\
\cline { 2 - 4 } & 0 & 2 & 1 \\
\cline { 2 - 4 } & 1 & 2 & 0,83 \\
\hline Média & 0,42 & 2,33 & 1,00 \\
\hline Mediana & 0,00 & 2,00 & \\
\hline DP & 0,51 & 0,65 & 1 \\
\hline P & & $<0,0001$ & \\
\hline
\end{tabular}




\subsection{Utilização dos minipigs para pesquisa odontológica}

Durante os quatro meses em que foi realizada esta pesquisa, os animais mostraram-se dóceis, facilitando os procedimentos de manejo. Mostraram-se resistentes, com boa recuperação pós-operatória e cicatrização satisfatória, considerando principalmente que as intervenções foram extremamente invasivas.

Os animais apresentaram excelente adaptação à nova condição pós-cirúrgica, e voltaram a se alimentar rapidamente após o período operatório.

O tempo médio das intervenções foi de 5 horas, mas em alguns casos este tempo foi ultrapassado, sempre com os animais sob anestesia geral, e não ocorreram complicações durante os procedimentos ou após as cirurgias, ou qualquer outro tipo de problema com os animais no período em que eles ficaram sob experimentação.

De maneira geral, os minipigs mostraram-se bons modelos experimentais para pesquisas na área odontológica, assim como para o desenvolvimento de pesquisas experimentais e treinamento em Cirurgia e Traumatologia Bucomaxilofacial. 


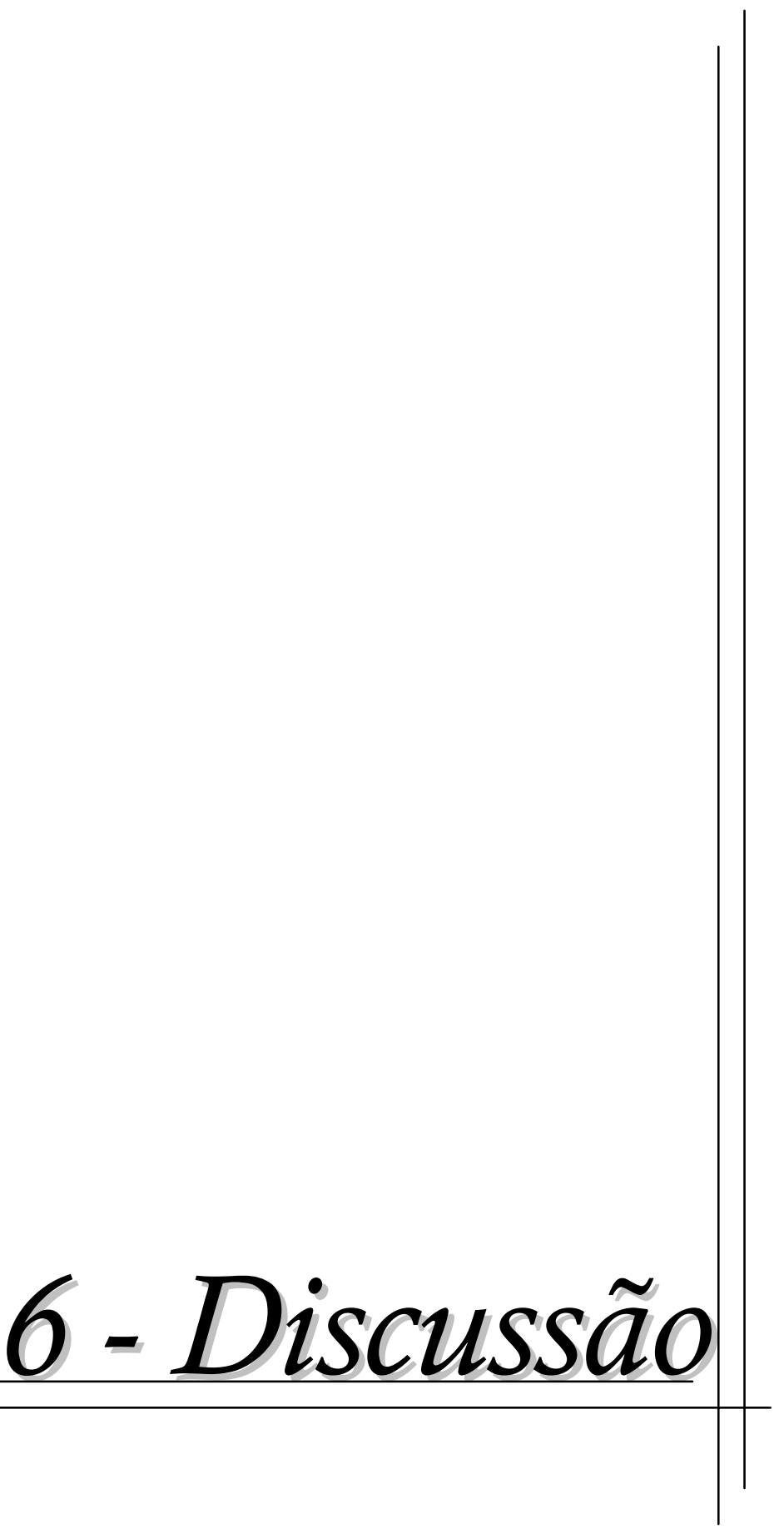




\section{6 - Discussão}

Objetivando proporcionar um melhor entendimento ao leitor, na interpretação dos resultados obtidos neste trabalho, abordamos seqüencialmente os aspectos concernentes à amostra, material e metodologia empregada, resultados obtidos na análise histológica, molecular e tomográfica, e finalmente, as implicações clínicas desses resultados.

\subsection{Amostra}

A pesquisa médico-odontológica desenvolveu-se com uma importante contribuição dos estudos em animais. Essa prática continua sendo largamente empregada no desenvolvimento de métodos e técnicas que possam auxiliar na "cura" ou alívio para os males que acometem o homem e outros animais ${ }^{89}$. Dentre várias espécies utilizadas em experimentação biomédica destaca-se o suíno (Sus scrofa domesticus) que é utilizado há muito tempo em pesquisas científicas.

Então, para esta pesquisa foi escolhido o suíno como modelo animal experimental uma vez que estão amplamente estabelecidas na literatura as semelhanças entre a embriologia ${ }^{176}$, a anatomia $a^{24,48,64,89,92,118,173,175,176}$, a fisiopatologia ${ }^{24,48,64,89,92,118,173,175,176}$ e a estrutura molecular ${ }^{24,48,64,173,175,176}$ dos suínos e do homem. Além disso, essas semelhanças são muito mais distantes quando a fisiologia do homem é comparada àquela do cão, rato, camundongo e outras espécies também utilizadas em experimentação ${ }^{64}$.

Apesar das semelhanças anatomofisiológicas, este animal teve seu uso restringido nas pesquisas em função do seu alto ganho de peso. Este fato levou cientistas a desenvolverem linhagens de suínos miniatura (minipigs) com dimensões compatíveis para a utilização dos mesmos em laboratório.

Neste trabalho, foram utilizados minipigs da colônia Minipig BR $-1^{89}$, animais selecionados e desenvolvidos, no Brasil, especialmente para pesquisa. Previamente ao desenvolvimento deste trabalho, foram realizados estudos básicos com esta colônia, referentes à caracterização dentária e esquelética ${ }^{116}$, e à padronização de técnicas radiográficas ${ }^{101}$, comparando as características 
físicas e radiográficas às de outras colônias, avaliando a possibilidade de esses animais serem utilizados para pesquisa médico-odontológica ${ }^{118}$.

Durante os quatro meses em que foi realizada esta pesquisa, os animais se mostraram dóceis, facilitando os procedimentos de manejo, assim como descreveram outros autores ${ }^{64,89,115,176}$. Os animais mostraram-se resistentes, com boa recuperação pós-operatória, mesmo sendo as intervenções extremamente invasivas.

Foram utilizados somente animais machos, de acordo com vários trabalhos na literatura $59,137,142,177$. Geralmente é feito desta forma, quando se estuda tecido ósseo, procurando evitar alterações que possam ocorrer com os níveis variados de estrogênio nas fêmeas. Entretanto, alguns pesquisadores utilizam animais de ambos os sexos ${ }^{87,189}$ ou fêmeas somente $e^{69,70}$.

Os animais, além de padronizados quanto à colônia (Minipig BR-1) e sexo (machos), também foram padronizados quanto à idade. Os animais utilizados eram adultos jovens (15 meses de idade) pesando em média $30 \mathrm{Kg}$, e apresentando maturidade do tecido ósseo ${ }^{58}$. Esta constante preocupação, na padronização, foi de extrema importância, diminuindo-se assim a variabilidade entre os animais, que poderia interferir nos resultados.

Com relação ao tamanho da amostra utilizada nesta pesquisa, procuramos seguir trabalhos recentes desenvolvidos em animais considerados de porte intermediário a grande, como cães ${ }^{5,69,70,132}$, macacos ${ }^{38,80,93,147,161}$ e suínos $^{112,155,171}$. Nesses estudos, os autores utilizaram um número reduzido de animais, em média 4, uma vez que estes não apresentam os problemas de especificidade de metodologia encontrados nos animais de pequeno porte, o que torna os resultados mais próximos às situações reais ${ }^{130}$.

Contudo, sempre que trabalhamos em pesquisas experimentais devemos ter o cuidado em extrapolar os resultados para os seres humanos ${ }^{130}$. Apesar destes animais, em especial os suínos, apresentarem muitas semelhanças anatomofisiológicas com os humanos, os resultados experimentais não superam aqueles obtidos em pesquisas clínicas ${ }^{130}$, que são capazes de fornecer a real situação que encontramos nos humanos.

Embora as pesquisas em animais de grande porte possuam este fator limitante, elas são de fundamental importância, pois constituem o estágio mais avançado de testes de novos materiais e técnicas antes da utilização 
destes em humanos. Portanto, as pesquisas em animais para serem relevantes precisam ter suas amostras padronizadas, eliminando ao máximo a variabilidade, devem seguir as recomendações dos comitês de ética em pesquisa $^{151}$, e procurar utilizar, na medida do possível, uma mesma amostra para vários trabalhos, buscando-se justificar a utilização dos animais para estudos experimentais.

De maneira geral, concordando com outros estudos $54,63,64,89,92,101,114-$ $116,133,134,159,162,173,174,176$, os suínos, em especial os minipigs, e em particular o Minipig BR-1, mostraram-se modelos experimentais adequados para pesquisas na área odontológica, inclusive para estudos em Cirurgia e Traumatologia Bucomaxilofacial.

\subsection{Material e Métodos}

\subsubsection{Contenção}

A correta contenção dos animais antes das intervenções constitui uma etapa extremamente importante do experimento. Para cada espécie animal, existe um procedimento diferente de contenção que deve ser seguido para garantir a saúde do mesmo e a segurança dos profissionais que estão realizando o experimento. Este fato é relevante, principalmente, quando se consideram pesquisas em suínos, animais que se tornam facilmente estressados, o que dificulta os procedimentos de sedação e interfere na estabilidade do animal durante todo o tempo de trabalho ${ }^{90}$.

Por isso, o manejo adequado dos animais durante a captura para iniciar os procedimentos de anestesia é o primeiro passo para se obter sucesso nas intervenções. A contenção recomendada para suínos é o cachimbo ${ }^{88,90}$, composto por uma corda que envolve a maxila do animal e deve ser apertada para que ele sinta um desconforto e se mantenha imobilizado. Este dispositivo de contenção foi utilizado neste trabalho, e evitou o estresse dos animais, proporcionou segurança aos pesquisadores e técnicos e facilitou os procedimentos de sedação.

\subsubsection{Anestesia}

Para a realização de todas as intervenções, os animais receberam anestesia geral. Previamente à intervenção, eles permaneceram em jejum alimentar de 12 horas e jejum hídrico de 6 horas $^{90,152}$. Isso porque, quando o 
estômago está cheio, pode haver risco de dilatação gástrica e vômito, resultando em uma pneumonia inalatória ${ }^{152}$.

É comum administrar drogas pré-anestésicas, via intramuscular, seguida pela aplicação endovenosa de agentes anestésicos. Injeções intramusculares podem ser administradas na extensa musculatura da coxa posterior ou no músculo do pescoço ${ }^{152}$. Optamos por iniciar a administração das drogas (Azaperone e Quetamina) via intramuscular, na região do pescoço; e para a manutenção da anestesia geral durante toda a intervenção, complementamos a dose inicial de quetamina com doses via endovenosa. A veia comumente utilizada para este fim nos suínos é a veia marginal da orelha $^{90,152}$, e esta técnica nos possibilitou maior estabilidade do procedimento anestésico e menor consumo de medicação.

As técnicas clássicas de monitoração desenvolvidas para cães não são facilmente aplicáveis em suínos, especialmente quando são utilizadas drogas combinadas. Os reflexos palpebrais e pupilares, por exemplo, não são confiáveis em suínos, particularmente se a atropina ou a quetamina estiverem incluídas no protocolo, e este foi o nosso caso. O melhor guia durante os procedimentos de sedação em suínos é o relaxamento dos músculos mandibulares (tônus mandibular) ou a ausência de qualquer reflexo da pata em resposta a um estímulo interdigital. Os indicadores mais sensíveis da superficialização da anestesia são o aumento da freqüência cardíaca e da

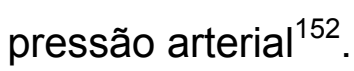

Não realizamos a ventilação artificial para os animais, porque não dispúnhamos dos equipamentos necessários, nem de pessoal treinado para este procedimento. Para tentar compensar esta limitação, fazíamos constante monitoração dos sinais vitais dos animais durante o procedimento cirúrgico, observando clinicamente os reflexos palpebrais e interdigitais, além de sua temperatura e freqüências respiratória e cardíaca.

Foram utilizados azaperone e quetamina ${ }^{90}$, seguindo-se o protocolo de sedação utilizado em outras pesquisas ${ }^{101,114-116}$. A administração do préanestésico, azaperone, pode imobilizar completamente o animal, mas sem promover analgesia. A quetamina é uma das drogas mais utilizadas nos procedimentos anestésicos em suínos, provavelmente pela alta dose de segurança (20-33 mg/Kg). É um efetivo agente moderador, mas não promove o 
relaxamento muscular suficiente, por isso é melhor utilizado em combinação com outros agentes ${ }^{152}$. Desta forma, a combinação azaperone e quetamina permitiu um bom tempo de trabalho e facilitou as manobras operatórias. Esse protocolo mostrou-se eficaz para sedação profunda do suíno, por um período de tempo de até 6 horas.

Durante todo o experimento, não ocorreu o óbito de nenhum animal, ou qualquer outra complicação, durante as cirurgias e controles, mostrando que os procedimentos adotados foram seguros e adequados.

\subsubsection{Técnica cirúrgica}

Desde a técnica descrita por TRAUNER; OBWEGESER ${ }^{158}, 1957$, até suas mais diversas variações utilizadas atualmente ${ }^{15,40,49,57,66,104,180,185}$, inúmeras publicações descreveram inovações da OSBRM que abordam seu desenho, instrumentais, técnicas de separação óssea, cuidados com reparos anatômicos e, sobretudo, os tipos mais adequados de fixação. Neste constante processo evolutivo da técnica de OSBRM, há um fluxo contínuo de pacientes sendo tratados com cirurgia com maiores ou menores índices de sucesso.

Dentre os desenhos de osteotomia bastante utilizados atualmente, muitos ainda seguem as descrições clássicas de TRAUNER; OBWEGESER ${ }^{158}$, modificadas por DAL PONT ${ }^{40}$ e BELL; SCHENDEL ${ }^{15}$, pois essas descrições abrangeram os aspectos gerais necessários para execução da técnica. A idéia de ser o mais paralelo possível permite o mínimo de alteração na posição condilar após avanços ou recuos mandibulares. Como dificilmente se obtém este paralelismo, pode-se afirmar que alguma adaptação, fisiológica ou patológica, dos côndilos rotineiramente é esperada. Apesar de não finalizarem sempre totalmente paralelas, as superfícies dos segmentos proximal e distal se relacionam de forma a gerar condições para que várias técnicas de osteossíntese possam ser efetivas dentro de suas limitações ${ }^{111}$.

Alguns cuidados cirúrgicos com reparos anatômicos são importantes para ressaltarmos algumas adaptações de técnica devido a diferenças na anatomia do minipig BR-1. Suas corticais vestibular e lingual acima do forame mandibular (entrada do feixe vásculo-nervoso) são freqüentemente unidas, o que limitou a altura máxima onde se inicia a osteotomia. Outra característica que acrescentou dificuldade de execução da osteotomia foi a espessura da 
cortical óssea encontrada durante as osteotomias, que em alguns animais chegou a mais de $12 \mathrm{~mm}$. Já a distância vestíbulo-lingual aumentada na região da base mandibular facilitou a execução da separação e fixação óssea. Essas pequenas modificações de técnica não influenciaram a posição das placas e nem fizeram com que os segmentos fossem posicionados de forma diferente à de uma cirurgia em humanos. Ao final de todo procedimento, os movimentos mandibulares eram checados e todos os animais puderam ser alimentados regularmente no dia seguinte à cirurgia.

\subsubsection{Análises histológica, molecular e tomográfica}

Para a análise histológica, as ATMs dos três grupos foram processadas seguindo o protocolo do laboratório da Disciplina de Histologia da Faculdade de Odontologia de Bauru-USP. Realizou-se a análise histológica descritiva, de maneira a descrever todos os eventos que ocorreram após a cirurgia de avanço mandibular e posterior fixação rígida e semi-rígida (Grupos 2 e 3, respectivamente), comparando-se os dois grupos entre si e com o grupo 1 (controle).

Optou-se por uma análise histológica puramente descritiva dos cortes seriados dos côndilos, corados por Hematoxilina e Eosina, pela execução de outros métodos mais sensíveis, o teste ELISA e as tomografias computadorizadas.

O teste ELISA, um método extremamente sensível, foi utilizado para detectar a presença de proteínas presentes em líquidos de organismos ou, até mesmo, extraídas de tecidos ${ }^{37,55}$. Neste trabalho, mais especificamente, o teste foi realizado para quantificar a presença de mediadores do processo inflamatório Interleucina-6 (IL-6), um mediador pró-inflamatório, e Interleucina10 (IL-10), um mediador antiinflamatório. É oportuno destacar que este teste é quantitativo e, portanto, revela a quantidade exata dos mediadores existentes na amostra avaliada.

Seguindo-se o mesmo raciocínio, a tomografia computadorizada poderia ser considerada um exame impreciso para procurar sinais de inflamação ativos. Contudo, ela vem sendo bastante utilizada para avaliar as características ósseas condilares ${ }^{79,135,182,187,188}$, como contorno, volume e presença ou não de alterações. Na metodologia utilizada para avaliação dos 
exames tomográficos, tomou-se o cuidado de avaliar o erro intra-examinador, para poder comprovar a reprodutibilidade das avaliações. Considerando que o resultado do teste Kappa demonstrou-se substancial (K entre 0,61 e 0,80) ${ }^{77}$, apenas os resultados obtidos pelo examinador na primeira avaliação foram considerados para o teste estatístico.

Foi necessária a realização de exames precisos e detalhados, como o teste ELISA e a tomografia computadorizada, para podermos diminuir o número de animais utilizados nos grupos experimentais e controle, e para obtermos resultados confiáveis e mais próximos da realidade. Ainda assim, é necessária cautela e bom senso ao analisar os dados encontrados e aplicá-los à prática clínica.

\subsection{Resultados}

O presente estudo demonstrou que houve diferenças nos côndilos mandibulares quando realizadas as análises histológica, molecular e tomográfica, comparando-se os três grupos estudados. Demonstrou-se haver maiores alterações histológicas e tomográficas, bem como a presença maior de IL-10 (mediador anti-inflamatório) no grupo 2 (fixação rígida). Algumas publicações têm apresentado amostras de alterações em côndilos após cirurgias para tratamento de DDFS ${ }^{135,187,188}$. Dependendo da severidade dessas alterações, sinais clínicos como recidivas dentárias e ósseas (ponto B) podem ocorrer ${ }^{6}$.

\subsubsection{Aspectos Histológicos}

As imagens obtidas a partir da avaliação histológica demonstraram haver características de normalidade nos côndilos para os grupos 1 (controle) e 3 (Fixação Semi-rígida).

No grupo controle, o disco articular era composto por tecido conjuntivo denso, rico em fibras colágenas, e mais delgado na região central; a membrana sinovial revestiu a superfície interna da cápsula fibrosa da articulação temporomandibular e as margens do disco articular; e o côndilo apresentou formato regular e simétrico, revestido por uma camada de tecido fibroso. Encontraram-se sinais de crescimento ativo, por se tratarem de animais jovens. 
No grupo 3 (Fixação semi-rígida), o côndilo e o disco articular apresentaram formato semelhante ao grupo controle. Nos côndilos houve, ainda, um aumento em espessura da tábua óssea, com neoformação de tecido ósseo de arranjo trabecular, que acompanhava toda extensão da região condilar. Associado a este espessamento na região lateral, a região medial apresentou extensas áreas de reabsorção por osteoclastos. Recobrindo o tecido ósseo, uma espessa camada de tecido conjuntivo ricamente celularizado e vascularizado e, mais externamente, a cápsula fibrosa mostrou-se desorganizada, com alguns feixes de tecido conjuntivo denso, indicando remodelação da mesma.

Já no grupo 2 (Fixação Rígida), os côndilos apresentaram formato irregular e mais assimétrico; o disco articular apresentou características similares ao do grupo controle, exceto na região medial, onde se mostrou mais desorganizado e menos denso; o côndilo apresentou superfície bastante irregular, com a presença de cartilagem condilar secundária descontínua.

Apresentando resultados parecidos, mas apenas com exames radiográficos e histológicos, ELLIS III; HINTON ${ }^{47}$ 1991, demonstraram haver significantemente mais reabsorção condilar posterior quando empregava-se a fixação rígida, em comparação à fixação não rígida. Os autores não analisaram diferentes tipos de fixação rígida, nem utilizaram métodos mais específicos, como a tomografia computadorizada e o teste ELISA, aplicados em nossa metodologia. Apesar disto, os resultados desses autores mostraram sinais de que realmente poderia ocorrer reabsorção por retroposicionamento condilar.

\subsubsection{Aspectos Moleculares}

$O$ teste ELISA demonstrou uma presença de níveis significantemente maiores de IL-10 ( $P=0,0436)$ em comparação ao grupo controle. Além disso, verificou-se a presença de níveis mais baixos de IL-6, sugerindo a presença de atividade inflamatória prévia, agora diminuída ou terminada.

O teste ELISA demonstrou uma presença de níveis maiores (não significantes) de IL-6 no grupo maleáveis em comparação ao grupo controle. Além disso, verificou-se a presença de níveis mais baixos de IL-10, sugerindo a presença de atividade inflamatória ativa. 
Estes resultados sugerem que pelos 4 meses subseqüentes às cirurgias, os côndilos do grupo maleável apresentaram algum grau de inflamação, mas que ao final não foi suficiente para que a forma dos côndilos apresentasse alterações relevantes. Já os côndilos do grupo rígido apresentaram alterações de forma nos côndilos e sinais de inflamação prévia, sugerindo um pico inflamatório mais intenso que no grupo maleável, responsável pela remodelação condilar presente nos côndilos deste grupo.

Outros autores já haviam testado marcadores para análise do líquido sinovial com teste ELISA, mas sempre relacionando apenas à DTM e não às DDFSs ou tipos de fixações para cirurgia ortognática.

Tominaga et al. ${ }^{156}, 2004$, analisaram amostras de líquido sinovial de pacientes sadios e com DTM por meio do teste ELISA. Em seus resultados puderam observar a presença da citocina IL-1, em sua forma solúvel, em concentração significantemente maior no grupo com DTM comparado ao controle. Esses dados comprovam a eficácia da utilização de marcadores imunológicos para IL-1 em líquido sinovial da articulação temporomandibular.

KUBOTA et al. ${ }^{75}, 1998$, analisaram através de testes ELISA o líquido sinovial de pacientes sadios comparados a amostras de pacientes potadores de DTM e com osteoartrite de joelho. Encontraram que as citocinas IL-1 e IL-6, assim como algumas metaloproteinases de matriz cartilaginosa, são eficientes marcadores para degradação da cartilagem da ATM.

Análises pós-cirúrgicas precoces adicionais seriam necessárias para afirmar com segurança sobre a intensidade e a duração da atividade inflamatória nas articulações, mas o curto período de tempo imposto pelas obrigações formais somadas ao alto custo de aquisição e manutenção dos animais as impossibilitaram.

\subsubsection{Aspectos Tomográficos}

Os resultados obtidos a partir da avaliação dos exames de tomografia computadorizada demonstraram escores significantemente maiores para o grupo com Fixação Rígida, em comparação ao grupo controle e grupo com Fixação Semi-rígida, considerando todas as alterações investigadas (Erosão: $P=0,0010$, Achatamento: $P<0,0001$, Osteófito: $P=0,0205$ ). Com 
exceção para osteófito, que demonstrou diferença significante apenas entre os grupos experimentais e grupo controle, isto é, tanto o grupo com Fixação Rígida quanto o grupo com Fixação Semi-rígida apresentaram escores médios iguais entre si, porém significante maiores que o escore do grupo controle.

Quando se somaram os valores dos escores para todas as alterações (erosão+achatamento+osteófito=total), houve novamente diferença estatisticamente significante $(P<0,0001)$ entre os grupos controle, Fixação Rígida e Fixação Semi-Rígida, sendo o grupo com Fixação Rígida aquele que demonstrou as maiores alterações. Estes resultados indicaram que a fixação Rígida em cirurgia de avanço mandibular promoveu maiores alterações nos côndilos avaliados.

$\mathrm{Na}$ literatura existem trabalhos que avaliam mudanças na forma dos côndilos de pacientes submetidos à correção cirúrgica de DDFS. YAMADA et al. ${ }^{188}, 2001$, observaram tomografias de 129 pacientes submetidos à cirurgia ortognática. Destes, 35,7\% apresentaram alteração condilar, sendo o resultado mais comum o osteófito (12\%), seguido pelo achatamento $(6,6 \%)$ e erosão $(5,8 \%)$. Os autores concluíram que a porcentagem de reabsorção condilar progressiva era mais freqüente em pacientes com retrusão mandibular e mordida aberta. Nestes casos, o diagnóstico por imagem preciso (Tomografia computadorizada e ressonância magnética) e a análise das condições etiológicas são necessários.

\subsection{Implicações clínicas}

Muitas publicações nas últimas décadas têm demonstrado a confiabilidade da utilização da fixação rígida no aspecto de resistência. Sua superioridade tanto em rigidez como, quando bem executada, em estabilidade posicional imediata são inegáveis. Contudo, também devem ser ressaltados seus reflexos para as ATMs. Esta técnica, quando bem empregada, atinge bons resultados, mas é sempre dependente de condições anatômicas favoráveis, além de treinamento adequado de toda a equipe.

ARNETT $^{6}$ 1993, explicou bem as falhas de técnica passíveis de ocorrer em posicionamento condilar. Essas falhas podem ocorrer quando se utiliza qualquer método de fixação interna, porém a fixação bicortical não possui as características intrínsecas de reversibilidade tão bem explicadas por 
STOELINGA; BORSTLAP ${ }^{149}, 2003$, em seu trabalho de revisão clínica sobre fixação de OSBRM.

A técnica de fixação semi-rígida tem sua eficiência comprovada devido a sua praticidade de aplicação, que depende diretamente do treinamento, propicia um tempo cirúrgico diminuído e, principalmente, riscos de problemas condilares reduzidos. Nosso trabalho apresenta dados obtidos por meio de método completo e inédito, que demonstrou fortes indícios da ocorrência de alterações condilares por uso da fixação rígida, em osteotomias sagitais bilaterais do ramo mandibular.

Acreditamos que as evidências aqui apresentadas podem indicar que as placas e parafusos monocorticais são eficientes o suficiente, e somente 0 suficiente, para suportar as forças mastigatórias e transmiti-las apenas em parte para as ATMs.

É cada vez mais evidente a preocupação dos autores que relatam após o avanço mandibular o "fenômeno" da retrusão mandibular até então chamada de idiopática. Esta migração posterior tardia, referida por ARNETT ${ }^{6}$, 1993, se deve à compressão dos côndilos, que pode ser facilmente observada nos cortes microscópicos deste trabalho, bem como nas imagens tomográficas.

Nossos resultados corroboram com diversos relatos da literatura ${ }^{6,7,9-}$ 11,21,39 e indicam que o relapse (perda de estabilidade posicional) da mandíbula não ocorre realmente no traço de osteotomia, mas sim no encurtamento do ramo ascendente, levando os pacientes a assumirem um retroposicionamento mandibular. Acreditamos, ainda, que mais pesquisas devem ser realizadas no intuito de elucidar as causas desse relapse. Porém, com base nos resultados obtidos, há forte indício de que a reabsorção condilar é real quando da utilização de Fixação Interna Rígida.

Mudanças posicionais da mandíbula após cirurgia de avanço podem gerar alterações condilares, independente da técnica empregada ${ }^{6,21,138}$. Contudo, a literatura ${ }^{6,7,10,39}$ afirma que as alterações condilares pós-cirúrgicas são mais evidentes quando a fixação rígida é empregada, assim como demonstraram nossos resultados. 


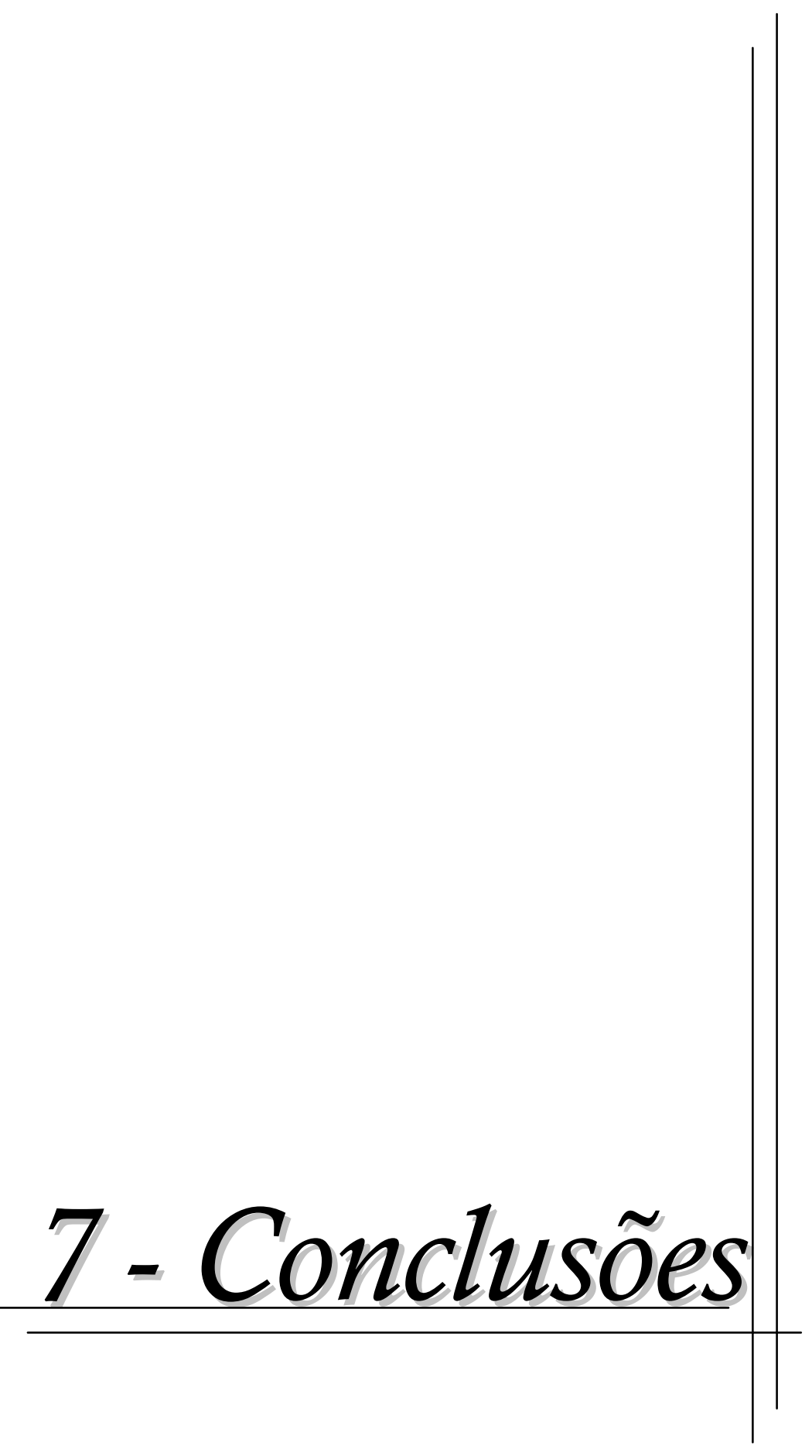




\section{7 - Conclusões}

Com base na metodologia executada, nossos resultados indicaram que a técnica realizada com Fixação Rígida (parafusos bicorticais) resultou numa maior remodelação óssea dos côndilos mandibulares, mas com indícios de um menor período de inflamação ativa quando comparada à técnica realizada com Fixação Semi-Rígida (mini-placas). Portanto, fatores intrínsecos da fixação rígida parecem transmitir maior impacto das forças mastigatórias pós-cirúrgicas para a ATM, em comparação à fixação semi-rígida.

Como objetivo secundário, este estudo permitiu avaliar profundamente o uso do minipig BR-1, que se mostrou viável como modelo experimental e para treinamento prático de procedimentos cirúrgicos em mandíbula. Além disso, foi possível notar que o animal reproduz muito das características humanas ao compararmos a função mastigatória e a morfologia das suas ATMs. 


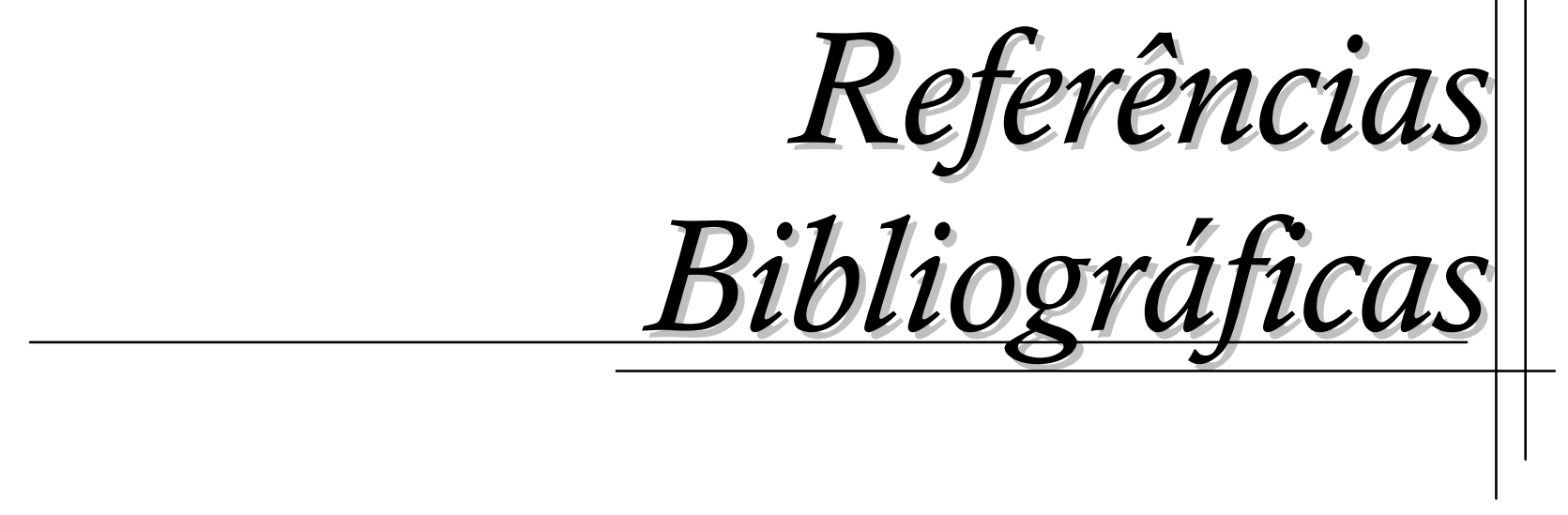




\section{Referências Bibliográficas}

1. Aghabeigi B, Cintra N, Merghji S, Evans A, Crean SJ. Temporomandibular joint synovial fluid sampling: estimation of dilution factor using calcium ion concentration. Int J Oral Maxillofac Surg. 2002;31:646-9.

2. Alder ME, Deahl T, Matteson SR, VanSickels JE, Tiner BD, Rugh JD. Short-term changes of condylar position after sagittal split osteotomy for mandibular advancement. Oral Surg Oral Med Oral Pathol Oral Radiol Endod. 1999;87:159-65.

3. Alexander G, Stivers M. Control of the proximal segment during application of rigid internal fixation of sagittal split osteotomy of the mandible. $\mathrm{J}$ Oral Maxillofac Surg. 2003;61:1113-4.

4. Angle AD, Rebellato J, Sheats RD. Transverse displacement of the proximal segment after bilateral sagittal split osteotomy advancement and its effect on relapse. J Oral Maxillofac Surg. 2007;65(1):50-9.

5. Araújo MG, Carmagnola D, Berglundh T, Thilander B, Lindhe J. Orthodontic movement in bone defects augument with Bio-Oss: An experimental study in dogs. J Clin Periodontol. 2001;28(1):73-80.

6. Arnett GW. A redefinition of bilateral sagittal osteotomy (BSO) advancement relapse. Am J Orthod Dentofac Orthop. 1993;104(5):506-15.

7. Arnett GW. Progressive mandibular retrusion-idiopathic condylar resorption. Part II. Am J Orthod Dentofac Orthop. 1996;110(2):117-27.

8. Arnett GW, Gunson MJ. Facial planing for orthodontists and oral surgeons. Am J Orthod Dentofac Orthop. 2004;126(3):290-5.

9. Arnett GW, McLaughlin RP. Planejamento facial e dentário para ortodontistas e cirurgiões bucomaxilofaciais. São Paulo: Artes Médicas; 2004.

10. Arnett GW, Milam SB, Gottesman L. Progressive mandibular retrusion idiopathic condylar resorption. Part I. Am J Orthod Dentofac Orthop. 1996;110(1):8-15.

11. Arnett GW, Tamborello JA. TMJ dysfunction from transorally placed lag screws: fact or fiction? J Oral Maxillofac Surg. 1988;46(7):625. 
12. Bailey LJ, Cevidanes LHS, Proffit WR. Stability and predictability of orthognathic surgery. Am J Orthod Dentofac Orthop. 2004;126(3):273-7.

13. Banks P, Brown A. Fraturas do esqueleto facial. São Paulo: Editora Santos; 2005.

14. Barros JJ, Souza LCM. Traumatismo buco-maxilo-facial. 2.ed. São Paulo: Roca; 2000.

15. Bell WH, Schendel SA. Biologic basis for modification of the sagittal ramus split operation. J Oral Surg. 1977;35:362-9.

16. Berger JL, Pangrazio-Kulbersh V, Bacchus SN, Kaczynski R. Stability of bilateral sagittal ramus osteotomy: rigida fixation versus transosseous wiring. Am J Orthod Dentofac Orthop. 2000;118(4):397-403.

17. Biasotto-Gonzalez DA. Abordagem interdisciplinar das disfunções temporomandibulares. Barueri: Manole; 2005.

18. Blair VP. Operations on jaw bones and face: study of aetiology and pathological anatomy of developmental malrelations of maxilla and mandible to each other and to facial outline and of operative treatment when beyond the scope of the orthodontist. Gynecol Obstet. 1907;4:67-78.

19. Booth DF. Control of the proximal segment by lower border wiring in the sagittal split osteotomy. Journal of Maxillofacial Surgery. 1981;9:126-8.

20. Borstlap WA, Maltha JC, Stoelinga PJ, VonDenHoff JW. The influence of the sagittal split osteotomy on the condylar cartilage structure and the subchondral vascularization of the temporomandibular joint: a preliminary study in goats. Oral Surg, Oral Med, Oral Pathol. 2005;100(2):138-45.

21. Borstlap WA, Stoelinga PJW, Hoppenreijs TJM, Hof MAVt. Stabilisation of sagittal split advancement osteotomies with miniplates: a prospective, multicentre study with two-year follow-up. Part III - Condylar remodelling and resorption. Int J Oral Maxillofac Surg. 2004;33:649-55.

22. Büchter A, Wiechmann D, Koerdt S, Wiesmann H, Piffko J, Meyer U. Load-related implant reaction of mini-implants used for orthodontic anchorage. Clin Oral Implants Res. 2005;16:473-9.

23. Buck D, Weaver $M$. Tooth movement in miniature swine labeled with tetracycline. J Dent Res. 1965;44:450.

24. Bustad L, McClellan R. Use of pigs in biomedical research. Nature. 1965;208:531-5. 
25. Bustad L, McClellan R. Miniature swine: development, management and utilization. Lab Anim Care. 1968;18(2):280-7.

26. Cadwell JB, Hayward JR, Lister RL. Correction of mandibular retrognathia by vertical L osteotomy: a new technic. J Oral Surg. 1968;26:25964.

27. Caldwell JB, Letterman GS. Vertical osteotomy in the mandibular rami for correction of prognathism. J Oral Surg. 1954;12:185-202.

28. Carlini JL. Considerações sobre a utilização da fixação rígida na osteotomia sagital de mandíbula. Rev Dental Press Ortod Ortop Fac. 1999;4(2):48-55.

29. Champy M, Lodde JP, Jaeger JH, Wilk A. Biomechanical basis of mandibular osteosynthesis according to the F.X. Michelet method. Rev Stomatol Chir Maxillofac. 1976;77(1):248-51.

30. Champy M, Lodde JP, Muster D, Wilk A, Gastelo L. Osteosynthesis using miniaturized screws on plates in facial and cranial surgery. Indications and results in 400 cases. Ann Chir Plast. 1977;22(4):261-4.

31. Champy M, Lodde JP, Schmitt R, Jaeger JH, Muster D. Mandibular osteosynthesis by miniature screwed plates via a buccal approach. J Maxillofac Surg. 1978;6(1):14-21.

32. Champy M, Wilk A, Schnebelen JM. Tretment of mandibular fractures by means of osteosynthesis without intermaxillary immobilization according to F.X. Michelet's technic. Zahn Mund Kieferheilkd Zentralbl. 1975;63(4):339-41.

33. Chuong C-J, Borotikar B, Schwartz-Dabney C, Sinn DP. Mechanical characteristics of the mandible after bilateral sagittal split ramus osteotomy: comparing 2 different fixation techniques. J Oral Maxillofac Surg. 2005;63:6876.

34. Clerq CAD, Abeloos JS, Mommaerts MY, Neyt LF. Temporomandibular joint symptoms in an orthognathic surgery population. J Craniomaxillofac Surg. 1995;23(3):195-9.

35. Cordey J, Mikuschka-Galgoczy E, Blumlein H, Schneider U, Perren SM. Importance of the friction between plate and bone in the anchoring of plates for osteosynthesis. Determination of the coefficient of metal-bone friction in animal in vivo. Helv Chir Acta. 1979;46(1-2):183-7. 
36. Cordey J, Schlapfer F, Cordey P, Divis M, Perren SM. Stripping of the bone screws at insertion. The relation of torque and angular displacement in predicting admissible torque values. Acta Orthop Belg. 1980;46(6):816-22.

37. Cunha FQ, Boukili MA, Motta JIB, Vargaftig BB, Ferreira SH. Blockade by fenspiride of endotoxin-indued neutrophil migration in the rat. Eur $\mathrm{J}$ Pharmacol. 1993;238(1):47-52.

38. Cuoghi O. Avaliação dos primeiros momentos da movimentação dentária induzida: estudo microscópico em macacos da espécie Cebus apella. Bauru: Faculdade de Odontologia de Bauru, Universidade de São Paulo; 1996.

39. Cutbirth M, Sickels JEV, Thrash WJ. Condylar resorption after bicortical screw fixation of mandibular advancement. J Oral Maxillofac Surg. 1998;56:178-82.

40. DalPont G. Retro-molar osteotomy for correction of prognathism. Minerva Chir. 1959;14(30):1138-41.

41. Dervis E, Tuncer E. Long-term evaluations of temporomandibular disorders in patients undergoing orthognathic surgery compared with a control group. Oral Surg Oral Med Oral Pathol Oral Radiol Endod. 2002;94(5):554-60.

42. Dingman RO. Surgical correction of mandibular prognathism. Am J Orthod Oral Surg. 1944;30:683-92.

43. Ehmer U, Broll P. Mandibular border movements and masticatory patterns before and after orthognathic surgery. Int J Adult Orthod Orthognath Surg. 1992;7(3):153-9.

44. Ellislll E. Rigid skeletal fixation of fractures. J Oral Maxillofac Surg. 1993;51:163-73.

45. Ellislll E. Condylar positioning devices for orthognathic surgery: are they necessary? J Oral Maxillofac Surg. 1994;52(6):536-52; discussion 52-4.

46. EllisIII E, Gallo JW. Relapse following mandibular advancement with dental plus skeletal maxillomandibular fixation. J Oral Surg. 1986;44:509-15.

47. EllisIll E, Hinton RJ. Histologic examination of the temporomandibular joint after mandibular advancement with and without rigid fixation: an experimental investigation in adult Macaca mulatta. J Oral Maxillofac Surg. 1991;49(12):1316-27.

48. England D, Winters L, Carpenter L. The development of breed of miniature swine: a preliminary report. Growth. 1954;18(4):207-14. 
49. Epker B, Worth F. Modifications in the sagittal osteotomy of the mandible. J Oral Surg. 1977;35:157-9.

50. Epker BN, Wylie GA. Control of the condylar-proximal mandibular segments after sagittal split osteotomies to advance the mandible. Oral Surgery, Oral Medicine, Oral Pathology. 1986;62(6):613-7.

51. Erkmen E, Simsek B, Yücel E, Kurt A. Comparison of different fixation methods following sagittal split ramus osteotomies using three-dimensional finite elements analysis. Part 1: advancement surgery - posterior loading. Int $J$ Oral Maxillofac Surg. 2005;34:551-8.

52. Fleiss JL. Statistical methods for rates and proportions. New York: John Wiley \& Sons; 1973.

53. Foley WL, Frost DE, PaulinJr WB, Tucker MR. Internal screw fixation: comparison of placement, pattern and rigidity. . J Oral Maxillofac Surg. 1989;47(7):720-3.

54. Freeman JA, Teng S, Herring SW. Rigid fixation and strain patterns in the pig zygomatic arch and suture. J Oral Maxillofac Surg. 1997;55(5):496-504.

55. Fukuhara YD, Reis ML, Dellalibera-Joviliano R, Cunha FQ, Donadi EA. Increased plasma levels of IL-1beta, IL-6, IL-8, IL-10 and TNF-alpha in patients moderately or severely envenomed by Tityus serrulatus scorpion sting. Toxicon. 2003;41(1):49-55.

56. Gaggl A, Schultes G, Santler G, Kärcher H, Simbrunner J. Clinical and magnetic resonance findings in the temporomandibular joints of patients before and after orthognathic surgery. Br J Oral Maxillofac Surg. 1999;37:41-5.

57. Gallo WJ, Moss M, Gaul JV, Shapiro D. Modification of the sagittal ramus-split osteotomy for retrognathia. J Oral Surg. 1976;34:178-9.

58. Gedrange T, Köbel C, Harzer W. Hard Palate deformation in animal model following quasi-statistic loading to stimulate that of orthodontic anchorage implants. Eur J Orthod. 2001;23(4):349-54.

59. Giunta D, Keller J, Nielsen F, Melsen B. Influence of indomethacin on bone turnover related to orthodontic tooth movement in miniature pigs. Am J Orthod Dentofac Orthop. 1995;108(4):361-6.

60. Harada K, Okada Y, Nagura H, Enomoto S. A new repositioning system for the proximal segment in sagittal split ramus osteotomy of the mandible. Int $J$ Oral Maxillofac Surg. 1994;23(1):71-3. 
61. Hatch JP, VanSickels JE, Rugh JD, Dolce C, Bays RA, Sakai S. Mandibular range of motion after bilateral sagittal split ramus osteotomy with wire osteosynthesis or rigid fixation. Oral Surg, Oral Med, Oral Pathol. 2001;91(3):274-80.

62. Helm G, Stepke MT. Maintenance of the preoperative condyle position in orthognathic surgery. J Craniomaxillofac Surg. 1997;25(1):34-8.

63. Herford AS, Hoffman R, Demirdji S, Boyne PJ, Caruso JM, Leggitt VL, et al. A comparison of synovial fluid pressure after immediate versus gradual mandibular advancement in the miniature pig. J Oral Maxillofac Surg. 2005;63:775-85.

64. Herring S. Animal models of temporomandibular disorders: how to choose.Temporomandibular disorders and related pain conditions, progress in pain research and management. In: Sessle B, Bryant P, Dionne R. Temporomandibular Disorders and Related Pain Conditions, Progress in Pain Research and Manegement. Seattle: IASP Press; 1995. p. 323-8.

65. Hobar PC. Methods of rigid fixation. Clin Plast Surg. 1992;19(1):31-9.

66. Hunsuck EE. A modified intraoral sagittal splitting technic for correction of mandibular prognathism. J Oral Surg. 1968;26(4):250-3.

67. Jacobs JD, Sinclair PM. Principles of orthodontic mechanics in orthognathic surgery cases. American Journal of Orthodontics. 1983;84(5):399407.

68. Jeter TS, Sickels JEV, Dolwick MF. Modified techniques for internal fixation of sagittal ramus osteotomies. J Oral Maxillofac Surg. 1984;42(4):270-2.

69. Kawamoto T, Motohashi N, Kitamura A, Baba Y, Suzuki S, Kuroda T. Experimental tooth movement into bone induced by recombinant human bone morphogenetic protein-2. Cleft Palate Craniofac J. 2003;40(5):538-43.

70. Kawamoto T, Motohashi N, Kitamura A, Baba Y, Takahashi K, Suzuki S, et al. A histological study on experimental tooth movement into bone induced by recombinant human bone morphogenetic protein-2 in beagle dogs. Cleft Palate Craniofac J. 2002;39(4):439-48.

71. Kempf KK. Transoral technique for rigid fixation of sagittal ramus osteotomies. J Oral Maxillofac Surg. 1987;45:1077-9. 
72. Kersey ML, Nebbe B, Major PW. Temporomandibular joint morphology changes with mandibular advancement surgery and rigid internal fixation: a systematic literature review. Angle Orthodont. 2003;73(1):79-85.

73. Kerstens HC, Tuinzing DB, Kwast WAVD. Temporomandibular joint symptoms on orthognathic surgery. J Craniomaxillofac Surg. 1989;17(5):215-8.

74. Kohn DH, Richmond EM, Dootz ER, Freinberg SE, Pietrzak WS. In vitro comparison of parameters affecting the fixation strength of sagittal split osteotomies. J Oral Maxillofac Surg. 1995;53:1374-83.

75. Kubota E, Kubota T, Matsumoto J, Shibata T, Murakami K-I. Synovial fluid cytokines and proteinases as markers of temporomandibular joint disease. J Oral Maxillofac Surg. 1998;56:192-8.

76. Landes CA, Sterz M. Proximal segment positioning in bilateral sagittal split osteotomy: intraoperative controlled positioning by a positioning splint. $J$ Oral Maxillofac Surg. 2003;61:1423-31.

77. Landis JR, Koch GG. The measurement of observer agreement for categorical data. Biometrics. 1977;33:159-74.

78. Learreta JA, Arellano JC, Yavich LG, Valle MG. Compêndio de diagnóstico de patologias da ATM. São Paulo: Artes Médicas; 2004.

79. Liang $H$, Tyndall DA, Ludlow JB, Lang LA, Nunn ME. Accuracy of mandibular cross-sectional imaging with tuned-aperture computed tomography (TACT), iteratively reconstructed TACT, and multidirectional, linear, and transverse panoramic tomography. Oral Surg, Oral Med, Oral Pathol. 2001;91(5):594-602.

80. Linder-Aronson S, Nordenram A, Anneroth G. Titanium implant anchorage in orthodontic treatment an experimental investigation in monkeys. Eur J Orthod. 1990;12(4):414-9.

81. Lindorf $\mathrm{HH}$. Functionally stable tandem screw fixation in sagittal ramus osteotomy. Surgical technique, new instrumentation and experiences. Dtsch Z Mund Kiefer Gesichtschir. 1984;8(5):367-73.

82. Lindorf $\mathrm{HH}$. Sagittal ramus osteotomy with tandem screw fixation. Technique and results. J Maxillofac Surg. 1986;14(6):311-6.

83. Lindorf $\mathrm{HH}$. Osteosynthesis in orthodontic surgery using screws and mini-plates. Inf Orthod Kieferorthop. 1988;20(3):329-50. 
84. Lindorf $\mathrm{HH}$, Steinhauser EW. Correction of jaw deformities involving simultaneous osteotomy of the mandible and maxilla. J Maxillofac Surg. 1978;6(4):239-44.

85. Luhr HG. The significance of condylar position using rigid fixation in orthognathic surgery. Clin Plast Surg. 1989;16(1):147-56.

86. Luna L. Manual of histologic satining methods of the Armed Forces Institute of Pathology. New York: McGraw-Hill Book Company; 1968.36-8.

87. Lundgren A, Sennerby L, Lundgren D. An experimental rabbit model for jaw-bone healing. Int Oral Maxillofac Impl. 1997;26(6):461-4.

88. Machado L. Os Suínos.: A Granja; 1967.

89. Mariano M. The miniature pig (minipig) in biomedical experimental research: BR-1 minipig. Acta Cir Bras (serial online). 2003;18(5):1-9.

90. Massone F. Anestesiologia veterinária: farmacologia e técnicas. Rio de Janeiro: Guanabara Koogan; 1994.

91. Mavreas D, Athanasiou AE. Tomographic assessment of alterations of the temporomandibular joint after orthognathic surgery. Eur J Orthod. 1992;14(1):3-15.

92. McKean C, Jump E, Weaver M. The calcification pattern of deciduous teeth in miniature swine. Arch Oral Biol. 1971;16(6):639-48.

93. Melsen $B$. Tissue reaction following application of intrusive and extrusive forces on teeth in adult monkeys. Am J Orthod Dentofac Orthop. 1986;89:46976.

94. Merten HA, Halling F. A new condylar positioning technique in orthognathic surgery. Technical note. J Craniomaxillofac Surg. 1992;20(7):3102.

95. Meyer U, Joos U, Mythili J, Stamm T, Hohoff A, Fillies T, et al. Ultrastructural characterization of the implant/bone interface of immediately loaded dental implants. Biomaterials. 2004;25:1959-67.

96. Michelet FX, Benoit JP, Festal F, Despujols P, Bruchet P, Arvor A. Fixation without blocking of sagittal osteotomies of the rami by means of endobuccal screwed plates in the treatment of antero-posterior abnormalities. Rev Stomatol Chir Maxillofac. 1971;72(4):531-7.

97. Michelet FX, Deymes J, Dessus B. Osteosynthesis with miniaturized screwed plates in maxillo-facial surgery. J Maxillofac Surg. 1973;1(2):79-84. 
98. Mommaerts MY, Hadjianghelou O. Positional changes after mandibular advancement by sagittal split osteotomies and wire osteosynthesis: Do combined orthodontics and the Dal Pont modification of the buccal osteotomy contribute to long-term stability? Journal of Cranio-Maxillofacial Surgery. 1990;18(3):93-106.

99. Mori $\mathrm{Y}$, Sugahara T, Hiraki T. Improvement of a condylar positioning system for the mandibular ramus sagittal split osteotomy. J Oral Maxillofac Surg. 1995;53:340-1.

100. Murphy MT, Houg RH, Barber JE. A in vitro comparison of the mechanical characteristics of three sagittal ramus osteotomy fixation techniques. J Oral Maxillofac Surg. 1997;55:489-94.

101. Navarro RL, Oltramari PVP, Henriques JFC, Capelozza ALA, Sant'Ana E, Granjeiro JM. Radiographic techniques for medical-dental research with minipigs. The Veterinary Journal. 2006; In press.

102. Neugebauer J, Traini T, Thams U, Piattelli A, Zöller J. Peri-implant bone organization under immediate loading state. Circularly polarized light analyses: a minipig study. J Periodontol. 2006;77(2):152-60.

103. Niederdellmann $H$, Buhrmann K, Collins FJ. Set screws. Aids in orthodontic surgery. Dtsch Z Mund Kiefer Gesichtschir. 1984;8(1):62-3.

104. Niederdellmann $H$, Shetty V. Technical improvements in the sagittal split ramus osteotomy. Oral Surgery, Oral Medicine, Oral Pathology. 1989;67(1):2530.

105. Niederdellmann H, Shetty V, Collins FJ. Controlled osteosynthesis utilizing the position screw. Int $\mathrm{J}$ Adult Orthodon Orthognath Surg. 1987;2(3):159-62.

106. Nishimura A, Sakurada S, Iwase M, Nagumo M. Positional changes in the mandibular condyle and amount of mouth opening after sagittal split ramus osteotomy with rigid or nonrigid osteosynthesis. J Oral Maxillofac Surg. 1997;55:672-8.

107. Nishimura M, Segami N, Kaneyama K, Fujimura K. Comparison of cytokine level in synovial fluid between successful and unsuccessful cases in arthrocentesis of the temporomandibular joint. J Oral Maxillofac Surg. 2004;62:284-7. 
108. Nkenke E, Fenner M, Vairaktaris E, Neukam F, Radespiel-Tröger M. Immediate versus delayed loading of dental implants in the maxillae of minigpis. Part II: histomorphometric analysis. Int $\mathrm{J}$ Oral Maxillofac Implants. 2005;20(4):540-6.

109. Noguchi K, Kuroda T, Nakamura T. The miniature pig as an experimental animal in dental research, especially in orthodontics (author's transl). Kokubyo Gakkai Zasshi. 1976;43(1):87-91.

110. Obeid G, Lindquist CC. Optimal placement of bicortical screws in sagittal split-ramus osteotomy of mandible. Oral Surgery, Oral Medicine, Oral Pathology. 1991;71(6):665-9.

111. Ochs MW. Bicortical screw stabilization of sagittal split osteotomies. J Oral Maxillofac Surg. 2003;61(12):1477-84.

112. Ödman J, Gröndahl K, Lekholm U, Thilander B. The effect of osseointegrated implants on the dentoalveolar development. A clinical and radiographic study in growing pigs. Eur J Orthod. 1991;13(4):279-86.

113. Okeson JP. Tratamento das desordens temporomandibulares e oclusão. 4.ed. São Paulo: Artes Médicas; 2000.

114. Oltramari P, Navarro R, Henriques J, Taga R, Cestari T, Ceolin D, et al. Orthodontic movement in bone defects filled with xenogenic graft: study in minipigs. Am J Orthod Dentofac Orthop. 2006; In press.

115. Oltramari PVP. Movimentação ortodôntica em defeitos ósseos preenchidos com enxerto xenógeno: estudo em minipigs. [Mestrado]. Bauru: Faculdade de Odontologia de Bauru, Universidade de São Paulo; 2005.

116. Oltramari PVP, Navarro RL, Capelozza ALA, Henriques JFC, Granjeiro JM. Dental and skeletal characterization of the BR-1 minipig. The Veterinary Journal. 2006; In press.

117. Özden B, Alkan A, Arici S, Erdem E. In vitro comparison of biomechanical characteristics of sagittal split osteotomy fixation techniques. Int J Oral Maxillofac Surg. 2006;35:837-41.

118. Panepinto L, Philips R. The Yucatan miniature pig: characterization and utilization in biomedical research. Lab Anim Sci. 1986;36(4):344-7.

119. Paulus GW. Semirigid bone fixation: a new concept in orthognathic surgery. J Craniofac Surg. 1991;2(3):146-51. 
120. Paulus GW, Steinhauser EW. A comparative study of wire osteosynthesis versus bone screws in the treatment of mandibular prognathism. Oral Surg Oral Med Oral Pathol. 1982;54(1):2-6.

121. Perren S, Cordey J, Enzler M, Matter P, Rahn BA, Schlapfer F. Mechanics of bone screw with internal fixation plates (author's transl). Unfallheilkunde. 1978;81(4):201-18.

122. Proffit WR, Fields HW, Ackerman JL, Bailey LJ, Tulloch JFC. Contemporary orthodontics. 3.ed. Saint Louis: Mosby; 2000.

123. Proffit WR, Fields HW, Moray LJ. Prevalence of malocclusion and orthodontic treatment need in the United States: estimates from the N-HANES III survey. Int J Adult Orthodon Orthognath Surg. 1998;13:97-106.

124. Proffit WR, Turvey TA, Phillips C. Orthognathic Surgery: a hierachy of stability. Int J Adult Orthodon Orthognath Surg. 1996;11(3):191-204.

125. Proffit WR, WhiteJr RP, Sarver DM. Contemporary treatment of dentofacial deformity. Saint Louis: Mosby; 2003.

126. Pullinger A, Hollender L. Assessment of mandibular condyle position: a comparison of transcranial radiographs and linear tomograms. Oral Surg Oral Med Oral Pathol. 1985;60(3):329-34.

127. Renzi G, Becelli R, Paolo CD, lannetti $G$. Indications to the use of condylar repositioning devices in the surgical treatment of dental-skeletal Class III. J Oral Maxillofac Surg. 2003;61:304-9.

128. Reyneke JP, Ferretti C. Intraoperative diagnosis of condylar sag after bilateral sagittal split ramus osteotomy. Br J Oral Maxillofac Surg. 2002;40:28592.

129. Rimondini L, Bruschi G, Scipioni A, Carrassi A, Nicoli-Aldini N, Giavaresi $G$, et al. Tissue healing in implants immediately placed into postextraction sockets: a pilot study in a mini-pig model. Oral Surg Oral Med Oral Pathol Oral Radiol Endod. 2005;100:E43-50.

130. Roberts W, Gordon R, Mostafa A. Rate of mesial translation of mandibular molars using implant-anchored mechanics. Angle Orthodont. 1996;66(5):331-8.

131. Rotskoff KS, Herbosa EG, Villa P. Maintenance of condyle-proximal segment postion in orthognathic surgery. J Oral Maxillofac Surg. 1991;49(1):27. 
132. Saito S, Sugimoto N, Morohashi T, Ozeki M, Kurabayashi H, Shimizu H, et al. Endosseous titanium implants as anchors for mesial tooth movement in the beagle dog. Am J Orthod Dentofac Orthop. 2000;118(6):601-7.

133. Saka B, Wree A, Anders L, Gundlach KKH. Experimental and comparative study of the blood supply to the mandibular cortex in Göttingen minipigs and in man. J Cranio-Maxillofac Surg. 2002;30:219-25.

134. Saka B, Wree A, Henkel KO, Anders L, Gundlach KKH. Blodd supply of the mandibular cortex: an experimental study in Göttingen minipigs with special reference to the condyle. J Cranio-Maxillofac Surg. 2002;30:41-5.

135. Sanromán JF, Gonzalez JMG, Hoyo AD, Gil FM. Morphometric and morphological changes in the temporomandibular joint after orthognathic surgery: a magnetic resonance imaging and computed tomography prospective study. J Cranio-Maxillofac Surg. 1997;25:139-48.

136. Sato J, Segami N, Kaneyama K, Kinoshi H, Yoshitake Y, Nishikawa K. Levels of fibroblast growth factor 2 in synovial fluids in human patients with internal dearangement of the temporomandibular joint. Oral Surg Oral Med Oral Pathol Oral Radiol Endod. 2003;96(6):673-9.

137. Schaberg S, Petri W, Gregory E, Auclair P, Jacob E. A comparison of freeze-dried allogenic and fresh autologous vascularized rib grafts in dog radial discontinuity defects. J Oral Maxillofac Surg. 1985;43(12):932-7.

138. Scheerlinck JPO, Stoelinga PJW, Blijdorp PA, Brouns JJA, Nijs MLL. Sagittal split advancement osteotomies stabilized with miniplates: a 2-5-year follow-up. Int J Oral Maxillofac Surg. 1994;23:127-31.

139. Schendel SA, Epker BN. Results after mandibular advancement surgery: an analysis of 87 cases. J Oral Surg. 1980;38:265-82.

140. Schierano G, Canuto R, Navone R, Peirone B, Martinasso G, Pagano M, et al. Biological factors involved in the osseointegration of oral titanium implants with different surfaces: a pilot study in minipigs. J Periodontol. 2005;76(10):1710-20.

141. Schultes G, Gaggl A, Kärcher H. Changes in the dimensions of milled mandibular models after mandibular sagittal split osteotomies. $\mathrm{Br} \mathrm{J}$ Oral Maxillofac Surg. 1998;36:196-201. 
142. Sheats R, Strauss R, Rubenstein L. Effect of a resorbable bone graft material on orthodontic tooth movement trough surgical defects in the cat mandible. J Oral Maxillofac Surg. 1991;49(12):1299-303.

143. Sherman WO. Vanadium steel bone plates and screws. Surg Gynecol Obstet. 1912:629-34.

144. Shetty V, Freymiller E, McBrearty D, Caputo AA. Functional stability of sagittal split ramus osteotomies: effects of positional screw size and placement configuration. J Oral Maxillofac Surg. 1996;54:601-9.

145. Shufford EL, Kraut RA. Passive rigid fixation of sagittal split osteotomy. Oral Surgery, Oral Medicine, Oral Pathology. 1989;68(2):150-3.

146. Sisson S, Grossman J. Anatomy of the domestic animals. Philadelphia: Saunders; 1959.464-8.

147. Smalley W. Implants for tooth movement: determining implant location and orientation. J Esthet Dent. 1995;7(2):62-72.

148. Spiessl B. Osteosynthesis in sagittal osteotomy using the ObwegeserDal Pont method. Fortschr Kiefer Gesichtschir. 1974;18:145-8.

149. Stoelinga PJW, Borstlap WA. The fixation of sagittal split osteotomies with miniplates: the versatility of a technique. J Oral Maxillofac Surg. 2003;61:1471-6.

150. Stroster TG, Pangrazio-Kulbersh V. Assessment of condylar position following bilateral sagittal split ramus osteotomy with wire fixation or rigid fixation. Int J Adult Orthodon Orthognath Surg. 1994;9(1):55-63.

151. Swindle M. The use of animals in surgical research. J Invest Surg. 1988;1(1):3-4.

152. Swindle M. Anesthetic and preoperative techniques in swine: an update. 1994.

153. Swindle M, Moody D, Philips L. Swine as models in biomedical research. lowa: lowa Satate University Press; 1992.

154. Tanaka A, Kumagai S, Kawashiri S, Takatsuka S, Nakagawa K, Yamamoto E, et al. Expression of matrix metalloproteinase-2 and -9 in synovial fluid of the temporomandibular joint accompanied by anterior disc displacement. J oral Pathol Med. 2001;30:59-64. 
155. Thilander B, Ödman J, Gröndahl K, Lekholm U. Aspects on osseointegrated implants inserted in growing jaws. A biometric and radiographic study in the young pig. Eur J Orthod. 1992;14(2):99-109.

156. Tominaga K, Habu M, Sukedai M, Hirota Y, Takahashi T, Fukuda J. IL$1 \beta$, IL-1 receptor antagonist and soluble type II IL-1 receptor in synovial fluid of patients with temporomandibular disorders. Arch Oral Biol. 2004;49:493-9.

157. Tominaga K, Yoshioka I, Khanal A, Furuta N, Habu M, Fukuda J. A simple method for bone positioning of mandibular segments. Int $\mathrm{J}$ Oral Maxillofac Surg. 2006;35:856-60.

158. Trauner $\mathrm{R}$, Obwegeser $\mathrm{H}$. The surgical correction of mandibular prognathism and retrognathia with consideration of genioplasty. Part I. Surgical procedures to correct mandibular prognathism and reshaping of the chin. Oral Surg Oral Med Oral Pathol. 1957;10(7):677-89.

159. Troulis MJ, Nahlieli O, Castano F, Kaban LB. Minimally invasive orthognatic surgery: endoscopic vertical ramus osteotomy. Int J Oral Maxillofac Surg. 2000;29(4):239-42.

160. Tucker MR, Ochs MW. Use of rigid internal fixation for management of intraoperative complications of mandibular sagittal split osteotomy. Int $\mathrm{J}$ Adult Orthodon Orthognath Surg. 1988;3(2):71-80.

161. Turley $P$. The loading of bioglass-coated aluminium oxide implants to produce sutural expansion of the maxillary complex in the pigtail monkey (Macaca menestrina). Arch Oral Biol. 1980;25:459-64.

162. Tuxen A, Kirkeby S. An animal model for human masseter muscle: histochemical characterization of mouse, rat, rabbit, cat, dog, pig, and cow masseter muscle. J Oral Maxillofac Surg. 1990;48(10):1063-7.

163. Uckan S, Schwimmer A, Kummer F, Greenberg AM. Effect of the angle of the screw on the stability of the mandibular sagittal split ramus osteotomy: a study in sheep mandibles. Br J Oral Maxillofac Surg. 2001;39:266-8.

164. VanSickels JE, Jeter TS, Theriot BA. Management of an unfavorable lingual fracture during a sagittal split osteotomy. J Oral Maxillofac Surg. 1985;43(10):808-9.

165. VanSickels JE, Larsen AJ, Thrash WJ. A retrospective study of relapse in rigidly fixated sagittal split osteotomies: Contributing factors. American Journal of Orthodontics and Dentofacial Orthopedics. 1988;93(5):413-8. 
166. VanSickels JE, Tiner BD, Alder ME. Condylar torque as a possible cause of hypomobility after sagittal split osteotomy: report of three cases. J Oral Maxillofac Surg. 1997;55:398-402.

167. VanSickels JE, Tiner BD, Keeling SD, Clark GM, Bays R, Rugh J. Condylar Position with rigid fixation versus wire osteosynthesis of a sagital split advancement. J Oral Maxillofac Surg. 1999;57(1):31-4.

168. Verna C, Dalstra M, Lee T, Cattaneo P, Melsen B. Microcracks in the alveolar bone following orthodontic tooth movement: a morphological and morphometric study. Eur J Orthod. 2004;26(5):459-67.

169. Wang $\mathrm{JH}$, Waite $\mathrm{DE}$. Evaluation of the surgical procedure of sagittal split osteotomy of the mandibular ramus. Oral Surgery, Oral Medicine, Oral Pathology. 1974;38(2):167-80.

170. Wang JH, Waite DE. Vertical osteotomy vc sagittal splt osteotomy of the mandibular ramus: comparison of operative and postoperative factors. J Oral Surg. 1975;33:596-600.

171. Ward D, Behrents R, Goldberg J. Temporomandibular synovial fluid pressure response to altered mandibular positions. Am J Orthod Dentofac Orthop. 1990;98(1):22-8.

172. Ward EC, McAuliffe M, Holmes SK, Lynham A, Monsour F. Impact of malocclusion and orthognatic reconstruction surgery on resonance and articulatory function: an axamination of variability in five cases. $\mathrm{Br} \mathrm{J}$ Oral Maxillofac Surg. 2002;40:410-7.

173. Weaver M, Jump E, McKean C. The eruption pattern of deciduous teeth in miniature swine. Anat Rec. 1966;154(1):81-6.

174. Weaver M, Jump E, McKean C. The eruption pattern of permanent teeth in miniature swine. Arch Oral Biol. 1969;14(3):323-31.

175. Weaver ME, McKean CF. Miniature Swine as Laboratory Animals. Lab Anim Care. 1965;15:49-56.

176. Weaver ME, Sorenson FM, Jump EB. The miniature pig as an experimental animal in dental research. Arch Oral Biol. 1962;7:17-23.

177. Wenfield I, Magalhães L, Magalhães J, Villa N. Estudo histológico de um novo biomaterial (Biobone) indicado para reparação óssea. Rev Paul Odontol. 1999;4:8-10. 
178. Westermark A, Shayeghi F, Thor A. Temporomandibular dysfunction in 1.516 patients before and after orthognathic surgery. Int $\mathrm{J}$ Adult Orthod Orthognath Surg. 2001;16(2):145-51.

179. Witherow H, Offord D, Eliahoo J, Stewart A. Postoperative fractures of the lingual plate after bilateral sagittal split osteotomies. $\mathrm{Br} \mathrm{J}$ Oral Maxillofac Surg. 2006;44:296-300.

180. Wolford L, Bennet MA, Rafferty CG. Modification of the mandibular ramus sagittal split osteotomy. Oral Surg Oral Med Oral Pathol. 1987;64(2):14655.

181. Wolford LM, Davis WM. The mandibular inferior border split: a modification in the sagittal split osteotomy. J Oral Maxillofac Surg. 1990;48:924.

182. Wolford LM, Reiche-Fischel O, Mehra P. Changes in temporomandibular joint dysfunction after orthognathic surgery. J Oral Maxillofac Surg. 2003;61:655-60.

183. Woods MG. Re: A retrospective study of relapse in rigidly fixated sagittal split/ osteotomies: Contributing factors. American Journal of Orthodontics and Dentofacial Orthopedics. 1988;94(5):446-7.

184. Wright JK, Axon HJ. Electrolysis and stainless steels in bone. J Bone Joint Surg. 1956;38-B(3):745-53.

185. Wyatt WM. Sagittal ramus split osteotomy: literature review and suggested modification of technique. Br J Oral Maxillofac Surg. 1997;35:137-41. 186. Yagami K, Nagumo M. A transoral approach for the three-dimensional repositioning of the proximal segment after mandibular sagittal split ramus osteotomy. J Oral Maxillofac Surg. 1996;54:1256-8.

187. Yamada K, Hanada K, Fukui T, Satou Y, Ochi K, Hayashi T, et al. Condylar bony change and self-reported parafunctional habits in prospective orthognathic surgery patients with temporomandibular disorders. Oral Surg Oral Med Oral Pathol Oral Radiol Endod. 2001;92(3):265-71.

188. Yamada K, Hanada K, Hayashi T, Ito J. Condilar bony change, disk displacement, and signs and simptoms of TMJ disorders in orthognathic surgery patients. Oral Surg Oral Med Oral Pathol Oral Radiol Endod. 2001;91:603-10. 
189. Young C, Sandstedt P, Skoglund A. A comparative study of anorganic xenogenic bone and autogenous bone implants for bone regeneration in rabbits. Int J Oral Maxillofac Implants. 1999;14(1):72-6. 


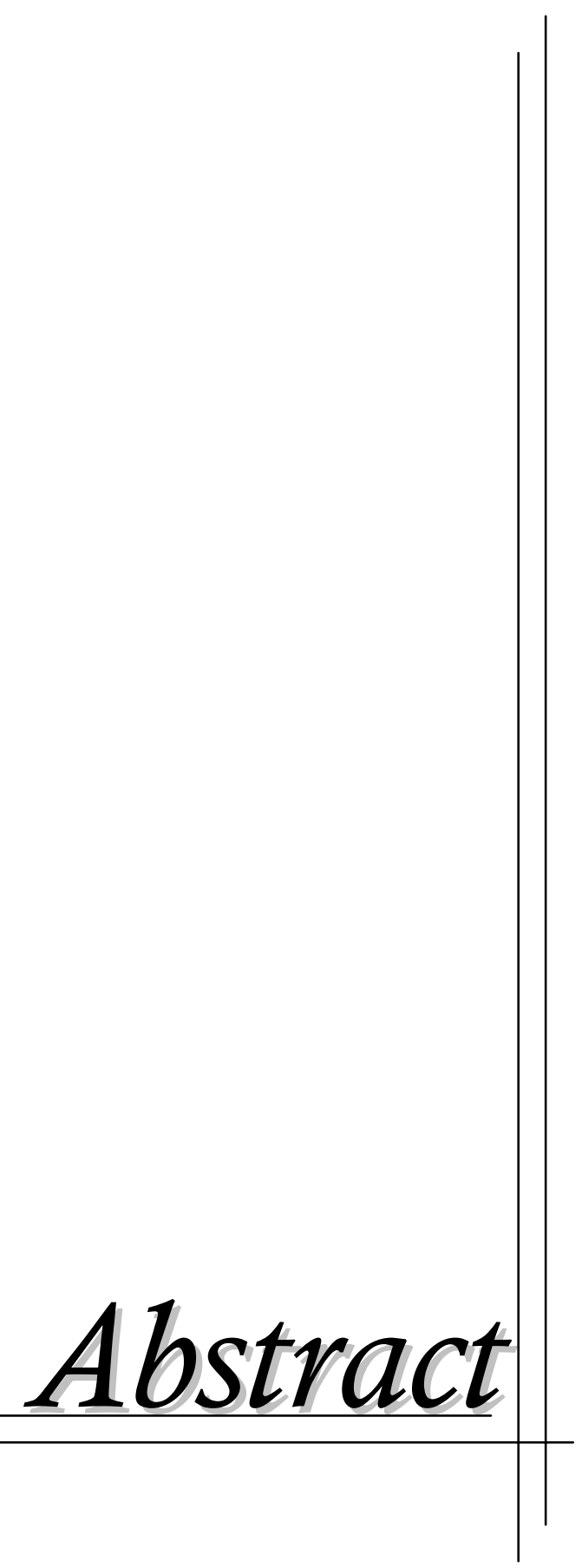




\section{Abstract}

\section{HISTOLOGICAL, MOLECULAR AND TOMOGRAPHIC CONDYLE} ANALYSIS AFTER MANDIBULAR ADVANCEMENT SURGERY -

\section{STUDY IN MINIPIGS}

This work aimed at elucidating the changes occurring in temporomandibular joint (TMJ) after surgical mandibular advancement with different fixation materials: miniplates (malleable fixation) and bi-cortical screws (rigid fixation). Twelve minipigs (Minipig BR-1) were operated and served as experimental groups; six non-operated age matched animals served as controls. Four months after the surgeries the animals were sacrificed, and all TMJs and sinovial fluid samples were collected. TMJs were histologically prepared after computerized tomography (CT) scanning, which aimed the detection of osteofite, erosion and flattening. The CT scans examination revealed significant alterations of condyles' shape (erosion, $\mathrm{P}=0,0010$ and osteophyte, $\mathrm{P}<0,0001)$ for group 2 when compared with groups 1 and 3 . The presence of a pro-inflammatory marker, interleukine (IL)-6, and an anti-inflammatory marker, IL-10 in sinovial fluid was assessed in ELISA experiments. Although CT revealed a tendency of bone remodelling in the rigid fixation group, the difference was not statistically significant. In the control group, the same levels of IL-6 and IL-10 were observed (83.2 pg/mL and $80.6 \mathrm{pg} / \mathrm{mL}$, respectively), compatible with no signs of inflammation. In the malleable fixation group higher levels of IL-6 in comparison with IL-10 indicated an active inflammatory process (140.0 $\mathrm{pg} / \mathrm{mL}$ and $95.6 \mathrm{pg} / \mathrm{mL}$, respectively). In contrast, in the rigid fixation group 
lower levels of IL-6 compared with IL-10 were found $(103.5 \mathrm{pg} / \mathrm{mL}$ and $138.9 \mathrm{pg} / \mathrm{mL}$, respectively). Rigid fixation evokes more pronounced signs of bone remodelling in TMJ, whereas malleable fixation promotes a more intense inflammatory activity than rigid fixation. Therefore, intrinsic features of rigid fixation seem to transmit a higher impact of postoperative masticatory forces to TMJ as compared with malleable fixation.

Keywords: Mandibular Advancement; Osteosynthesis; Temporomandibular Joint; Bone Remodeling 


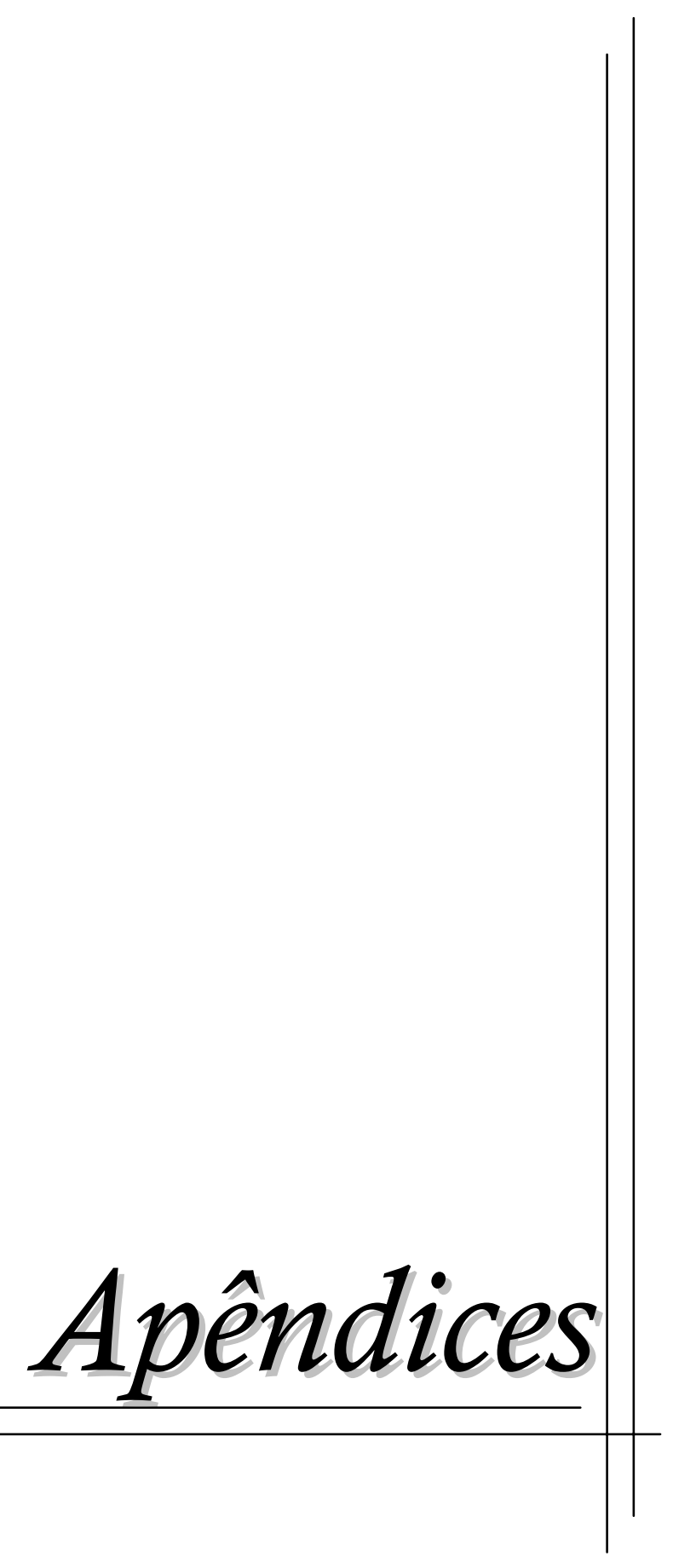




\section{Apêndices}

Os apêndices 1 a 3 referem-se aos valores reais individuais de cada variável, para cada animal, dos grupos 1, 2 e 3 .

Apêndice 1 - Valores individuais, média e erro-padrão para IL-6 e IL-10, no grupo 1 (controle)

\begin{tabular}{|c|c|c|c|}
\hline GRUPO & Animal/Lado & IL-6 & IL-10 \\
\hline 1 & $74 \mathrm{D}$ & - & - \\
\hline 1 & $74 \mathrm{E}$ & - & - \\
\hline 1 & $79 \mathrm{D}$ & 159,232 & 136,911 \\
\hline 1 & $79 E$ & 108,422 & 109,895 \\
\hline 1 & $80 \mathrm{D}$ & 68,571 & 16,843 \\
\hline 1 & $80 \mathrm{E}$ & 64,586 & 37,885 \\
\hline 1 & $81 \mathrm{D}$ & 31,709 & 39,356 \\
\hline 1 & $81 \mathrm{E}$ & 76,541 & 39,356 \\
\hline 1 & $89 \mathrm{D}$ & 31,709 & 58,867 \\
\hline 1 & $89 \mathrm{E}$ & 108,422 & 30,351 \\
\hline 1 & $91 \mathrm{D}$ & 147,277 & 219,457 \\
\hline 1 & $91 \mathrm{E}$ & 35,694 & 117,400 \\
\hline \multicolumn{2}{|c|}{ Média } & 83,216 & 80,632 \\
\hline \multicolumn{2}{|c|}{ Erro-Padrão } & 14,652 & 20,263 \\
\hline
\end{tabular}

Apêndice 2 - Valores individuais, média e erro-padrão para IL-6 e IL-10, no grupo 2 (Fixação Rígida)

\begin{tabular}{|c|c|c|c|}
\hline GRUPO & Animal/Lado & IL-6 & IL-10 \\
\hline 2 & $141 \mathrm{D}$ & 65,582 & 79,879 \\
\hline 2 & $141 E$ & 47,649 & 190,941 \\
\hline 2 & $142 \mathrm{D}$ & 135,322 & 111,396 \\
\hline 2 & $142 \mathrm{E}$ & 511,914 & 172,931 \\
\hline 2 & $151 \mathrm{D}$ & 66,579 & 136,911 \\
\hline 2 & $151 \mathrm{E}$ & 21,746 & 105,393 \\
\hline 2 & $155 \mathrm{D}$ & 111,411 & 117,400 \\
\hline 2 & $155 \mathrm{E}$ & 51,635 & 189,440 \\
\hline 2 & $156 \mathrm{D}$ & 27,724 & 45,359 \\
\hline 2 & $156 \mathrm{E}$ & 62,594 & 141,413 \\
\hline 2 & $158 \mathrm{D}$ & 62,594 & 210,452 \\
\hline 2 & $158 \mathrm{E}$ & 77,538 & 165,427 \\
\hline \multicolumn{2}{|c|}{ Média } & 103,524 & 138,912 \\
\hline \multicolumn{2}{|c|}{ Erro-Padrão } & 38,231 & 14,256 \\
\hline
\end{tabular}


Apêndice 3 - Valores individuais, média e erro-padrão para IL-6 e IL-10, no grupo 3 (Fixação Semi-rígida)

\begin{tabular}{|c|c|c|c|}
\hline GRUPO & Animal/Lado & IL-6 & IL-10 \\
\hline 3 & $147 \mathrm{D}$ & 345,536 & 76,877 \\
\hline 3 & $147 \mathrm{E}$ & 69,568 & 91.885 \\
\hline 3 & $149 \mathrm{D}$ & 70,564 & 163,926 \\
\hline 3 & $149 \mathrm{E}$ & 70,564 & 193.943 \\
\hline 3 & $150 \mathrm{D}$ & 48,646 & 60,368 \\
\hline 3 & $150 \mathrm{E}$ & 42,668 & 105.393 \\
\hline 3 & $153 \mathrm{D}$ & 31,709 & 136,911 \\
\hline 3 & $153 \mathrm{E}$ & 97,463 & 54.364 \\
\hline 3 & $154 \mathrm{D}$ & 335,573 & 78,378 \\
\hline 3 & $154 \mathrm{E}$ & 61,597 & 15.342 \\
\hline 3 & $161 \mathrm{D}$ & 133,329 & 118,900 \\
\hline 3 & $161 \mathrm{E}$ & 373,432 & 51.363 \\
\hline \multicolumn{2}{|c|}{ Média } & 140,054 & 95,638 \\
\hline \multicolumn{2}{|c|}{ Erro-Padrão } & 37,652 & 14,741 \\
\hline
\end{tabular}

